Cochrane Database of Systematic Reviews

\title{
Recall intervals for oral health in primary care patients (Review)
}

Fee PA, Riley P, Worthington HV, Clarkson JE, Boyers D, Beirne PV

Fee PA, Riley P, Worthington HV, Clarkson JE, Boyers D, Beirne PV.

Recall intervals for oral health in primary care patients.

Cochrane Database of Systematic Reviews 2020, Issue 10. Art. No.: CD004346.

DOI: 10.1002/14651858.CD004346.pub5.

www.cochranelibrary.com 
TABLE OF CONTENTS

HEADER 1

ABSTRACT

PLAIN LANGUAGE SUMMARY

SUMMARY OF FINDINGS

BACKGROUND

OBJECTIVES

METHODS

RESULTS

Figure 1.

Figure 2.

DISCUSSION

AUTHORS' CONCLUSIONS

ACKNOWLEDGEMENTS

REFERENCES

CHARACTERISTICS OF STUDIES

DATA AND ANALYSES

Analysis 1.1. Comparison 1: 24 months versus 12 months: 2 -year outcome data, Outcome 1: Caries (dmfs/DMFS increment) ...

Analysis 2.1. Comparison 2: Risk based versus 6 months: 4-year outcome data, Outcome 1: Prevalence of moderate to extensive caries (ICDAS 3 to 6)

Analysis 2.2. Comparison 2: Risk based versus 6 months: 4-year outcome data, Outcome 2: Mean number of surfaces with any caries (ICDAS 1 to 6)

Analysis 2.3. Comparison 2: Risk based versus 6 months: 4-year outcome data, Outcome 3: Gingival bleeding: percentage of sites

Analysis 2.4. Comparison 2: Risk based versus 6 months: 4-year outcome data, Outcome 4: Probing pocket depth $(\mathrm{mm}) \quad \ldots . . . .$.

Analysis 2.5. Comparison 2: Risk based versus 6 months: 4-year outcome data, Outcome 5: Patient OHIP-14 (0 to 56 scale where lower score is better)

Analysis 3.1. Comparison 3: 24 months versus 6 months: 4-year outcome data, Outcome 1: Prevalence of moderate to extensive caries (ICDAS 3 to 6)

Analysis 3.2. Comparison 3: 24 months versus 6 months: 4-year outcome data, Outcome 2: Mean number of surfaces with any caries (ICDAS 1 to 6 )

Analysis 3.3. Comparison 3: 24 months versus 6 months: 4-year outcome data, Outcome 3: Gingival bleeding: percentage of sites

Analysis 3.4. Comparison 3: 24 months versus 6 months: 4-year outcome data, Outcome 4: Probing pocket depth (mm) ........ Analysis 3.5. Comparison 3: 24 months versus 6 months: 4-year outcome data, Outcome 5: Patient OHIP-14 (0 to 56 scale where lower score is better)

Analysis 4.1. Comparison 4: Risk-based versus 24 months: 4-year outcome data, Outcome 1: Prevalence of moderate to extensive caries (ICDAS 3 to 6 )

Analysis 4.2. Comparison 4: Risk-based versus 24 months: 4-year outcome data, Outcome 2: Mean number of surfaces with any caries (ICDAS 1 to 6)

Analysis 4.3. Comparison 4: Risk-based versus 24 months: 4-year outcome data, Outcome 3: Gingival bleeding: percentage of sites

Analysis 4.4. Comparison 4: Risk-based versus 24 months: 4-year outcome data, Outcome 4: Probing pocket depth (mm) ......

Analysis 4.5. Comparison 4: Risk-based versus 24 months: 4-year outcome data, Outcome 5: Patients OHIP-14 (0 to 56 scale where lower score is better)

ADDITIONAL TABLES

APPENDICES

WHAT'S NEW

HISTORY

CONTRIBUTIONS OF AUTHORS

DECLARATIONS OF INTEREST

SOURCES OF SUPPORT

DIFFERENCES BETWEEN PROTOCOL AND REVIEW

INDEX TERMS 
[Intervention Review]

\section{Recall intervals for oral health in primary care patients}

Patrick A Fee ${ }^{1 a}$, Philip Riley ${ }^{2 b}$, Helen V Worthington 2 , Janet E Clarkson ${ }^{3}$, Dwayne Boyers ${ }^{4}$, Paul V Beirne 5

1Dundee Dental School, University of Dundee, Dundee, UK. ${ }^{2}$ Cochrane Oral Health, Division of Dentistry, School of Medical Sciences, Faculty of Biology, Medicine and Health, The University of Manchester, Manchester, UK. ${ }^{3}$ Division of Oral Health Sciences, Dundee Dental School, University of Dundee, Dundee, UK. ${ }^{4}$ Health Economics Research Unit, University of Aberdeen, Aberdeen, UK. ${ }^{5}$ Department of Epidemiology and Public Health, University College Cork, Cork, Ireland

aPatrick Fee and Philip Riley contributed equally to this work.. bPhilip Riley and Patrick Fee contributed equally to this work.

Contact address: Patrick A Fee, p.fee@dundee.ac.uk.

Editorial group: Cochrane Oral Health Group.

Publication status and date: New search for studies and content updated (conclusions changed), published in Issue 10, 2020.

Citation: Fee PA, Riley P, Worthington HV, Clarkson JE, Boyers D, Beirne PV. Recall intervals for oral health in primary care patients. Cochrane Database of Systematic Reviews 2020, Issue 10. Art. No.: CD004346. DOI: 10.1002/14651858.CD004346.pub5.

Copyright @ 2020 The Cochrane Collaboration. Published by John Wiley \& Sons, Ltd.

\section{A B S T R A C T}

\section{Background}

There is ongoing debate about the frequency with which patients should attend for a dental check-up and the effects on oral health of the interval between check-ups. Recommendations regarding optimal recall intervals vary between countries and dental healthcare systems, but 6-month dental check-ups have traditionally been advocated by general dental practitioners in many high-income countries.

This review updates a version first published in 2005, and updated in 2007 and 2013.

\section{Objectives}

To determine the optimal recall interval of dental check-up for oral health in a primary care setting.

\section{Search methods}

Cochrane Oral Health's Information Specialist searched the following databases: Cochrane Oral Health's Trials Register (to 17 January 2020), the Cochrane Central Register of Controlled Trials (CENTRAL; in the Cochrane Library, 2019, Issue 12), MEDLINE Ovid (1946 to 17 January 2020), and Embase Ovid (1980 to 17 January 2020). We also searched the US National Institutes of Health Trials Registry (ClinicalTrials.gov) and the World Health Organization International Clinical Trials Registry Platform for ongoing trials. We placed no restrictions on the language or date of publication when searching.

\section{Selection criteria}

We included randomised controlled trials (RCTs) assessing the effects of different dental recall intervals in a primary care setting.

\section{Data collection and analysis}

Two review authors screened search results against inclusion criteria, extracted data and assessed risk of bias, independently and in duplicate. We contacted study authors for clarification or further information where necessary and feasible. We expressed the estimate of effect as mean difference (MD) with 95\% confidence intervals (Cls) for continuous outcomes and risk ratios (RR) with 95\% Cls for dichotomous outcomes. We assessed the certainty of the evidence using GRADE.

\section{Main results}

We included two studies with data from 1736 participants. One study was conducted in a public dental service clinic in Norway and involved participants under 20 years of age who were regular attenders at dental appointments. It compared 12-month with 24-month recall intervals and measured outcomes at two years. The other study was conducted in UK general dental practices and involved adults 
who were regular attenders, which was defined as having attended the dentist at least once in the previous two years. It compared the effects of 6-month, 24-month and risk-based recall intervals, and measured outcomes at four years. The main outcomes we considered were dental caries, gingival bleeding and oral-health-related quality of life. Neither study measured other potential adverse effects.

\section{4-month versus 12-month recall at 2 years' follow-up}

Due to the very low certainty of evidence from one trial, it is unclear if there is an important difference in caries experience between assignment to a 24-month or a 12-month recall. For 3- to 5-year-olds with primary teeth, the mean difference (MD) in dmfs (decayed, missing, and filled tooth surfaces) increment was 0.90 (95\% $\mathrm{Cl}-0.16$ to $1.96 ; 58$ participants). For 16 - to 20 -year-olds with permanent teeth, the MD in DMFS increment was 0.86 (95\% Cl -0.03 to $1.75 ; 127$ participants). The trial did not assess other clinical outcomes of relevance to this review.

\section{Risk-based recall versus 6-month recall at 4 years' follow-up}

We found high-certainty evidence from one trial of adults that there is little to no difference between risk-based and 6-month recall intervals for the outcomes: number of tooth surfaces with any caries (ICDAS 1 to 6 ; MD $0.15,95 \% \mathrm{Cl}-0.77$ to 1.08 ; 1478 participants); proportion of sites with gingival bleeding (MD 0.78\%, 95\% Cl-1.17\% to 2.73\%; 1472 participants); oral-health-related quality of life (MD in OHIP-14 scores $-0.35,95 \% \mathrm{Cl}-1.02$ to $0.32 ; 1551$ participants). There is probably little to no difference in the prevalence of moderate to extensive caries (ICDAS 3 to 6) between the groups (RR 1.04, 95\% Cl 0.99 to 1.09 ; 1478 participants; moderate-certainty evidence).

\section{4-month recall versus 6-month recall at 4 years' follow-up}

We found moderate-certainty evidence from one trial of adults that there is probably little to no difference between 24-month and 6-month recall intervals for the outcomes: number of tooth surfaces with any caries (MD $-0.60,95 \% \mathrm{Cl}-2.54$ to $1.34 ; 271$ participants); percentage of sites with gingival bleeding (MD $-0.91 \%, 95 \% \mathrm{Cl}-5.02 \%$ to $3.20 \% ; 271$ participants). There may be little to no difference between the groups in the prevalence of moderate to extensive caries (RR 1.05, 95\% Cl 0.92 to $1.20 ; 271$ participants; low-certainty evidence). We found high-certainty evidence that there is little to no difference in oral-health-related quality of life between the groups (MD in OHIP-14 scores $-0.24,95 \% \mathrm{Cl}-1.55$ to $1.07 ; 305$ participants).

\section{Risk-based recall versus 24-month recall at 4 years' follow-up}

We found moderate-certainty evidence from one trial of adults that there is probably little to no difference between risk-based and 24month recall intervals for the outcomes: prevalence of moderate to extensive caries (RR 1.06, 95\% Cl 0.95 to 1.19; 279 participants); number of tooth surfaces with any caries (MD $1.40,95 \% \mathrm{Cl}-0.69$ to $3.49 ; 279$ participants). We found high-certainty evidence that there is no important difference between the groups in the percentage of sites with gingival bleeding (MD $-0.07 \%, 95 \% \mathrm{Cl}-4.10 \%$ to $3.96 \% ; 279$ participants); or in oral-health-related quality of life (MD in OHIP-14 scores $-0.37,95 \% \mathrm{Cl}-1.69$ to $0.95 ; 298$ participants).

\section{Authors' conclusions}

For adults attending dental check-ups in primary care settings, there is little to no difference between risk-based and 6-month recall intervals in the number of tooth surfaces with any caries, gingival bleeding and oral-health-related quality of life over a 4-year period (highcertainty evidence). There is probably little to no difference between the recall strategies in the prevalence of moderate to extensive caries (moderate-certainty evidence).

When comparing 24-month with either 6-month or risk-based recall intervals for adults, there is moderate- to high-certainty evidence that there is little to no difference in the number of tooth surfaces with any caries, gingival bleeding and oral-health-related quality of life over a 4-year period.

The available evidence on recall intervals between dental check-ups for children and adolescents is uncertain.

The two trials we included in the review did not assess adverse effects of different recall strategies.

\section{PLAIN LANGUAGE SUMMARY}

\section{How often should you see your dentist for a check-up?}

\section{Why have a dental check-up?}

A dental check-up helps to keep your mouth healthy and lets your dentist see if you have any dental problems. It allows your dentist to deal with any problems early, or even better, to prevent problems from developing. Leaving problems untreated may make them harder to treat in the future.

\section{What happens in a check-up?}

At each check-up your dentist will usually: 
- examine your teeth, gums and mouth;

- ask about your general health and if you have had any problems with your teeth, mouth or gums since your last check-up;

- advise you about tooth-cleaning habits, and your diet, smoking and alcohol use.

- if appropriate, recommend treatment needed for any dental problems.

After your check-up, the dentist will recommend a date for your next check-up. Traditionally, check-ups are recommended every six months. However, some people are at higher risk of developing dental problems and may need more frequent check-ups, while others may not need check-ups so often.

\section{Why we did this Cochrane Review}

Having check-ups every six months might help to keep your mouth healthy and avoid dental problems in future, but could also lead to unnecessary dental treatments. However, having check-ups less often might let dental problems get worse and lead to difficult and expensive treatment and care.

We wanted to identify the best time interval to have between dental check-ups.

\section{What did we do?}

We searched for randomised controlled studies in which people were assigned at random to different time intervals between check-ups. Randomised controlled studies usually give the most reliable evidence.

Search date: we included evidence published up to 17 January 2020.

\section{What we found}

We found two studies with 1736 people who had regular dental check-ups. One study was conducted in a public dental clinic in Norway in children and adults aged under 20 years. It compared 12-monthly and 24-monthly check-ups, and measured results after two years.

The other study was in adults at 51 dental practices in the UK. It compared six-monthly, 24 -monthly and risk-based check-ups (where time between check-ups was set by dentists and depended on an individual's risk of dental disease), and measured results after four years.

The studies looked at how different intervals between check-ups affected:

- how many people had tooth decay;

- how many tooth surfaces were affected by decay;

- gum disease (percentage of bleeding sites in the gums); and

- quality of life related to having healthy teeth and gums.

No studies measured other potential unwanted effects.

\section{What are the results of our review?}

In adults, there was little to no difference between six-monthly and risk-based check-ups in tooth decay (number of tooth surfaces affected), gum disease and quality of life after four years; and probably little to no difference in how many people had moderate-to-extensive tooth decay.

There was probably little to no difference between 24-monthly and six-monthly or risk-based check-ups in tooth decay (number of people and number of tooth surfaces affected), gum disease or well-being, and may be little to no difference in how many people had moderate-to-extensive tooth decay.

We did not find enough reliable evidence about the effects of 12-monthly and 24-monthly check-ups in children and adolescents after two years. This was because of problems with the way that the study was conducted.

\section{How reliable are these results?}

We are confident that there is little to no difference between six-monthly and risk-based check-ups in adults for number of tooth surfaces with decay, gum disease and quality of life.

We are moderately confident there is little to no difference between 24-monthly check-ups and six-monthly or risk-based check-ups in number of tooth surfaces with decay, gum disease and quality of life. 


\section{Conclusions}

Whether adults see their dentist for a check-up every six months or at personalised intervals based on their dentist's assessment of their risk of dental disease does not affect tooth decay, gum disease, or quality of life. Longer intervals (up to 24 months) between check-ups may not negatively affect these outcomes.

Currently, there is not enough reliable evidence available about how often children and adolescents should see their dentist for a check-up. 
S U M MARY OF FINDINGS

Summary of findings 1 . 24-month recall versus 12-month recall

Clinical examination with 24-month recall compared with clinical examination with 12-month recall for oral health

Population: primary care dental patients (aged $\leq 20$ years)

Settings: public dental clinic

Intervention: clinical examination with 24-month recall

Comparison: clinical examination with 12-month recall

\begin{tabular}{|c|c|c|c|c|c|c|}
\hline \multirow[t]{2}{*}{ Outcomes } & \multicolumn{2}{|c|}{$\begin{array}{l}\text { Anticipated absolute effects (95\% } \\
\mathrm{CI})\end{array}$} & \multirow{2}{*}{$\begin{array}{l}\text { Relative } \\
\text { effect } \\
(95 \% \mathrm{CI})\end{array}$} & \multirow{2}{*}{$\begin{array}{l}\text { Num- } \\
\text { ber of } \\
\text { partici- } \\
\text { pants } \\
\text { (stud- } \\
\text { ies) }\end{array}$} & \multirow{2}{*}{$\begin{array}{l}\text { Certainty } \\
\text { of the evi- } \\
\text { dence } \\
\text { (GRADE) }\end{array}$} & \multirow[t]{2}{*}{ Comments } \\
\hline & $\begin{array}{l}\text { Risk with } \\
\text { 12-month } \\
\text { recall }\end{array}$ & $\begin{array}{l}\text { Risk with 24-month re- } \\
\text { call }\end{array}$ & & & & \\
\hline $\begin{array}{l}\text { Caries (primary teeth) } \\
\text { dmfs increment in 3- to 5-year-olds } \\
\text { Follow-up: } 2 \text { years }\end{array}$ & $\begin{array}{l}\text { Mean } \\
0.90\end{array}$ & $\begin{array}{l}\text { MD } 0.90 \text { higher } \\
\text { (from } 0.16 \text { lower to } 1.96 \\
\text { higher) }\end{array}$ & - & $\begin{array}{l}58 \\
(1 \mathrm{RCT})\end{array}$ & $\begin{array}{l}\oplus \odot \ominus \ominus \\
\text { VERY } \\
\text { LOW'1 }\end{array}$ & $\begin{array}{l}\text { The evidence is very uncertain about the ef- } \\
\text { fect of assignment to a } 24 \text {-month recall inter- } \\
\text { val compared with a 12-month recall interval. }\end{array}$ \\
\hline $\begin{array}{l}\text { Caries (permanent teeth) } \\
\text { DMFS increment in } 16 \text { - to } 20 \text {-year-olds } \\
\text { Follow-up: } 2 \text { years }\end{array}$ & $\begin{array}{l}\text { Mean } \\
0.79\end{array}$ & $\begin{array}{l}\text { MD } 0.86 \text { higher (from } \\
0.03 \text { lower to } 1.75 \text { high- } \\
\text { er) }\end{array}$ & - & $\begin{array}{l}127 \\
(1 \mathrm{RCT})\end{array}$ & $\begin{array}{l}\oplus \ominus \odot \odot \\
\text { VERY } \\
\text { LOW1 }\end{array}$ & $\begin{array}{l}\text { The evidence is very uncertain about the ef- } \\
\text { fect of assignment to a } 24 \text {-month recall inter- } \\
\text { val compared with a 12-month recall interval. }\end{array}$ \\
\hline Periodontal disease & \multicolumn{6}{|c|}{ Not reported } \\
\hline Oral-health-related quality of life & \multicolumn{6}{|c|}{ Not reported } \\
\hline Other harms & \multicolumn{6}{|c|}{ Not reported } \\
\hline
\end{tabular}

*The risk in the intervention group (and its $95 \% \mathrm{Cl}$ ) is based on the assumed risk in the comparison group and the relative effect of the intervention (and its $95 \% \mathrm{Cl}$ ). Only 1 trial provided data for the comparison between 24-month and 12-month recall intervals (Wang 1992); the assumed and corresponding risks are therefore based on the data from this trial.

CI: confidence interval; dmfs/DMFS: decayed, missing, filled surfaces (primary/permanent teeth); MID: minimal important difference;MD: mean difference.

GRADE Working Group grades of evidence

High certainty: we are very confident that the true effect lies close to that of the estimate of the effect 
Moderate certainty: we are moderately confident in the effect estimate: the true effect is likely to be close to the estimate of the effect, but there is a possibility that it is substantially different

Low certainty: our confidence in the effect estimate is limited: the true effect may be substantially different from the estimate of the effect

Very low certainty: we have very little confidence in the effect estimate: The true effect is likely to be substantially different from the estimate of effect

1 We downgraded the certainty of evidence by 2 levels for risk of bias because of concerns over a) selection bias arising from unclear methods of sequence generation and allocation concealment, and b) detection bias due to an absence of blinding of the outcome assessors for the clinical outcomes. We also downgraded the certainty of evidence

by 1 level for imprecision; the 95\% confidence intervals included little to no difference and an appreciable difference exceeding a minimal important difference (MID).

\section{Summary of findings 2. Risk-based recall versus 6-month recall}

\section{Clinical examination with risk-based recall compared with clinical examination with 6-month recall for oral health}

Population: primary care dental patients (aged $\geq 18$ years)

Setting: general dental practices

Intervention: clinical examination with risk-based recall

Comparison: clinical examination with 6-month recall

\begin{tabular}{|c|c|c|c|c|c|c|}
\hline \multirow[t]{2}{*}{ Outcomes } & \multicolumn{2}{|c|}{$\begin{array}{l}\text { Anticipated absolute } \\
\text { effects }{ }^{*}(95 \% \mathrm{Cl})\end{array}$} & \multirow{2}{*}{$\begin{array}{l}\text { Relative } \\
\text { effect } \\
(95 \% \mathrm{CI})\end{array}$} & \multirow{2}{*}{$\begin{array}{l}\text { Num- } \\
\text { ber of } \\
\text { partici- } \\
\text { pants } \\
\text { (stud- } \\
\text { ies) }\end{array}$} & \multirow{2}{*}{$\begin{array}{l}\text { Certain- } \\
\text { ty of } \\
\text { the evi- } \\
\text { dence } \\
\text { (GRADE) }\end{array}$} & \multirow[t]{2}{*}{ Comments } \\
\hline & $\begin{array}{l}\text { Risk } \\
\text { with 6- } \\
\text { month } \\
\text { recall }\end{array}$ & $\begin{array}{l}\text { Risk with } \\
\text { Risk-based } \\
\text { recall }\end{array}$ & & & & \\
\hline $\begin{array}{l}\text { Caries (adults } \mathbf{1 8 +} \text { years) } \\
\text { Prevalence of moderate to exten- } \\
\text { sive caries } \\
\text { Assessed with ICDAS (Codes } 3 \text { to } 6 \text { ) } \\
\text { Follow-up: } 4 \text { years }\end{array}$ & $\begin{array}{l}798 \text { per } \\
1000\end{array}$ & $\begin{array}{l}829 \text { per } 1000 \\
\text { (790 to } 869)\end{array}$ & $\begin{array}{l}\text { RR } 1.04 \\
(0.99 \text { to } \\
1.09)\end{array}$ & $\begin{array}{l}1478 \\
(1 \mathrm{RCT})\end{array}$ & $\begin{array}{l}\oplus \oplus \oplus \ominus \\
\text { MODER- } \\
\text { ATE1 }\end{array}$ & $\begin{array}{l}\text { Assignment to a risk-based recall interval probably results in little to } \\
\text { no difference in the prevalence of moderate to extensive caries com- } \\
\text { pared to a } 6 \text {-month recall interval. } \\
\text { Minimal important difference (MID) }=5 \%{ }^{2} \text { (we considered that a dif- } \\
\text { ference of }<5 \% \text { ( } 50 \text { per 1000) is unlikely to be perceived as important } \\
\text { by patients.) }\end{array}$ \\
\hline $\begin{array}{l}\text { Caries } \\
\text { Number of tooth surfaces with any } \\
\text { caries } \\
\text { Assessed with ICDAS (Codes } 1 \text { to } 6 \text { ) }\end{array}$ & $\begin{array}{l}\text { Mean } \\
14.7\end{array}$ & $\begin{array}{l}\text { MD } 0.15 \\
\text { higher (from } \\
0.77 \text { lower } \\
\text { to } 1.08 \text { high- } \\
\text { er) }\end{array}$ & - & $\begin{array}{l}1478 \\
(1 \mathrm{RCT})\end{array}$ & $\begin{array}{l}\oplus \oplus \oplus \oplus \\
\text { HIGH }\end{array}$ & $\begin{array}{l}\text { Assignment to a risk-based recall interval results in little to no differ- } \\
\text { ence in the number of tooth surfaces with any caries compared to a } \\
6 \text {-month recall interval.2 }\end{array}$ \\
\hline
\end{tabular}




\section{Periodontal disease}

Gingival bleeding: percentage of sites

Assessed with Gingival index of Löe

Follow-up: 4 years

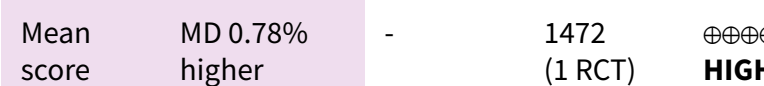

Assignment to a risk-based recall interval results in little to no difference in gingival bleeding compared to a 6 -month recall interval.

MID $=4.5 \% 2$ (i.e. we considered that a difference of $<4.5 \%$ is unlikely to be perceived as important by patients)

Assignment to a risk-based recall interval results in little to no difference in probing pocket depths compared to a 6-month recall interval: MD $0.03 \mathrm{~mm}\left(95 \% \mathrm{Cl}-0.01\right.$ to 0.07 ) (high-certainty evidence) ${ }^{2}$

Assignment to a risk-based recall interval results in little to no differ

\section{Oral-health-related quality of life}

Assessed with OHIP-14

\section{Mean MD 0.35}

score points low-

er (from 1.02

$\oplus \oplus \oplus \oplus$

lower to

Scale from: 0 to 56 points, with lower scores indicating better qual-

0.32 higher) ence in oral-health-related quality of life at 4 years compared to a 6 month recall interval.

MID = 2 points 2

ity of life.

Follow-up: 4 years

Other harms

Not reported

*The risk in the intervention group (and its $95 \% \mathrm{Cl}$ ) is based on the assumed risk in the comparison group and the relative effect of the intervention (and its $95 \% \mathrm{Cl}$ ). Only 1 trial (INTERVAL unpublished) provided data for the comparison between risk based and 6-month recall intervals. The assumed and corresponding risks are therefore based on the data from this trial.

CI: confidence interval; ICDAS: International Caries Detection and Assessment System; MID: minimal important difference; MD: mean difference; OHIP: Oral Health Impact Profile; RD: risk difference; RR: risk ratio; RRI: relative risk increase; RRR: relative risk reduction; SMD: standardised mean difference

\section{GRADE Working Group grades of evidence}

High certainty: we are very confident that the true effect lies close to that of the estimate of the effect

Moderate certainty: we are moderately confident in the effect estimate: the true effect is likely to be close to the estimate of the effect, but there is a possibility that it is substantially different

Low certainty: our confidence in the effect estimate is limited: the true effect may be substantially different from the estimate of the effect

Very low certainty: we have very little confidence in the effect estimate: the true effect is likely to be substantially different from the estimate of effect

1 We downgraded the certainty of evidence by 1 level for imprecision even though the limits of the confidence interval accompanying the risk ratio estimate did not reach the suggested GRADE threshold that should be considered for downgrading (a relative risk reduction (RRR) or relative risk increase (RRI) greater than $25 \%$ ). Our decision was based on the $95 \%$ confidence interval accompanying the risk difference estimate that included little to no difference and an appreciable difference exceeding a minimal important difference (RD 3\%, 95\% Cl-1\% to 7\%).

2 The methods used to identify MIDs for each outcome are described in the section of the review entitled "Summary of findings tables and methods used to assess the certainty of evidence". For the outcomes "number of tooth surfaces with any caries" and "probing pocket depths", we used a standardised mean difference (SMD) of 0.2 as the MID.

3 This was a participant-reported subjective outcome and participants were aware of the assigned recall interval. We did not consider that reporting of the outcome was likely to have been influenced by this knowledge to such an extent that it would introduce a material bias and therefore we did not downgrade the certainty of evidence. A detailed explanation for this decision is provided in the section of the review entitled "Results of applying GRADE to assess the certainty of evidence". 
Clinical examination with 24-month recall compared with clinical examination with 6-month recall for oral health

Population: primary care dental patients (aged $\geq 18$ years)

Setting: general dental practices

Intervention: clinical examination with 24-month recall

Comparison: clinical examination with 6-month recall

\begin{tabular}{|c|c|c|c|c|c|c|}
\hline \multirow[t]{2}{*}{ Outcomes } & \multicolumn{2}{|c|}{$\begin{array}{l}\text { Anticipated absolute } \\
\text { effects }^{*}(95 \% \mathrm{Cl})\end{array}$} & \multirow{2}{*}{$\begin{array}{l}\text { Relative } \\
\text { effect } \\
(95 \% \mathrm{CI})\end{array}$} & \multirow{2}{*}{$\begin{array}{l}\text { Num- } \\
\text { ber of } \\
\text { partici- } \\
\text { pants } \\
\text { (stud- } \\
\text { ies) }\end{array}$} & \multirow{2}{*}{$\begin{array}{l}\text { Certain- } \\
\text { ty of } \\
\text { the evi- } \\
\text { dence } \\
\text { (GRADE) }\end{array}$} & \multirow[t]{2}{*}{ Comments } \\
\hline & $\begin{array}{l}\text { Risk } \\
\text { with 6- } \\
\text { month } \\
\text { recall }\end{array}$ & $\begin{array}{l}\text { Risk with } \\
\text { 24-month } \\
\text { recall }\end{array}$ & & & & \\
\hline $\begin{array}{l}\text { Caries } \\
\text { Prevalence of moderate to ex- } \\
\text { tensive caries } \\
\text { Assessed with ICDAS (Codes } 3 \\
\text { to 6) }\end{array}$ & $\begin{array}{l}752 \text { per } \\
1000\end{array}$ & $\begin{array}{l}789 \text { per } \\
1000 \\
(692 \text { to } 902)\end{array}$ & $\begin{array}{l}\text { RR } 1.05 \\
(0.92 \text { to } \\
1.20)\end{array}$ & $\begin{array}{l}271 \\
(1 \mathrm{RCT})\end{array}$ & $\begin{array}{l}\oplus \oplus \ominus \ominus \\
\text { LOW'1 }\end{array}$ & $\begin{array}{l}\text { Assignment to a } 24 \text {-month recall interval probably results in little to no } \\
\text { difference in the prevalence of moderate to extensive caries compared } \\
\text { to a } 6 \text {-month recall interval. } \\
\text { Minimal Important Difference (MID) }=5 \%{ }^{2} \text { (i.e. we considered that a dif- } \\
\text { ference of }<5 \% \text { ( } 50 \text { per } 1000 \text { ) is unlikely to be perceived as important by } \\
\text { patients). }\end{array}$ \\
\hline Follow-up: 4 years & & & & & & \\
\hline $\begin{array}{l}\text { Caries } \\
\text { Number of tooth surfaces with } \\
\text { any caries } \\
\text { Assessed with ICDAS (Codes } 1 \\
\text { to 6) } \\
\text { Follow-up: } 4 \text { years }\end{array}$ & $\begin{array}{l}\text { Mean } \\
14.7\end{array}$ & $\begin{array}{l}\text { MD } 0.60 \\
\text { lower (from } \\
2.54 \text { lower } \\
\text { to } 1.34 \text { high- } \\
\text { er) }\end{array}$ & - & $\begin{array}{l}271 \\
(1 \mathrm{RCT})\end{array}$ & $\begin{array}{l}\oplus \oplus \oplus \ominus \\
\text { MODER- } \\
\text { ATE3 }^{3}\end{array}$ & $\begin{array}{l}\text { Assignment to a 24-month recall interval probably results in little to no } \\
\text { difference in the number of tooth surfaces with any caries compared to } \\
\text { a 6-month recall interval. }{ }^{2}\end{array}$ \\
\hline $\begin{array}{l}\text { Periodontal disease } \\
\text { Percentage of sites with gingi- } \\
\text { val bleeding } \\
\text { Assessed with Gingival index of } \\
\text { Löe } \\
\text { Follow-up: } 4 \text { years }\end{array}$ & $\begin{array}{l}\text { Mean } \\
\text { score } \\
35.3 \%\end{array}$ & $\begin{array}{l}\text { MD } 0.91 \% \\
\text { lower (from } \\
5.02 \% \text { low- } \\
\text { er to } 3.20 \% \\
\text { higher) }\end{array}$ & - & $\begin{array}{l}271 \\
(1 \mathrm{RCT})\end{array}$ & $\begin{array}{l}\oplus \oplus \oplus \ominus \\
\text { MODER- } \\
\text { ATE3 }^{3}\end{array}$ & $\begin{array}{l}\text { Assignment to a } 24 \text { month recall interval probably results in little to no } \\
\text { difference in gingival bleeding compared to a } 6 \text {-month recall interval. } \\
\text { MID }=4.5 \% 2 \text { (i.e. we considered that a difference of }<4.5 \% \text { is unlikely to } \\
\text { be perceived as important by patients). } \\
\text { Assignment to a } 24 \text {-month recall interval probably results in little to } \\
\text { no difference in probing pocket depths compared to a } 6 \text {-month recall }\end{array}$ \\
\hline
\end{tabular}




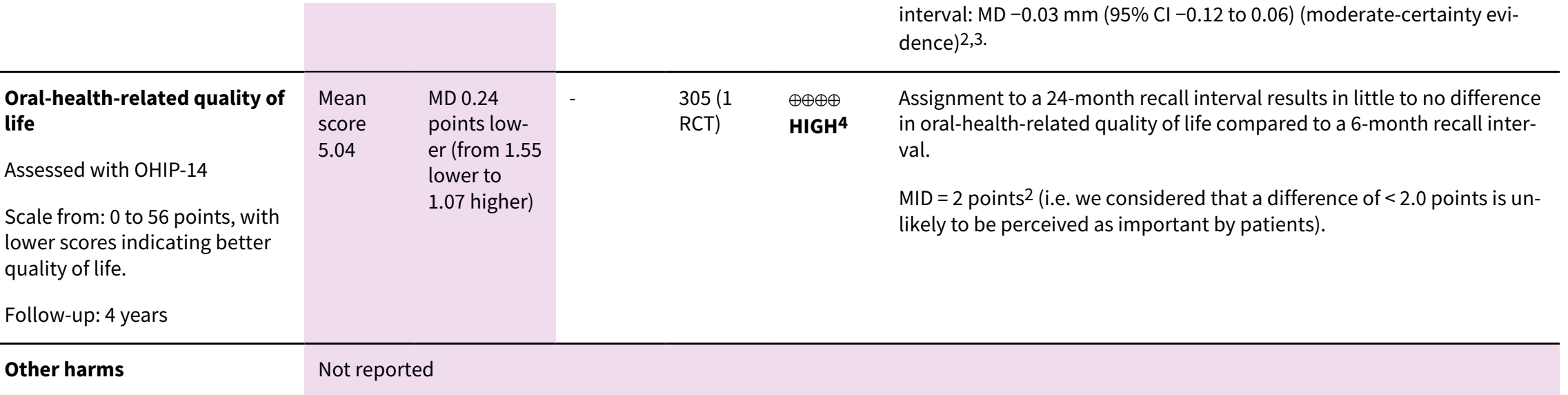

${ }^{*}$ The risk in the intervention group (and its $95 \% \mathrm{Cl}$ ) is based on the assumed risk in the comparison group and the relative effect of the intervention (and its $95 \% \mathrm{Cl}$ ). Only 1 trial (INTERVAL) provided data for the comparison between 24-month and 6-month recall intervals; the assumed and corresponding risks are therefore based on the data from this trial.

CI: confidence interval; ICDAS: International Caries Detection and Assessment System; MID: minimal important difference;MD: mean difference; OHIP: Oral Health Impact Profile; RD: risk difference; RR: risk ratio; RRI: relative risk increase; RRR: relative risk reduction; SMD: standardised mean difference

\section{GRADE Working Group grades of evidence}

High certainty: we are very confident that the true effect lies close to that of the estimate of the effect

Moderate certainty: we are moderately confident in the effect estimate: The true effect is likely to be close to the estimate of the effect, but there is a possibility that it is substantially different

Low certainty: our confidence in the effect estimate is limited: The true effect may be substantially different from the estimate of the effect

Very low certainty: we have very little confidence in the effect estimate: The true effect is likely to be substantially different from the estimate of effect

1 We downgraded the certainty of evidence by 2 levels for imprecision even though the limits of the confidence interval accompanying the risk ratio estimate did not reach the suggested GRADE threshold that should be considered for downgrading (a relative risk reduction (RRR) or relative risk increase (RRI) greater than 25\%). Our decision was based on the $95 \%$ confidence interval accompanying the risk difference estimate which included little to no difference and an appreciable difference exceeding a minimal important difference in both directions [RD $4 \%(95 \% \mathrm{Cl}-6 \%$ to $14 \%)$ ].

2 The methods used to identify MIDs for each outcome are described in the section of the review entitled "Summary of findings tables and methods used to assess the certainty of evidence". For the outcomes "number of tooth surfaces with any caries" and "probing pocket depths" we used a standardised mean difference (SMD) of 0.2 as the MID.

3 We downgraded the certainty of evidence by 1 level for imprecision. The $95 \%$ confidence interval included little to no difference and an appreciable difference exceeding a minimal important difference.

4 This was a participant-reported subjective outcome and participants were aware of the assigned recall interval. We did not consider that reporting of the outcome was likely to have been influenced by this knowledge to such an extent that it would introduce a material bias and therefore we did not downgrade the certainty of evidence. A detailed explanation for this decision is provided in the section of the review entitled "Results of applying GRADE to assess the certainty of evidence". 


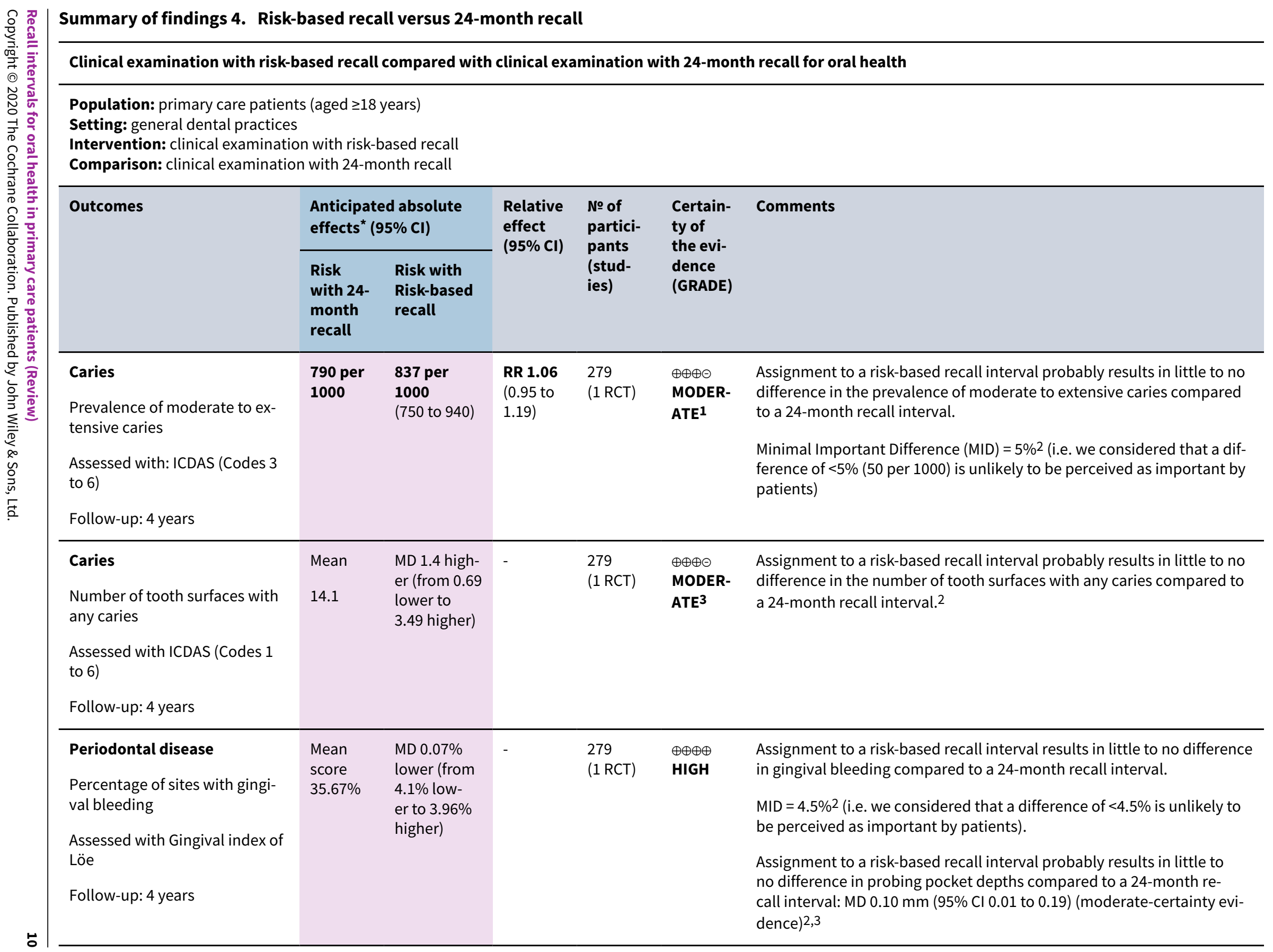


Oral-health-related quality of

life

Assessed with: OHIP-14

Scale from: 0 to 56 points, with lower scores indicating better quality of life.

Follow-up: 4 years

\section{0.37}

points low-

er (from 1.69

lower to

0.95 higher)
$298(1$

$\mathrm{RCT})$ $\oplus \oplus \oplus \oplus$

HIGH 4 in oral-health-related quality of life compared to a 24-month recall in-

terval.

$M I D=2$ points 2 (i.e. we considered that a difference of $<2.0$ points unlikely to be perceived as important by patients)

Other harms

Not reported

${ }^{*}$ The risk in the intervention group (and its $95 \% \mathrm{Cl}$ ) is based on the assumed risk in the comparison group and the relative effect of the intervention (and its $95 \% \mathrm{Cl}$ ). Only 1 trial (INTERVAL unpublished) provided data for the comparison between risk-based and 24 month recall intervals. The assumed and corresponding risks are therefore based on the data from this trial.

CI: confidence interval; ICDAS: International Caries Detection and Assessment System; MID: minimal important difference;MD: mean difference; OHIP: Oral Health Impact Profile; RD: risk difference; RR: risk ratio; RRI: relative risk increase; RRR: relative risk reduction; SMD: standardised mean difference

\section{GRADE Working Group grades of evidence}

High certainty: we are very confident that the true effect lies close to that of the estimate of the effect

Moderate certainty: we are moderately confident in the effect estimate: The true effect is likely to be close to the estimate of the effect, but there is a possibility that it is substantially different

Low certainty: our confidence in the effect estimate is limited: The true effect may be substantially different from the estimate of the effect

Very low certainty: we have very little confidence in the effect estimate: The true effect is likely to be substantially different from the estimate of effect

1 We downgraded the certainty of evidence by 1 level for imprecision even though the limits of the confidence interval accompanying the risk ratio estimate did not reach the suggested GRADE threshold that should be considered for downgrading (a relative risk reduction (RRR) or relative risk increase (RRI) greater than 25\%). Our decision was based on the $95 \%$ confidence interval accompanying the risk difference estimate, which included little to no difference and an appreciable difference exceeding a minimal important difference (RD $4.7 \%, 95 \% \mathrm{Cl}-4 \%$ to $14 \%$ ).

2 The methods used to identify MIDs for each outcome are described in the section of the review entitled "Summary of findings tables and methods used to assess the certainty of evidence". For the outcomes "number of tooth surfaces with any caries" and "probing pocket depths" we used a standardised mean difference (SMD) of 0.2 as the MID.

3 We downgraded the certainty of evidence by 1 level for imprecision. The $95 \%$ confidence interval included little to no difference and an appreciable difference exceeding a minimal important difference.

4 This was a participant-reported subjective outcome and participants were aware of the assigned recall interval. We did not consider that reporting of the outcome was likely to have been influenced by this knowledge to such an extent that it would introduce a material bias and therefore we did not downgrade the certainty of evidence. A detailed explanation for this decision is provided in the section of the review entitled "Results of applying GRADE to assess the certainty of evidence". 


\section{B A C K G R O U N D}

Oral disorders affect 3.5 billion people worldwide and impose substantial health and economic burdens on patients, healthcare payers and society. In 2015 the estimated direct costs of providing dental healthcare were USD 356.8 billion, corresponding to $4.6 \%$ of global health expenditure (Righolt 2018). A substantial proportion of that expenditure is attributed to the provision of non-complex procedures delivered by general dental practitioners (GDPs) such as routine dental check-ups and associated interventions. For example, in 2018 to 2019, National Health Service (NHS) dentists in England completed 39.7 million courses of treatment, of which simple clinical examinations were the most commonly carried out treatments for children and adults (NHS Digital 2019). In Scotland, in 2018 to 2019, the NHS delivered 2.8 million simple clinical exams (Statement of Dental Remuneration code 1a) at a total British pound sterling (GBP) cost of 25.3 million, accounting for $15 \%$ of all primary care dental spending (Information Services Division 2019).

Decisions about how frequently to recall patients for routine dental check-ups directly affect dentist workloads and may have a significant impact on healthcare costs and outcomes. In this context there has been a longstanding international debate regarding the clinical effectiveness and cost-effectiveness of assigning different recall intervals between routine dental check-up examinations (Clarkson 2009; DTB 1985; Elderton 1985a; Elderton 1985b; Kay 1999; Lahti 2001; Lock 1986; Perlus 1994; Renson 1977; Renson 2000; Sheiham 1977; Sheiham 1980; Sheiham 2000). This debate is complex and multifaceted. Decision-makers must consider the potential beneficial and adverse effects of different recall intervals on oral health. In addition they must also consider the long-term cost-effectiveness of resource allocation decisions, including the impact of the recall interval on the frequency of delivery of checkups and any associated dental interventions and the downstream cost implications associated with the treatment of any dental problems (e.g. fillings, extractions etc.) that may potentially arise due to an alteration of the recall interval. Finally, decision-makers must consider these issues from various stakeholder perspectives including the healthcare sector perspective, patient perspective and a wider societal perspective with a view to ensuring that scarce resources are being used to obtain the best value for money.

This review examines the evidence pertaining to the effects on oral health and the resource implications of different recall intervals between dental check-ups provided in primary care settings.

\section{Description of the intervention}

In the context of the provision of continuing dental care to patients, a 'recall visit' may be defined as "the planned, unprecipitated return of a patient who, when last seen was in good oral health" (Royal College 1997). A 'recall examination' (also referred to as a 'routine dental check-up' or an 'oral health review') is the examination performed at this planned return appointment. The 'recall interval' is the time period, usually specified in months or years, between recall examinations.

There is no universally recognised definition of the term 'routine dental check-up'. However, it can be considered as involving many of the following components: clinical examination (including documenting a patient's medical history), the provision of advice, charting (including assessment and recording of any malocclusion and monitoring of periodontal status), an explanation of the risks, as well as the costs, of any required treatment and a report (National Health Service 2020; National Health Service Regulations 2010). The principal function of the clinical examination component of the check-up is to detect the signs and symptoms of oral disease, in particular dental caries and periodontal disease. It is also recommended that an examination for oral cancer, including a thorough medical and social history and a systematic examination of the oral mucosa, should form an integral part of all routine dental examinations (BDA 2000; Clovis 2002; Conway 2002; Field 1995).

The 'advice' component of the dental recall examination is amenable to wide interpretation, but may be presumed to allude to professional advice directed towards the prevention of oral disease. It is recommended that preventive advice is tailored to meet the individual needs of patients and may incorporate: instruction on appropriate oral hygiene practices for the prevention of dental caries and periodontal disease (e.g. advice on the use of fluoride toothpaste and spitting out after brushing without rinsing, advice on the timing and frequency of appropriate toothbrushing and flossing); dietary advice (e.g. reducing the amount and frequency of intake of sugar-containing foods and drinks); and advice aimed at modifying risk factors for oral disease such as smoking cessation advice and alcohol-related health advice (NICE 2015; Public Health England 2014).

Other functions that can be ascribed to the recall examination include the regular monitoring of stages of dental development to ensure that interventions are appropriate and timely (e.g. orthodontic treatment for malocclusions); the detection of the oral manifestations of systemic disease and appropriate referral for further investigation; the maintenance of dentist/patient rapport; and the regular repetition and reinforcement of professional advice with a view to improving patient motivation and enhancing compliance with preventive recommendations. Recall examinations in the public dental services in some countries also regularly include specific preventive care such as the application of a fluoride gel or varnish (Wang 1995). In addition, it is common practice in many countries to provide a scale and polish treatment in conjunction with a recall examination. A 'routine scale and polish' involves the mechanical removal of local irritational factors (plaque, calculus, debris and staining) from the crown and root surfaces of teeth, which does not involve periodontal surgery or any form of adjunctive periodontal therapy such as the use of chemotherapeutic agents or root planing (Lamont 2018).

A dental check-up may therefore be associated with a package of dental services for a number of oral diseases and conditions (Spencer 2009). The recall interval between check-ups influences the frequency with which these services are provided. In many countries a 6-month recall interval has become an established practice and is commonly recommended by dental practitioners engaged in primary care (AAPD 2013; Anthonappa 2008; Clarkson 2009; Frame 2000; Gussy 2013; Patel 2010; Scott 2002). However, the clinical and cost-effectiveness of 6-month recall intervals have increasingly been questioned in light of recent changes in the epidemiology of dental diseases and in the interests of costcontainment and the efficient use of scarce resources (Audit Commission 2002; DH 2000; DH 2002; HDA 2001; Sheiham 2000; Tan 2006). 


\section{How the intervention might work}

The time period between dental check-ups may impact on oral health by influencing the periodicity of clinical examinations and any associated primary and secondary preventive measures. Short recall intervals (more frequent dental check-ups) may improve oral health by increasing the frequency with which the oral health of patients is reassessed and monitored and by allowing prompt preventive or therapeutic care to be delivered, which may impact favourably on the clinical course of disease. Consequently, this might lessen the cost burden to patients and the healthcare system if reductions in the need for downstream treatment of dental disease could be averted.

However, short recall intervals may also increase the potential for iatrogenic over-diagnosis and over-treatment. Any unnecessary or premature over-treatment in the absence of clinical need or patient preference may consequently increase costs to the health system, as well as to patients in terms of co-charges and the opportunity cost of time and travel. Such allocation of scarce resource may be inefficient and prevent dental professionals spending time on activities that might generate greater benefit for patients or society.

In contrast, longer recall intervals may reduce iatrogenesis and short-term resource consumption but may also compromise oral health by reducing the frequency of the delivery of preventive advice and delaying the diagnosis of dental disease, thereby resulting in more extensive and costly care. In England it has also been argued that lengthening recall intervals for patients at low risk of (or from) dental disease "can allow NHS dentists and their teams to tackle health inequalities through having more time and resources to focus on providing access to new patients and prevention" (DH 2011).

In recent years the concept of assigning risk-based recall intervals has gained increasing support internationally, arising from changes in the epidemiology of dental diseases, particularly dental caries. Since the 1970s the prevalence and severity of dental caries in many developed countries has decreased dramatically and the rate of progression of the disease has slowed (Brown 1995; Mejare 1999; Mejare 2004; Pitts 1983). Caries experience in many contemporary populations also exhibits a skewed distribution with a majority of children and adolescents having little or no disease, whilst for a minority the caries experience remains relatively high (Hausen 1997). In particular, it has been consistently observed that caries experience is generally more extensive and severe in lower socioeconomic status groups (Burt 1999). Variations in the distribution of dental disease within populations, when considered in conjunction with variations in the risk of developing oral disease between individual patients, casts doubt on the appropriateness of assigning a 'fixed and universal' recall interval (e.g. six months) for all patients. In this context it has been argued that recall intervals should be patient-specific (individualised) based on an assessment of the patient's risk of (or from) oral disease (AAPD 2013; Clarkson 2009; Deep 2000; DH 2000; HDA 2001; Lahti 2001; Perlus 1994; Riordan 1997). Dental healthcare providers can then appropriately modify the recall interval over time in accordance with any change in the patient's risk.

The rationale underpinning the risk-based recall approach for the management of dental caries is that it should be possible to extend recall intervals for those individuals classified as 'low caries risk' without incurring any undue detrimental effect on their oral health status and ultimately reducing resource consumption. Relatively shorter recall intervals can then be adopted for those individuals with the greatest need who are classified as 'high caries risk'. Similarly, for periodontal disease it has been argued that recall intervals should be individualised and based on an evaluation of the patient's oral hygiene, disease activity, individual susceptibility and disease history (Brothwell 1998). In the UK, the justification for regular screening of all patients for oral cancer at 6-month intervals has also been questioned on the grounds that the number of cases of oral malignancy is small and usually confined to patients at 'high risk' (due to tobacco use and excessive consumption of alcohol) over the age of 45 years (Sheiham 1977; Sheiham 1980). In Scotland, where the incidence of oral cancer is highest in the UK, it has been estimated that a dentist potentially encounters only one case of oral cancer every ten years. Furthermore, approximately $54 \%$ of patients diagnosed with oral cancer in Scotland had not attended an NHS primary care dentist in the two years preceding diagnosis, thus radically decreasing the opportunity for early detection of the disease in general dental practice (Purkayastha 2018).

\section{Why it is important to do this review}

Traditionally, patients have been encouraged to attend for routine dental check-ups at regular 6-month intervals, irrespective of their risk of developing dental disease. There is, however, a weak evidence-base underpinning this recommendation. The evidence regarding the potential beneficial and harmful effects of dental check-up recall intervals on oral health outcomes is primarily derived from observational epidemiological studies. Systematic reviews have highlighted the methodological limitations of these studies and the very low certainty of the evidence (Davenport 2003; Patel 2010).

Risk-assessment-derived recall intervals for dental check-up examinations have recently been endorsed by professional expert bodies, adopted by school dental service programmes, incorporated into dental health service reform initiatives and advocated in clinical practice guidelines in several countries (AAPD 2013; DHSC 2018; Lam 2012; Riordan 1997; Steele 2009). In England and Wales the National Institute for Health and Care Excellence (NICE) has issued guidance recommending that the interval between oral health reviews "should be determined specifically for each patient and tailored to meet his or her needs, on the basis of an assessment of disease levels and risk of or from dental disease" (NICE 2004). The guideline recommendations are based on low-quality evidence and the clinical experience of the guideline development group. An update of this guidance in June 2018 found no new evidence that would alter the recommendations. However, the guideline surveillance report noted that "an important ongoing trial was identified - Investigation of NICE Technologies for Enabling Risk-Variable-Adjusted-Length Dental Recalls Trial (INTERVAL Dental Recalls Trial). We will monitor the progress of this trial and assess the results for any impact on the guideline when available" (NICE 2018).

Previous versions of this Cochrane Review have highlighted the absence of good-quality evidence pertaining to the clinical effectiveness and cost-effectiveness of recall intervals between dental check-ups (Beirne 2005; Beirne 2007; Riley 2013). Continuous updates of this review are required to incorporate any new evidence from RCTs, including the INTERVAL Dental Recalls Trial, that can be used to inform clinical practice guideline recommendations and to facilitate clinical decision-making. 
Finally, this review was identified as a priority title during an extensive prioritisation exercise undertaken by the Cochrane Oral Health Group in order to identify a core portfolio of clinically important titles to maintain in the Cochrane Library (Cochrane OHG priority review portfolio; Worthington 2015).

\section{O B J E C T IVES}

To determine the optimal recall interval of dental check-up for oral health in a primary care setting.

\section{METHODS}

\section{Criteria for considering studies for this review}

\section{Types of studies}

We included randomised controlled trials (RCTs) in this review.

\section{Types of participants}

We included trials involving children and adults receiving dental check-ups in primary care settings, irrespective of their level of risk for oral disease.

\section{Types of interventions}

We included studies comparing recall intervals for dental check-ups of any fixed length against any of the following comparators.

- Different fixed-length interval

- Risk-based interval (decided by the clinician)

- No recall or patient-driven attendance (may be symptomatic)

We excluded studies where the type of check-up was different in each group being compared, for example in terms of clinical examination only, clinical examination plus preventive advice, etc.

\section{Types of outcome measures}

\section{Clinical status outcomes}

- Dental caries measured using any appropriate scale

- Periodontal disease measured using any appropriate scale

- Presence/absence of mucosal lesions, potentially malignant lesions, cancerous lesions

- Size and stage of cancerous lesions at diagnosis

- Dento-facial development

\section{Psychosocial (patient-centred) outcomes}

- Any assessment of patients' oral-health-related quality of life, provided this was recorded in a reproducible and validated format

- Patient/parent satisfaction with provider of care (i.e. dentist, hygienist, therapist)

- Patient/parent satisfaction with actual care received

- Patient oral comfort

- Patient/parent satisfaction with appearance

\section{Cost outcomes}

Costs to patient (patient-perspective costs)

Costs to patients may consist of:
- direct out-of-pocket costs incurred by patients (e.g. out-ofpocket payments for care received (patient co-charges));

- indirect costs (e.g. foregone wages, costs of transportation, childcare expenses or other opportunity costs of time and travel).

\section{Costs to the health system (health-system-perspective costs and} resource use)

Costs to the health system may include:

- the direct costs of providing and paying for the publicly provided care (including full payment for patients exempt from patient charges);

- resources used to deliver care;

* dentist, hygienist, therapist and other personnel time;

* materials, overheads, equipment used;

- costs to the healthcare system or third party provider.

\section{Other outcomes}

- Improvements in oral health knowledge and attitudes, harms (such as fluorosis, overtreatment), changes in dietary habits and any other oral-health-related behavioural changes where reported

\section{Search methods for identification of studies}

\section{Electronic searches}

Cochrane Oral Health's Information Specialist conducted systematic searches in the following databases for randomised controlled trials and controlled clinical trials. There were no language, publication year or publication status restrictions.

- Cochrane Oral Health's Trials Register (searched 17 January 2020) (Appendix 1);

- Cochrane Central Register of Controlled Trials (CENTRAL; 2019, Issue 12) in the Cochrane Library (searched 17 January 2020) (Appendix 2);

- MEDLINE Ovid (1946 to 17 January 2020) (Appendix 3);

- Embase Ovid (1980 to 17 January 2020) (Appendix 4).

We modelled subject strategies on the search strategy designed for MEDLINE Ovid. Where appropriate, we combined them with subject strategy adaptations of the Highly Sensitive Search Strategy designed by Cochrane for identifying randomised controlled trials and controlled clinical trials as described in the Cochrane Handbook for Systematic Reviews of Interventions Chapter 6 (Lefebvre 2011).

\section{Searching other resources}

We searched the following trial registries for ongoing studies.

- US National Institutes of Health Ongoing Trials Register (ClinicalTrials.gov; searched 17 January 2020) (Appendix 5);

- World Health Organization International Clinical Trials Registry Platform (apps.who.int/trialsearch; searched 17 January 2020) (Appendix 6).

We checked the reference lists of all potentially eligible trials for more relevant studies. We also scanned reference lists from review articles identified in the searches for further studies. 
We contacted, where possible, the author(s) of eligible published studies and any researchers involved in the ongoing debate on recall intervals to obtain information on additional published or unpublished studies possibly eligible for inclusion.

We checked that none of the included studies in this review were retracted due to error or fraud.

\section{Data collection and analysis}

\section{Selection of studies}

Two review authors, independently and in duplicate, assessed the titles, keywords and abstracts (when available) of all reports identified by the search strategy. The review authors remained unblinded regarding the author(s), their institutional affiliations and the site of publication of reports. The search was designed to be sensitive and include controlled clinical trials; we filtered out those not randomised early in the selection process. We obtained the full report for all studies appearing to meet the inclusion criteria or in instances where there was insufficient information from the title, keywords and abstract to make a clear decision. One study was unpublished but we were able to obtain a prepublication copy of the manuscript as four of the authors of this review were trial investigators for that study. Two review authors independently assessed all of the potentially relevant studies for eligibility. Instances of disagreement in the study selection process were referred to other members of the review team and ultimately resolved by discussion among all review team members. We recorded studies rejected at this or subsequent stages in the Characteristics of excluded studies table, noting reasons for exclusion. All of the studies meeting the inclusion criteria were subjected to data extraction and risk of bias assessment.

\section{Data extraction and management}

Two review authors extracted data independently and in duplicate, using specially designed and piloted data extraction forms. We extracted details of the trial methods, participants, interventions and outcomes, and present these in the Characteristics of included studies table. We resolved disagreements on data extraction by discussion among all of the review team members. Four review authors were trial investigators for one of the included studies and were therefore not involved in the data extraction for that study (INTERVAL 2020).

\section{Assessment of risk of bias in included studies}

Two review authors assessed the risk of bias in the included studies, independently and in duplicate, using the 'Risk of bias' tool described in Chapter 8 of the Cochrane Handbook for Systematic Reviews of Interventions (Higgins 2011a). Four review authors were trial investigators for one of the included studies and were therefore not involved in the risk of bias assessment for that study (INTERVAL 2020). For each trial we assessed the following six domains.
1. Random sequence generation (selection bias)
2. Allocation concealment (selection bias)
3. Blinding of outcome assessment (detection bias)
4. Incomplete outcome data (attrition bias)
5. Selective reporting (reporting bias)
6. Other bias (any other potential source of bias that may feasibly alter the magnitude of the effect estimate)

For each domain we reached a judgement of low risk of bias, high risk of bias, or unclear risk of bias. We provided justification for all judgements in the 'Risk of bias' tables and in the Risk of bias in included studies section of the review. Our judgements were based on the risk of material bias (rather than the risk of any bias) and we only expressed concerns about issues that we considered were likely to affect the ability to draw reliable conclusions from included trials. For the purposes of this review, we defined 'material bias' as "bias of sufficient magnitude to have a notable impact on the results or conclusions of the trial, recognising that subjectivity is involved in any such judgement" (Higgins 2011b). We summarised the risk of bias as follows.

\begin{tabular}{llll}
\hline Risk of bias & Interpretation & In outcome & In included studies \\
\hline Low risk of bias & $\begin{array}{l}\text { Plausible bias unlikely to seriously } \\
\text { alter the results }\end{array}$ & $\begin{array}{l}\text { Low risk of bias for all key } \\
\text { domains }\end{array}$ & $\begin{array}{l}\text { Most information is from studies at low risk of } \\
\text { bias }\end{array}$ \\
\hline $\begin{array}{l}\text { Unclear risk of } \\
\text { bias }\end{array}$ & $\begin{array}{l}\text { Plausible bias that raises some } \\
\text { doubt about the results }\end{array}$ & $\begin{array}{l}\text { Unclear risk of bias for } \\
\text { one or more key domains }\end{array}$ & $\begin{array}{l}\text { Most information is from studies at low or un- } \\
\text { clear risk of bias }\end{array}$ \\
\hline High risk of bias & $\begin{array}{l}\text { Plausible bias that seriously weak- } \\
\text { ens confidence in the results }\end{array}$ & $\begin{array}{l}\text { High risk of bias for one } \\
\text { or more key domains }\end{array}$ & $\begin{array}{l}\text { The proportion of information from studies at } \\
\text { high risk of bias is sufficient to affect the inter- } \\
\text { pretation of results }\end{array}$ \\
\hline
\end{tabular}

We did not consider blinding of participants and personnel (performance bias) as a risk of bias domain. This decision was informed by our judgement that the intervention under consideration in this review (the recall interval between dental check-ups) could be considered a 'complex intervention' and also took into account contemporary debates over blinding in pragmatic randomised controlled trials. We elaborate on the rationale for our decision below.
Our review addressed a question of direct relevance to everyday clinical dental practice and sought to quantify the pragmatic effect on oral health of assigning different recall intervals between dental check-ups. In this context our review focused on evidence from pragmatic randomised controlled trials conducted in primary care settings. In such settings we considered that alteration of the recall interval between dental check-ups could be regarded as a complex intervention that involved a number of separate but interacting components that may impact on oral 
health outcomes in several ways. For example, a component of many complex healthcare interventions is the "therapeutic relationship" or "patient-practitioner interaction" (Foster 2012). Reducing the frequency of such interaction by lengthening the recall interval between dental check-ups might be anticipated to have a detrimental impact on oral health outcomes. However, any negative impact could potentially be countered by other plausible changes in patient or provider behaviour. For example, patients attending less frequently may adopt more intensive personal oral hygiene practices to reduce the risk of a deterioration in oral health between dental check-ups. In addition dental care providers may engage in greater advocacy of oral hygiene measures during dental examinations for patients attending less frequently. In pragmatic RCTs that seek to estimate complex intervention effects in real world settings, any such changes in patient or provider behaviour should be regarded as integral components of the complex intervention and not as forms of performance bias per se; that is, any patient and care provider behaviour changes arising from knowledge of the assigned recall interval should be incorporated into estimates of effectiveness, thereby rendering the findings more applicable to usual care settings. We therefore did not consider it appropriate to consider participant or care provider knowledge of the assigned recall interval between dental check-ups as a risk of bias issue in this review. This decision is supported by contemporary debates over blinding in pragmatic trials where it has been argued that blinding may be neither feasible nor desirable in such trials (Mansournia 2017); that pragmatism is heavily compromised by blinding (Dal-Ré 2018); and that a trial with blinded interventions is not fully pragmatic (Ford 2016).

\section{Measures of treatment effect}

For continuous outcomes (e.g. caries - decayed, missing, filled surfaces), we used the mean values and standard deviations reported in the study in order to express the estimate of effect of the intervention as mean difference (MD) with $95 \%$ confidence interval (CI). If different scales were used, we would have expressed the treatment effect as standardised mean difference (SMD) and 95\% Cl.

For dichotomous outcomes (e.g. presence/absence of mucosal lesions), we expressed the estimate of effect of the intervention as a risk ratio (RR) with $95 \% \mathrm{Cl}$.

\section{Unit of analysis issues}

The included trials were parallel group trials where participants were individually randomised to the comparison groups. Unit of analysis issues did not arise in the review. If cluster-RCTs had been included we would have checked to ensure that trial authors analysed results taking into account the clustering present in the data. Otherwise we would have used the methods outlined in Section 16.3.4 of the Cochrane Handbook for Systematic Reviews of Interventions in order to perform an approximately correct analysis (Higgins 2011b).

\section{Dealing with missing data}

We contacted the authors of included studies to attempt to clarify risk of bias issues arising from missing data. It was not necessary to estimate missing standard deviations as outlined in Section 7.7.3 of the Cochrane Handbook for Systematic Reviews of Interventions (Higgins 2011b). We did not use any additional statistical methods or carry out any further imputation to account for missing data.

\section{Assessment of heterogeneity}

If meta-analyses had been performed, we would have assessed the possible presence of heterogeneity by visual inspection of the point estimates and $\mathrm{Cls}$ on the forest plots; if the $\mathrm{Cls}$ had poor overlap then we would have considered heterogeneity to be present. We would also have assessed heterogeneity statistically using a $\mathrm{Chi}^{2}$ test, where a $\mathrm{P}$ value less than 0.1 indicates statistically significant heterogeneity. Furthermore, we would have quantified heterogeneity using the $\mathrm{I}^{2}$ statistic. A guide to interpretation of the $I^{2}$ statistic given in Section 9.5.2 of the Cochrane Handbook for Systematic Reviews of Interventions is as follows (Higgins 2011b).

- $0 \%$ to $40 \%$ : might not be important;

- $30 \%$ to $60 \%$ : may represent moderate heterogeneity;

- $50 \%$ to $90 \%$ : may represent substantial heterogeneity;

- $75 \%$ to $100 \%$ : considerable heterogeneity.

\section{Assessment of reporting biases}

If there had been more than 10 studies in a meta-analysis, we would have assessed possible publication bias by visually inspecting a funnel plot for asymmetry. If detected, we would have carried out further investigation using the methods described by Egger 1997 for continuous outcomes and Rücker 2008 for dichotomous outcomes.

\section{Data synthesis}

We performed no meta-analyses in this review. We would only have carried out a meta-analysis where studies of similar comparisons reported the same outcomes. We would have combined MDs (standardised mean differences where studies had used different scales) for continuous outcomes, and would have combined RRs for dichotomous outcomes. Our general approach was to use a random-effects model. With this approach, when pooling studies the $\mathrm{Cls}$ for the average intervention effect would be wider than those that would have been obtained using a fixed-effect approach, leading to a more conservative interpretation.

\section{Subgroup analysis and investigation of heterogeneity}

If there were sufficient numbers of studies, we planned to conduct subgroup analyses, where possible, according to age and for participants at different levels of risk for oral disease.

\section{Sensitivity analysis}

If there were sufficient numbers of studies, we planned to conduct sensitivity analyses by excluding studies at high and unclear risk of bias from the meta-analyses.

\section{'Summary of findings' tables and methods used to assess the certainty of evidence}

We produced a 'Summary of findings' (SoF) table for each comparison using the GRADEpro GDT online tool (www.guidelinedevelopment.org). We included the following outcomes in the SoF tables.

- Dental caries: prevalence of moderate to extensive caries (ICDAS 3 to 6$)$

- Dental caries: number of tooth surfaces with any caries (ICDAS 1 to 6$)$

- Periodontal disease: proportion of sites with gingival bleeding

- Oral-health-related quality of life 


\section{- Other harms}

The outcomes included in the SoF tables were not defined a priori in the protocol for this review, which was originally published in 2003 prior to the use of SoF tables and the adoption of the GRADE system within Cochrane Reviews (GRADE 2004). We selected outcomes based on discussion and consensus within the review team regarding the outcomes that would be considered most important by patients and clinicians. For example, we decided to include the composite outcome of "prevalence of moderate to extensive caries" (ICDAS codes 3 to 6 ) on the grounds that it included 'obvious' carious lesions that would be of concern to patients. Furthermore ICDAS codes 3 to 6 include lesions that would be considered for restorative intervention by clinicians (localised enamel breakdown due to caries with no visible dentine, underlying dark shadow from dentine, distinct cavity with visible dentine, extensive distinct cavity with visible dentine). We also included the number of tooth surfaces with any caries (ICDAS 1 to 6 ) in the SoF tables because this outcome incorporated both advanced lesions and initial stage decay (code 1: initial caries; code 2: distinct visual change in enamel). These initial lesions would not be perceptible to patients but would be of interest to clinicians as they may be amenable to preventive intervention with a view to reducing the risk of progression to more advanced lesions.

Our selection of caries' outcomes also took into consideration the need to avoid 'multiplicity issues' when analysing data, as described in Section 16.7.2 of the Cochrane Handbook for Systematic Reviews of Interventions (Higgins 2011b). For each comparison considered in the review we could have presented individual results for each of the seven codes (0 to 6 ) in the ICDAS system. However, performing seven individual analyses under each comparison would significantly increase the risk of generating spurious findings by chance alone. We therefore considered it appropriate to use composite caries outcomes in the review that we considered to be of the greatest clinical relevance.

We assessed the certainty of the body of evidence in relation to each comparison and outcome using the evidence grading system developed by the GRADE collaboration (Schünemann 2009). We categorised the certainty of each body of evidence as high, moderate, low or very low. We used the recommended 'informative statements' specified by the GRADE collaboration to provide a narrative description of the review findings for each outcome in the SoF tables and throughout the main text of the review (Santesso 2019). We took the following factors into consideration when deciding whether or not to downgrade the certainty of evidence in relation to each outcome.

\section{Risk of bias}

The procedures used to assess the risk of bias are described in the Assessment of risk of bias in included studies section of the review. We downgraded the certainty of evidence by one level if we judged that there was a plausible source of material bias that reduced our confidence in an effect estimate. We downgraded the certainty of evidence by two levels if we judged that there was a crucial risk of material bias that seriously weakened our confidence in an effect estimate.

\section{Inconsistency}

Where outcomes were reported in only one trial (i.e. a single trial evidence-base) we judged that inconsistency was unknown and we did not downgrade the certainty of evidence. Where outcomes were reported from several trials we planned to assess inconsistency by examining: any variations between the effect estimates reported in included trials; the degree of overlap of the Cls accompanying effect estimates; and the results of any statistical tests for heterogeneity in meta-analyses and the value of the $\mathrm{I}^{2}$ statistic (which describes the percentage of total variation across studies that is due to heterogeneity rather than chance). We planned to consider downgrading the certainty of evidence if inconsistency was large and unexplained, particularly if there were some trials suggesting substantial benefit associated with a specific recall interval and other trials indicating no effect or harm from the same recall interval.

\section{Imprecision}

We assessed imprecision by considering the numbers of participants included in analyses and the confidence intervals (Cls) around effect estimates. We downgraded by one level for imprecision where the $95 \% \mathrm{Cl}$ accompanying an effect estimate included little or no effect and appreciable benefit or appreciable harm. We downgraded by two levels if we judged that there was serious imprecision due to a very wide confidence interval.

We used minimal important differences (MIDs) as thresholds for appreciable benefit or appreciable harm. We identified MIDs for each outcome using methods recommended by the US Agency for Healthcare Research and Quality and the GRADE collaboration (AHRQ 2012 and Santesso 2019, respectively). These methods included:

- reviews of the literature to identify empirical studies of the smallest change in a particular outcome that patients perceive as important;

- using MIDs specified in the power calculations of relevant studies;

- using MIDs suggested by prominent authorities;

- discussions within the systematic review team.

The defined MIDs were also used throughout the review to facilitate the interpretation of results and to evaluate statistical significance (or the absence thereof) in the context of clinical relevance.

\section{MIDs for dichotomous outcomes}

We used the suggested GRADE threshold for appreciable benefit or appreciable harm of a relative risk reduction or a relative risk increase greater than $25 \%$. We also considered the importance of absolute effects (i.e. risk differences (RD)), however, and the precision of absolute estimates based on how likely it seemed to us that some people would make different decisions if the true effect was near one end or the other of the $95 \%$ confidence interval (as recommended in EPOC 2018). In this context, we used a RD of $5 \%$ as the MID for the composite caries outcome "prevalence of moderate to severe caries". This figure was based on discussion and consensus among the review team as we were unable to identify an MID for this outcome from other sources.

\section{MIDs for continuous outcomes}

Gingivitis: we used a $4.5 \%$ difference in the proportion of sites with gingival bleeding as the MID. This value was based on the smallest effect size specified in the power calculations performed for the INTERVAL dental recall trial. 
Oral-health-related quality of life: a review of the literature on oral-health-related quality of life measured using the Oral Health Impact Profile-14 (OHIP-14) indicated that MIDs were dependent on the population and the type of treatment received. Reported MIDs, expressed as standardised mean differences, varied from 0.32 (Locker 2004) to 0.5 (Baba 2008). When expressed in terms of scale points, reported MIDs varied from two points in patients undergoing prosthodontic treatment (Bassetti 2016) to five points in elderly people undergoing routine dental treatment (Locker 2004). We used the lower identified value as the MID, that is a conservative two-point difference (approximately $3.5 \%$ of the scale range of 56 points).

For all other continuous outcomes (e.g. the number of tooth surfaces with any caries) it was not possible to specify an MID, due either to an absence of information in the scientific literature or due to an absence of review team consensus. For these outcomes we considered the intervention effect expressed in standard deviation units (SD) as standardised mean differences (SMDs) (also known as a Cohen's effect size) and we used an SMD of 0.2 as the threshold value for defining appreciable benefit or harm (0.2 represents a "small effect" as defined by Cohen 1988), that is we considered downgrading for imprecision if the $95 \% \mathrm{Cl}$ accompanying a point estimate included little or no effect and if the upper or lower confidence limits crossed an effect size (SMD) of 0.2 in either direction.

\section{Indirectness}

We assessed indirectness by considering:

- populations (i.e. differences between the characteristics of trial participants and the population of interest in the review);

- interventions (i.e. differences between the intervention or manner of intervention delivery in trials (including rigour, intensity of delivery and delivery setting) and the intervention as defined in the review);

- comparisons (i.e. the absence of direct 'head-to-head' comparisons between two or more interventions of interest);

- outcomes (i.e. the use of surrogate endpoints in place of participant-important outcomes).

Taking these assessments into account, we judged the degree to which the evidence we found directly answered the review question and addressed the review objectives. We downgraded by one level if we judged that indirectness existed or by two levels if we deemed indirectness to be severe or if there were several sources of indirectness.

\section{Publication bias}

We assessed publication bias by considering the size of the included studies and the number of included events. We planned to conduct tests for funnel plot asymmetry if we found at least 10 trials to include in a meta-analysis (Sterne 2011). We planned to downgrade the certainty of evidence by a maximum of one level only if publication bias was strongly suspected. We planned not to downgrade if publication bias was either undetected or was deemed unlikely to have occurred based on our search strategy.

\section{Incorporating economic evidence}

We adopted the "brief economic commentary" (BEC) approach to incorporate an economic perspective into the review. The methodology follows that described in Chapter 20 of the Cochrane Handbook for Systematic Reviews of Interventions version 6.0 (Higgins 2019; Shemilt 2019). The aim of the BEC was to summarise the availability and principal findings of trial- and model-based full economic evaluations (defined as a comparative assessment of costs and outcomes within a cost-effectiveness, cost-utility or cost-benefit analysis framework). We included full economic evaluations that compared fixed-length, risk-based, or no recalls for children or adults receiving dental check-ups in a primary care setting, regardless of oral disease risk. We excluded studies evaluating different types of check-ups (e.g. simple versus extensive). This BEC focuses on the principal findings of the eligible economic evaluations and discusses the likely implications regarding whether different approaches to assigning recall intervals for dental check-ups might be considered an efficient use of scarce resources from a health system, patient and societal perspective.

We conducted an initial search of PubMed to identify cost-of-illness studies describing, measuring and valuing the total resources used in the management of the most common oral diseases. We used the results of this search to inform the Background section of the review. We conducted a supplementary search strategy to identify relevant health economic evaluations to inform the BEC. The search process to identify full economic evaluation studies included a search of NHSEED up to March 2015 and a supplementary search of MEDLINE (1946 to April 2020) and Embase (1980 to April 2020) using the Scottish Intercollegiate Guideline Network filters for identifying economic studies. The full search strategy for the identification of economic evidence is available in Appendix 7, Appendix 8 and Appendix 9.

We extracted basic data on the characteristics of any identified economic evaluation including the analytical framework (trial-based or model-based analysis), the type of economic valuation (cost-effectiveness, cost-utility, cost-benefit analysis), the analytical perspectives, time horizon, setting, main cost items (including currency and price year). We also collected data on the principal findings of analyses including verbatim text on conclusions drawn by authors and text that summarised any uncertainty surrounding the authors' principal conclusions (in the form of the results of any sensitivity analyses conducted).

We did not critically appraise any identified economic evaluations. The BEC simply focused on the extent to which principal findings of eligible economic evaluations indicated that one recall interval might be judged favourably (or unfavourably) over another recall interval from an economic perspective, when implemented in a primary care setting. The findings of the BEC are provided in the Discussion section of the review.

\section{RES U LT S}

\section{Description of studies}

\section{Results of the search}

The searches yielded 2289 references and, following deduplication, this number was reduced to 1423 references. Two review authors screened the titles and abstracts against the inclusion criteria for this review, independently and in duplicate, discarding 1419 references in the process. We obtained full-text copies of four references, one of which was unpublished but 
the authors provided a prepublication copy of the manuscript. We examined the full-text copies independently and in duplicate, resulting in two being excluded: two studies, therefore, met the inclusion criteria for this review. We present the study flow process diagrammatically in Figure 1. 
Figure 1. Study flow diagram.
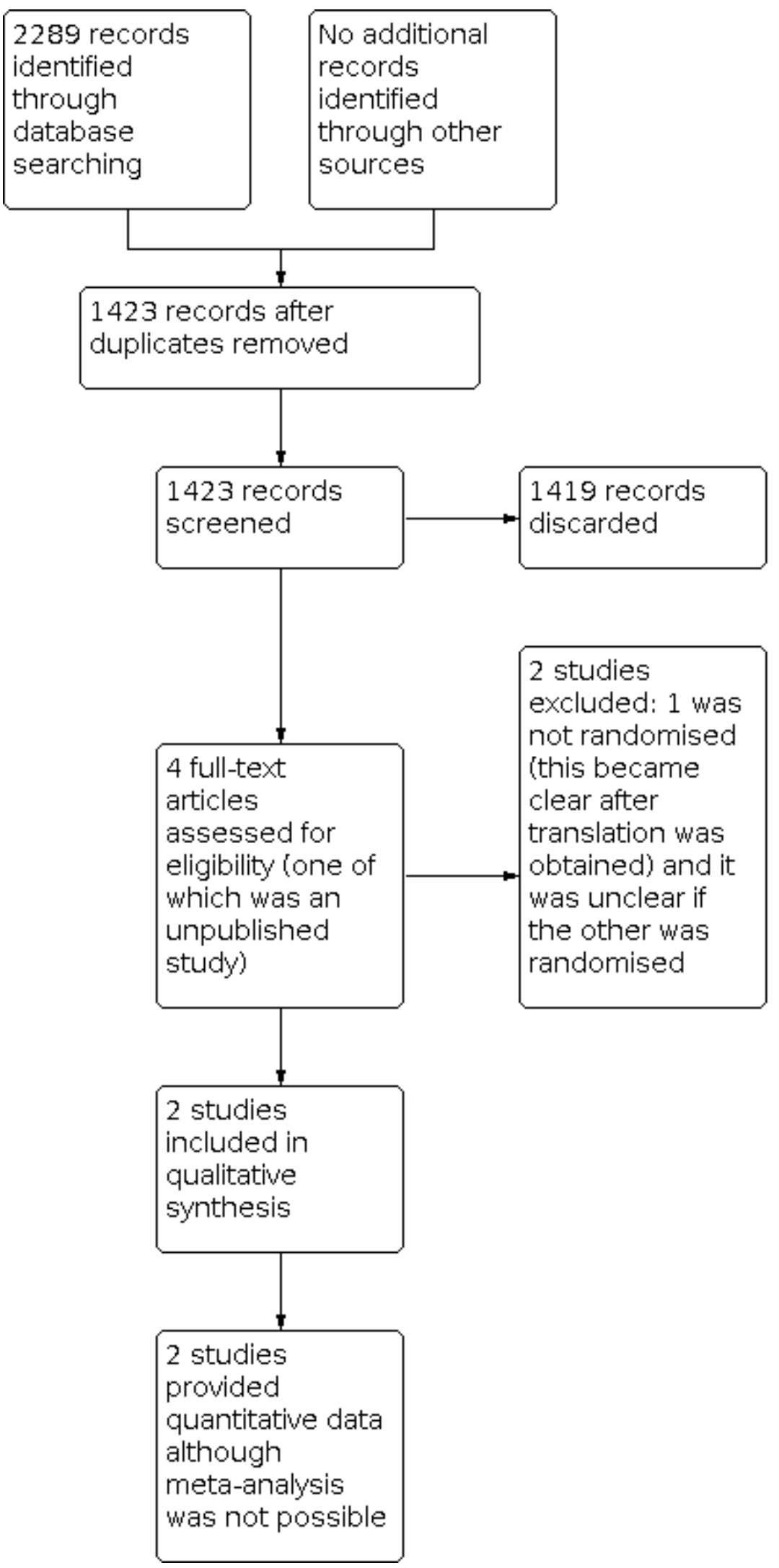


\section{Included studies}

We included two studies in this review (INTERVAL 2020; Wang 1992) (Characteristics of included studies table).

\section{Characteristics of the trial designs and settings}

One study was a multicentre trial and took place in 51 general dental practices across the UK (INTERVAL 2020), whilst the other study was conducted in a single public dental clinic in Norway (Wang 1992). Both studies were parallel-group in design. The UK study incorporated three trial arms within two strata as described in 'Characteristics of the interventions' below.

\section{Characteristics of the participants}

The UK study included dentate adults (aged 18 years and older) who had visited their dentist within the previous two years, and who received dental care in part or fully as a National Health Service patient (including dental examination) (INTERVAL 2020). The other study recruited three different age groups (3-, 16- and 18-yearolds) and all had previously received regular dental care, including preventive services and health promotion (Wang 1992). Children classified as 'risk' patients were not included in the study. The criteria used for the classification of risk patients were:

- 3-year-olds (more than zero decayed, missing or filled primary teeth $(\mathrm{dmft})$ );

- 16-year-olds (at least one decayed surface and four or more initial carious lesions and more than 10 decayed, missing or filled permanent teeth (DMFT));

- 18-year-olds (at least one decayed surface and four or more initial carious lesions and more than 12 DMFT).

\section{Characteristics of the interventions}

The UK trial compared 6-month recall, with risk-based and 24month recall (INTERVAL 2020). The other study compared 12-month recall with 24-month recall (Wang 1992). Therefore the following comparisons were included in this review.

- Risk-based versus 6-month recall (INTERVAL 2020)

- Risk-based versus 24-month recall (INTERVAL 2020)

- 24-month versus 6-month recall (INTERVAL 2020)

- 24-month recall versus 12-month recall (Wang 1992)

\section{Characteristics of the outcomes}

\section{Clinical status outcomes}

- Dental caries: both studies reported this outcome but in different ways. One study reported the incremental number of decayed, missing, filled and sound tooth surfaces (dmfs/DMFS) from baseline examination to 24 months (Wang 1992). A tooth surface was recorded as decayed if the carious process extended into the dentine as assessed clinically and radiographically. The other study used ICDAS reported as: 1) prevalence of caries of different severity; 2) mean number of surfaces with caries of different severity (INTERVAL 2020)

- Periodontal disease: one study reported both the percentage of sites bleeding and mean pocket depth (mm) (INTERVAL 2020)

- Presence/absence of mucosal lesions, potentially malignant lesions, cancerous lesions: no studies reported this outcome
- Size and stage of cancerous lesions at diagnosis: no studies reported this outcome

- Dento-facial development: no studies reported this outcome

Psychosocial (patient-centred) outcomes

- Patient/parent satisfaction with provider of care: no studies reported this outcome

- Patient/parent satisfaction with actual care received: one study reported patient satisfaction on a 1 to 7 scale where higher score is better (INTERVAL 2020)

- Patient oral comfort: no studies reported this outcome

- Patient/parent satisfaction with appearance: no studies reported this outcome

- Oral-health-related quality of life: one study reported OHIP-14 0 to 56 scale where lower score is better (INTERVAL 2020)

Costs

\section{Patient perspective costs}

- One study reported this outcome as GBP per patient over the 4year study period (INTERVAL 2020)

\section{Health system perspective costs and resource use}

- One study reported this outcome in terms of monetary cost as GBP per patient over 4-year period (INTERVAL 2020), whilst the other study reported this outcome in terms of time in minutes (Wang 1992). In the latter study, the time used for each patient was recorded in four categories: clinical examination; operative treatment; acute visits (unscheduled extra visits initiated by the patient); and minutes wasted when the patient did not show up. All time values were rounded up to the nearest five minutes. All of these categories were added together to give the 'total time'

\section{Other outcomes}

- Improvements in oral health knowledge and attitudes: one study reported knowledge on a 1 to 9 scale and attitudes on a 1 to 7 , both where a higher score is better (INTERVAL 2020)

- Harms (such as fluorosis, overtreatment): no studies reported this outcome

- Changes in dietary habits: no studies reported this outcome

- Any other oral-health-related behavioural changes: one study reported oral health behaviour on a 1 to 9 scale where a higher score is better (INTERVAL 2020)

\section{Excluded studies}

We excluded two studies from this review (Grimm 1986; Schulz 1989) (Characteristics of excluded studies table). Both studies were reported in German and, after obtaining translations, it was clear that one study was not an RCT (Grimm 1986); whilst it was not clear whether or not the other study was an RCT (Schulz 1989), and we were unable to contact the authors.

\section{Risk of bias in included studies}

The main author of one study was contacted to provide additional information for our risk of bias assessment (Wang 1992). Unfortunately, the required information was no longer available. 


\section{Allocation}

One study used a trials unit for the randomisation process resulting in low risk of bias for both the sequence generation and allocation concealment components of selection bias (INTERVAL 2020). The other study report did not describe the method of sequence generation or allocation concealment: we therefore assessed the study as being at unclear risk of selection bias (Wang 1992).

\section{Blinding of outcome assessment (detection bias)}

\section{Patient-assessed outcomes}

One trial reported oral-health-related quality of life measured using the Oral Health Impact Profile (OHIP-14) (INTERVAL 2020). Although this was a participant-assessed subjective outcome and participants were aware of the assigned recall interval, we judged that there was a low risk of detection bias. We took the following three factors into consideration in reaching this judgement.

\section{Predicted direction of bias}

The anticipated effect of any detection bias on oral-health-related quality of life could reasonably be expected to operate in favour of the shorter 6-month recall interval (e.g. patients assigned to the shorter 6-month interval may perceive that their oral health was being monitored more closely, that any oral health problems would be detected earlier than they might have been if they were assigned to a 24-month recall interval and they may attach some 'quality of life' value to the increased frequency of patientpractitioner interaction (the 'therapeutic relationship') associated with a 6-month recall). However, the trial results provided no evidence of a bias in favour of the 6-month interval; for example, the mean OHIP-14 score was slightly lower (indicating a clinically insignificant better quality of life) in patients assigned to the 24month recall interval compared with the 6-month interval (see Effects of interventions).

Level of concordance between the clinical measures of oral health and oral-health-related quality of life

In INTERVAL 2020 there was 'little to no difference' in clinical outcomes (caries, periodontal disease) between 24-month, 6month and risk-based intervals (see Effects of interventions). These clinical findings were commensurate with the 'little to no difference' in oral-health-related quality of life between the three recall interval groups.

\section{Multidimensional nature of the outcome measurement instrument}

OHIP-14 is a multidimensional (7 separate dimensions) instrument designed to measure people's perception of the social impact of oral disorders on their well-being. We considered it unlikely that knowledge of assigned recall interval would influence participants' responses to several dimension-specific questions thereby rendering it less likely that any bias would have a material effect on the overall OHIP-14 scores (e.g. some dimension-specific questions include: have you had trouble pronouncing some words because of problems with your teeth, mouth or dentures?; have you been a bit irritable with other people because of problems with your teeth, mouth or dentures?)

Taking these factors into consideration we judged that patient assessment of oral-health-related quality of life was unlikely to have been influenced by knowledge of the recall interval to such an extent that it would introduce a material bias; that is, a bias of sufficient magnitude to have a notable impact on the results or conclusions of the trial. We therefore considered that a low risk of detection bias judgement was appropriate. The other study did not report any patient-assessed outcomes and therefore is not applicable here (Wang 1992).

\section{Clinician-assessed outcomes}

The clinical outcome assessors were blinded to group allocation in one study (INTERVAL 2020). Therefore we judged that there was a low risk of detection bias for all clinician-assessed outcomes. In the other study one dentist and one dental hygienist provided all dental care and examined all the participants (Wang 1992). It is therefore possible that they could have been aware of the participants' allocated group when assessing the outcomes. We therefore judged that there was a high risk of detection bias for the clinical outcomes assessed.

\section{Incomplete outcome data}

We assessed both studies as being at low risk of attrition bias. In one study, attrition was equal across treatment groups and, in all cases, was due to participants leaving the area (Wang 1992). In the other study, attrition varied across outcomes and was consistently high but sensitivity analyses did not indicate that the results were affected by the attrition (INTERVAL 2020).

\section{Selective reporting}

We assessed both studies as being at low risk of reporting bias. For one study, we were able to check the original trials registry record to confirm that the authors reported outcomes according to their protocol (INTERVAL 2020). The other study is older and predates routine trial registration (Wang 1992). Therefore we were limited to confirming that the outcomes stated in the Methods section were reported in full.

\section{Other potential sources of bias}

We did not detect any other possible biases and therefore assessed both studies as being at low risk of bias for this domain.

\section{Overall risk of bias}

We considered one study included in this review to be at low risk of bias across all domains and therefore considered it to be at low risk of bias overall (INTERVAL 2020). We considered the other study to be at high risk of detection bias and therefore at high risk of bias overall (Wang 1992). The risk of bias across the six domains assessed is presented graphically in Figure 2. 
Figure 2. Risk of bias summary: review authors' judgements about each risk of bias item for each included study.

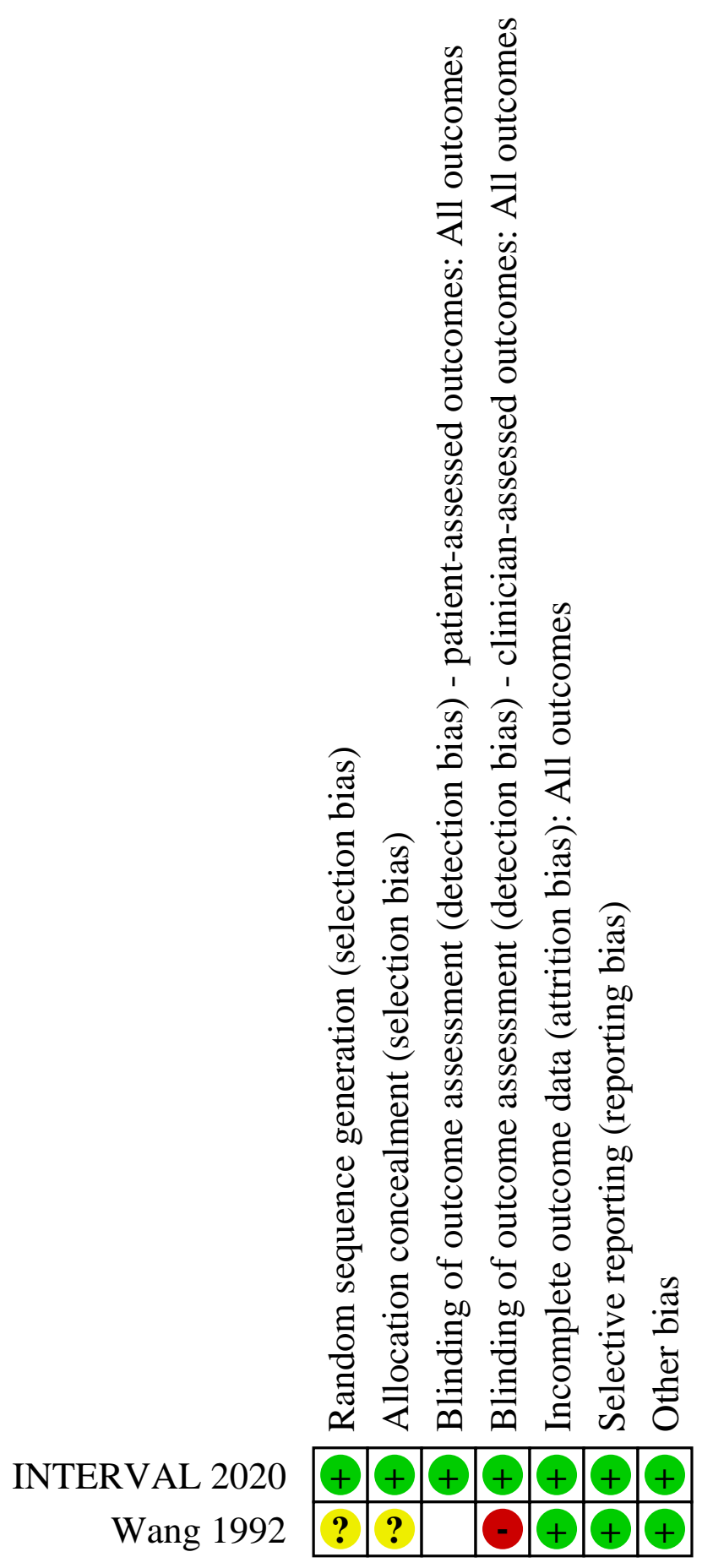




\section{Effects of interventions}

See: Summary of findings 1 24-month recall versus 12 -month recall; Summary of findings 2 Risk-based recall versus 6-month recall; Summary of findings 3 24-month recall versus 6-month recall; Summary of findings 4 Risk-based recall versus 24-month recall

\section{Comparison 1: 24-month recall versus 12-month recall at 2 years' follow-up}

\section{Clinical status outcomes}

\section{Dental caries}

It is unclear if there is an important difference between the groups (very low certainty evidence*; Analysis 1.1).

- For 3- to 5-year-olds with primary teeth, the MD in dmfs increment was 0.90 ( $95 \% \mathrm{Cl}-0.16$ to $1.96 ; 1$ trial, 58 participants)

- For 16- to 20-year-olds with permanent teeth, the MD in DMFS increment was $0.86(95 \% \mathrm{Cl}-0.03$ to $1.75 ; 1$ trial, 127 participants)

*We downgraded GRADE ratings for outcomes by one level for imprecision and by two levels for risk of bias (see the section entitled "Results of applying GRADE to assess the certainty of evidence").

\section{Cost outcomes}

\section{Health-system perspective costs and resource use ( Table 1)}

- For 3- to 5-year-olds with primary teeth, the MD in time used by each participant was -10 minutes $(95 \% \mathrm{Cl}-26.70$ to 6.70$)$ in favour of 24-month recall

- For 16- to 20-year-olds with permanent teeth, the MD in time used by each participant was -23.70 minutes $(95 \% \mathrm{Cl}-43.28$ to -4.12 ) in favour of $24-$ month recall.

${ }^{\star *}$ We did not conduct GRADE ratings for outcomes that were not included in 'Summary of findings' tables.

\section{Comparison 2: Risk-based recall versus 6-month recall at 4 years' follow-up}

\section{Clinical status outcomes}

\section{Dental caries}

- There was little to no difference between the groups in the prevalence of moderate to extensive caries (ICDAS 3 to 6): RR $1.04,95 \% \mathrm{Cl} 0.99$ to 1.09 ; 1 trial, 1478 participants; moderatecertainty evidence*; Analysis 2.1 .

- There was little to no difference between the groups in the number of tooth surfaces with any caries: MD $0.15,95 \% \mathrm{Cl}-0.77$ to $1.08 ; 1478$ participants, high-certainty evidence; Analysis 2.2.

*GRADE rating for this outcome was downgraded by one level for imprecision (see the section entitled "Results of applying GRADE to assess the certainty of evidence").

\section{Periodontal disease -gingival bleeding}

- There was little to no difference between the groups in the percentage of sites with gingival bleeding: MD $0.78 \%, 95 \% \mathrm{Cl}$
-1.17 to 2.73; 1 trial, 1472 participants; high-certainty evidence; Analysis 2.3.

- There was little to no difference between the groups in probing pocket depths: MD $0.03 \mathrm{~mm}, 95 \% \mathrm{Cl}-0.01$ to $0.07 ; 1$ trial, 1463 participants; high-certainty evidence; Analysis 2.4.

\section{Psychosocial (patient-centred) outcomes}

\section{Oral-health-related quality of life}

- There was little to no difference between the groups in oralhealth-related quality of life measured using OHIP-14 (scale from: 0 to 56 points, with lower scores indicating better quality of life): $\mathrm{MD}-0.35,95 \% \mathrm{Cl}-1.02$ to $0.32 ; 1$ trial, 1551 participants; high-certainty evidence; Analysis 2.5.

\section{Cost outcomes ${ }^{\star *}$}

\section{Patient perspective costs}

The mean difference between the groups in total costs in British pounds sterling (MD GBP) incurred by patients was $-9.49,95 \% \mathrm{Cl}$ -23.05 to $4.07 ; 1944$ participants; Table 2.

\section{Healthcare system perspective costs and resource use}

The mean difference between the groups in total cost to provider per patient was MD GBP 13.77, 95\% Cl -1.56 to 29.11; 2006 participants; Table 2.

\section{other outcomes **}

Root caries

The prevalence of root caries in the risk-based recall group versus the 6-month group was $22 \%$ versus $24 \%$ (RR $0.93,95 \% \mathrm{Cl} 0.76$ to 1.13; 1 trial, 1306 participants; Table 2).

\section{Patient satisfaction with actual care received}

Using a 1 to 7 scale where a higher score is a better outcome, the mean difference in patient satisfaction score between the groups was MD 0.03 (95\% Cl-0.03 to 0.09; 1 trial, 1607 participants; Table 2).

\section{Oral health knowledge}

Using a 1 to 9 scale where a higher score is a better outcome, the mean difference in oral health knowledge between the groups was MD -0.01 ( $95 \% \mathrm{Cl}-0.03$ to $0.01 ; 1$ trial, 1604 participants; Table 2).

\section{Oral health attitudes}

Using a 1 to 7 scale where a higher score is a better outcome, the mean difference in oral health attitudes between the groups was MD 0.04 ( $95 \% \mathrm{Cl}-0.04$ to 0.12 ; 1607 participants; Table 2).

\section{Oral health behaviours}

Using a 1 to 9 scale where a higher score is a better outcome, the mean difference in oral health behaviours between the groups was MD $0.00(95 \% \mathrm{Cl}-0.01$ to $0.01 ; 1608$ participants; Table 2).

** We did not conduct GRADE ratings for outcomes that were not included in 'Summary of findings' tables. 
Comparison 3: 24-month recall versus 6-month recall at 4 years' follow-up

\section{Clinical status outcomes}

\section{Dental caries}

- There was little to no difference between the groups in the prevalence of moderate to extensive caries (ICDAS 3 to 6): RR $1.05,95 \% \mathrm{Cl} 0.92$ to 1.20 ; 1 trial, 271 participants; low-certainty evidence*; Analysis 3.1.

- There was little to no difference between the groups in the number of tooth surfaces with any caries: MD $-0.60,95 \% \mathrm{Cl}-2.54$ to 1.34 ; 1 trial, 271 participants; moderate-certainty evidence ${ }^{\star *}$; Analysis 3.2

*We downgraded GRADE rating by two levels for imprecision.

${ }^{\star *}$ We downgraded GRADE rating by one level for imprecision (see the section entitled 'Results of applying GRADE to assess the certainty of evidence').

\section{Periodontal disease - gingival bleeding}

- There was little to no difference between the groups in the percentage of sites with gingival bleeding: MD $-0.91 \%, 95 \% \mathrm{Cl}$ $-5.02 \%$ to $3.20 \%$; 1 trial, 271 participants; moderate-certainty evidence*; Analysis 3.3.

- There was little to no difference between the groups in probing pocket depths: MD $-0.03 \mathrm{~mm}(95 \% \mathrm{Cl}-0.12$ to $0.06 ; 1$ trial; 270 participants; moderate-certainty evidence* Analysis 3.4 )

${ }^{*}$ GRADE rating was downgraded by one level for imprecision (see the section entitled "Results of applying GRADE to assess the certainty of evidence").

\section{Psychosocial (patient-centred) outcomes}

\section{Oral-health-related quality of life}

- There was little to no difference between the groups in oralhealth-related quality of life measured using OHIP-14 (scale from: 0 to 56 points, with lower scores indicating better quality of life): MD $-0.24,95 \% \mathrm{Cl}-1.55$ to $1.07 ; 1$ trial, 305 participants; high-certainty evidence; Analysis 3.5.

\section{Cost outcomes**}

\section{Patient-perspective costs}

The mean difference between the groups in total costs incurred by patients was MD GBP $-53.00,95 \% \mathrm{Cl}-76.91$ to $-29.09 ; 1$ trial, 375 participants; Table 3.

\section{Healthcare-system-perspective costs and resource use}

The mean difference between the groups in total cost to provider per patient was MD GBP $-16.00,95 \% \mathrm{Cl}-51.76$ to $19.76 ; 1$ trial, 404 participants; Table 3.

\section{Other outcomes**}

\section{Root caries}

The prevalence of root caries in the 24-month group versus the 6month group was $17 \%$ versus $15 \%$ (RR $1.17,95 \% \mathrm{Cl} 0.65$ to $2.11 ; 1$ trial, 238 participants; Table 3).

\section{Patient satisfaction with actual care received}

Using a 1 to 7 scale where a higher score is a better outcome, the mean difference in patient satisfaction scores between the groups was MD -0.11 ( $95 \% \mathrm{Cl}-0.26$ to $0.04 ; 308$ participants; Table 3).

\section{Oral health knowledge}

Using a 1 to 9 scale where a higher score is a better outcome, the mean difference in oral health knowledge between the groups was MD -0.01 ( $95 \% \mathrm{Cl}-0.05$ to 0.03; 1 trial, 308 participants; Table 3).

\section{Oral health attitudes}

Using a 1 to 7 scale where a higher score is a better outcome, the mean difference in oral health attitudes between the groups was MD 0.17 (95\% Cl -0.01 to $0.35 ; 1$ trial, 308 participants; Table 3).

\section{Oral health behaviours}

Using a 1 to 9 scale where a higher score is a better outcome, the mean difference in oral health behaviours between the groups was MD $0.00(95 \% \mathrm{Cl}-0.03$ to $0.03 ; 1$ trial, 308 participants; Table 3$)$.

**We did not conduct GRADE ratings for outcomes that we did not include in 'Summary of findings' tables.

\section{Comparison 4: Risk-based recall versus 24-month recall at 4 years' follow-up}

\section{Clinical status outcomes}

\section{Dental caries}

- There was little to no difference between the groups in the prevalence of moderate to extensive caries (ICDAS 3 to 6): RR 1.06 ( $95 \% \mathrm{Cl} 0.95$ to 1.19 ; 1 trial, 279 participants; moderate-certainty evidence*; Analysis 4.1).

- There was little to no difference between the groups in the number of tooth surfaces with any caries: MD $1.40(95 \% \mathrm{Cl}-0.69$ to 3.49; 1 trial, 279 participants; moderate-certainty evidence*; Analysis 4.2).

${ }^{*}$ GRADE rating was downgraded by one level for imprecision (see the section entitled "Results of applying GRADE to assess the certainty of evidence").

\section{Periodontal disease}

\section{Gingival bleeding}

- There was little to no difference between the groups in the percentage of sites with gingival bleeding: MD $-0.07 \%(95 \%$ $\mathrm{Cl}-4.10 \%$ to $3.96 \%$; 1 trial, 279 participants; high-certainty evidence; Analysis 4.3).

- There was little to no difference between the groups in probing pocket depths: MD $0.10 \mathrm{~mm}(95 \% \mathrm{Cl} 0.01$ to $0.19 ; 1$ trial, 279 participants; moderate-certainty evidence; Analysis 4.4).

${ }^{*}$ GRADE rating was downgraded by one level for imprecision (see the section entitled "Results of applying GRADE to assess the certainty of evidence").

\section{Psychosocial (patient-centred) outcomes}

\section{Oral-health-related quality of life}

- There was little to no difference between the groups in oralhealth-related quality of life measured using OHIP-14 (scale 
from: 0 to 56 points, with lower scores indicating better quality of life): MD -0.37 (95\% Cl -1.69 to $0.95 ; 1$ trial, 298 participants; high-certainty evidence; Analysis 4.5).

\section{Cost outcomes **}

\section{Patient perspective costs}

The mean difference between the groups in total costs incurred by patients was GBP $34.00(95 \% \mathrm{Cl} 9.78$ to $58.22 ; 1$ trial, 375 participants; Table 4)

\section{Healthcare system perspective costs and resource use}

The mean difference between the groups in total cost to provider per patient was GBP $17.00(95 \% \mathrm{Cl}-14.34$ to $48.34 ; 1$ trial, 404 participants; Table 4).

\section{Other outcomes ${ }^{\star \star}$}

\section{Root caries}

The prevalence of root caries in the risk-based group versus the 24month group was $21 \%$ versus $17 \%$ (RR $1.21,95 \% \mathrm{Cl} 0.72$ to $2.03 ; 1$ trial, 247 participants; Table 4).

\section{Patient satisfaction with actual care received}

Using a 1 to 7 scale where a higher score is a better outcome, the mean difference in patient satisfaction scores between the groups was: MD 0.16 ( $95 \% \mathrm{Cl} 0.01$ to $0.31 ; 1$ trial, 304 participants; Table 4).

\section{Oral health knowledge}

Using a 1 to 9 scale where a higher score is a better outcome, the mean difference in oral health knowledge between the groups was: MD $-0.01(95 \% \mathrm{Cl}-0.05$ to $0.03 ; 1$ trial, 303 participants; Table 4).

\section{Oral health attitudes}

Using a 1 to 7 scale where a higher score is a better outcome, the mean difference in oral health attitudes between the groups was: MD -0.02 (95\% Cl -0.20 to $0.16 ; 1$ trial, 304 participants; Table 4).

\section{Oral health behaviours}

Using a 1 to 9 scale where a higher score is a better outcome, the mean difference in oral health behaviours between the groups was: MD 0.01 (95\% Cl -0.02 to 0.04; 1 trial, 304 participants; Table 4).

${ }^{\star \star}$ GRADE ratings were not conducted for outcomes that were not included in 'Summary of findings' tables.

\section{Results of applying GRADE to assess the certainty of evidence Risk of bias}

We downgraded the certainty of the evidence by two levels for the caries outcomes reported in Wang 1992. We had concerns over a) selection bias arising from unclear methods of sequence generation and allocation concealment and b) detection bias due to an absence of blinding of the personnel assessing clinical outcomes. We judged the INTERVAL 2020 trial to have a low risk of bias for all key domains and therefore we did not downgrade the certainty of evidence for the outcomes reported.

\section{Inconsistency}

We did not perform any meta-analyses as the two included trials were conducted on different populations and involved different comparisons: one trial involved participants aged 3, 16 and 18 years and compared a 24-month recall versus a 12 -month recall (Wang 1992); the other trial involved adults and compared: riskbased recall versus 6-month recall; risk-based recall versus 24month recall; and 24-month recall versus 6-month recall (INTERVAL 2020). As all outcomes for the four comparisons were reported in single trials only we judged that inconsistency was unknown and we did not downgrade the certainty of evidence.

\section{Imprecision}

\section{Outcomes reported in Wang 1992}

We downgraded the certainty of evidence by one level for imprecision for the two caries outcomes reported in this trial. The 95\% Cls accompanying effect estimates included both 'little or no effect' and an appreciable difference exceeding the defined minimal important differences (MIDs).

\section{Outcomes reported in INTERVAL unpublished}

We downgraded the certainty of evidence for imprecision for the composite outcome "prevalence of moderate to extensive caries". For all comparisons the limits of the confidence intervals $(\mathrm{Cl})$ accompanying the risk ratio estimates did not reach the suggested GRADE threshold that should be considered for downgrading (a relative risk reduction or increase greater than $25 \%$ ). However, we based our downgrading decision on the $95 \% \mathrm{Cls}$ accompanying the absolute effect estimates (RD), which all included both 'little to no effect' and an appreciable difference exceeding the defined minimal important difference (MID) of $5 \%$. We downgraded by one level where the $\mathrm{Cl}$ crossed the MID in one direction only and by two levels where the $\mathrm{Cl}$ crossed the MID in both directions.

For the comparisons "24-month recall versus 6-month recall" and "risk-based recall versus 24-month recall" we also downgraded for imprecision for the following outcomes: number of tooth surfaces with any caries and periodontal probing depths.

Both trials included in this review involved populations (primary care patients) and interventions of direct relevance to the review questions and review objectives. Furthermore, the trials involved direct head-to-head comparisons between different recall intervals between clinical dental examinations. We therefore judged that there were no indirectness issues pertaining to populations, interventions and comparisons.

In relation to indirectness of outcomes, the nature of periodontal disease (in particular, its generally slow rate of progression) has traditionally necessitated the use of surrogate endpoints in trials. We considered that the surrogate outcomes of bleeding on probing (used to measure gingivitis) and probing (periodontal pocket) depth measured in one of the trials included in this review (INTERVAL 2020) were adequately reflective of true endpoints of importance to patients and we did not downgrade the certainty of evidence. Bleeding on probing is indicative of gingival inflammation and therefore is likely to correlate with bleeding on brushing, which may be perceived as important by patients (Lang 2009). In addition, there is evidence that the absence of bleeding on probing is a reasonable indication of periodontal stability (Lang 2009). We also considered that probing depth (as an indicator 
of loss of periodontal support) was a reasonable and plausible substitute outcome for the long-term patient-important outcomes of tooth loss or loss of masticatory efficiency associated with tooth mobility or tooth loss. These long-term outcomes cannot be feasibly measured in short-term trials conducted on the type of population considered in this review.

We judged that there were no indirectness issues in relation to any of the other outcomes included in the 'Summary of findings' tables for this review.

\section{Publication bias}

Due to the small number of trials $(n=2)$ included in this review, we did not formally assess the likelihood of publication bias via the construction and examination of funnel plots. Our search for relevant trials was comprehensive and included a sensitive search, without language restrictions, of electronic databases and clinical trials registers. Although we cannot entirely exclude the possibility of publication bias, we considered that there was a low likelihood that we had overlooked relevant trials. Therefore, we did not downgrade the certainty of evidence level for publication bias.

\section{DISCUSSION}

\section{Summary of main results}

In this latest update of this systematic review, we included one new study (INTERVAL 2020). This review includes two studies with data available from 1736 participants. One small study, with 185 participants included in the analysis, compared the effects of 24month and 12-month recall intervals and measured outcomes at two years. This study was conducted in a public dental service clinic in Norway and involved participants under the age of 20 years who were regular attenders at dental appointments. The other study compared the effects of 6-month, 24-month and risk-based recall intervals and measured outcomes at four years. This study was conducted in 51 UK general dental practices and involved adults who were regular attenders at dental appointments. In this study over the four year follow-up period there was a clear difference in the number of check-ups received between the different trial arms. Participants eligible for the 24-month recall stratum who had a clinical outcome assessment had a mean of 3.7 (SD 1.9) checkups in the risk-based arm, 2.5 (SD 2.2) in the 24-month and 5.1 (SD 3.7) in the six-month recall arm. Participants who were ineligible for the 24-month recall who had a clinical outcome assessment had a mean of 5.0 (SD 2.3) check-ups during the trial in the risk-based arm and 5.4 (SD 2.0) in the six-month arm.

The principal results for each of the main comparisons were as follows.

\section{1) 24-month recall versus 12-month recall at 2 years' follow-up}

Due to the very low certainty of evidence from the one trial that provided evidence for this comparison, it is unclear if there is an important difference in caries experience between assignment to a 24-month or a 12-month recall. This finding applies to the specific age groups considered in this trial, namely 3 - to 5-year-olds with primary teeth and 16 - to 20 -year-olds with permanent teeth. The trial did not assess other clinical outcomes of relevance to this review (Summary of findings 1 ).

\section{2) Risk-based recall versus 6-month recall at 4 years' follow-up}

One trial provided data from approximately 1500 participants for this comparison. We found moderate- to high-certainty evidence that there is little to no difference between risk-based and 6month recall intervals at four years for the outcomes: prevalence of moderate to extensive caries (ICDAS 3 to 6); number of tooth surfaces with any caries (ICDAS 1 to 6); percentage of sites with gingival bleeding; and oral-health-related quality of life (Summary of findings 2).

\section{3) 24-month recall versus 6-month recall at 4 years' follow-up}

One trial provided data from approximately 300 participants for this comparison. We found high-certainty evidence that there is little to no difference in oral-health-related quality of life between these recall intervals. There is probably little to no difference in the number of tooth surfaces with any caries (ICDAS 1 to 6) or the percentage of sites with gingival bleeding (moderate-certainty evidence).There may be little to no difference in the prevalence of moderate to extensive caries (ICDAS 3 to 6 ) (low-certainty evidence) (Summary of findings 3).

\section{4) Risk-based recall versus 24-month recall at 4 years' follow- up}

One trial provided data from approximately 300 participants for this comparison. We found high-certainty evidence that there is little to no difference in the percentage of sites with gingival bleeding or in oral-health-related quality of life between these recall intervals. There is probably little to no difference in the prevalence of moderate to extensive caries (ICDAS 3 to 6 ) or in the number of tooth surfaces with any caries (ICDAS 1 to 6 ) (moderatecertainty evidence) (Summary of findings 4).

The two included studies did not report on other potential harms for any of the four comparisons mentioned above.

\section{Overall completeness and applicability of evidence}

Our search for relevant trials was comprehensive and included a sensitive search, without language restrictions, of electronic databases and clinical trials registers.

The two included studies were conducted in primary dental care settings and involved populations and interventions of direct relevance to the review questions and review objectives (INTERVAL 2020; Wang 1992). However, only one of the trials involved children and adolescents and compared 24-month with 12-month recall intervals (Wang 1992). In addition, this trial provided very low certainty evidence and the only clinical outcome reported was dental caries (dmfs and DMFS increment). There is, therefore, a paucity of evidence pertaining to the effects of different recall intervals on the oral health of children and adolescents.

The second trial was conducted in general dental practices in the UK and involved adult participants aged 18 years and older (with a mean age of approximately 45 years) who were regular attenders (defined as having attended the dentist at least once in the previous two years) (INTERVAL 2020). This trial provided moderate- to highcertainty evidence of the comparative effects of 6-month, 24-month and risk-based recall intervals on dental caries, gingivitis and oralhealth-related quality of life outcomes. The results of this trial are therefore applicable to healthcare systems where these recall 
intervals are offered to regularly attending adult patients in primary care settings.

The results of this review are also particularly relevant to the delivery of primary care dental services in light of the extraordinary impact of the COVID-19 global pandemic on dental services world wide. Dental services essentially closed down for five months, limiting access even to emergency dental care. As dental services tentatively re-open, with evidence on safety procedures being evaluated (e.g. Burton 2020; Kumbargere Nagraj 2020; SDCEP 2020), the issue of reduced access to dental care may be a challenge for dental services and patients for some time. There is, therefore, impetus to reform dental services to meet the challenges of prioritising care for populations with high need and pursuing minimally-invasive prevention-oriented practice. Serious consideration must also be given to ceasing ineffective treatments that utilise valuable resources without improving health outcomes. The results of this review provide reassurance that intervals between dental recall appointments can be extended beyond six months without detriment to the oral health of patients.

\section{Findings from the brief economic commentary}

To supplement the main systematic review of the effectiveness, we sought to identify trial-based and decision-model-based economic evaluations of different recall intervals for dental check-ups for children and adult patients in primary dental care. The search strategy approach described in Methods identified two relevant economic evaluations.

The first was INTERVAL 2020, a within-trial economic evaluation reporting cost-utility analysis' (CUA), cost-effectiveness analysis' (CEA) and cost-benefit analyses' (CBA) results for two comparisons: risk-based versus 6-month dental recalls in high-risk patients (those considered clinically unsuitable for a 24-month recall); and risk-based versus 6-month versus 24-month in lower risk (those considered clinically suitable for a 24-month recall). The population was adult patients in UK primary dental care and the time horizon for the evaluation was four years, reflecting the trial follow-up period. Different perspectives of benefits (qualityadjusted life years (QALYs), willingness to pay (WTP) for dental health outcomes, WTP for societal benefit) and costs (NHS dental, NHS dental + other healthcare resource use and NHS + participantincurred costs) were considered. A general population discrete choice experiment (DCE) was used to value benefits in terms of WTP. Sensitivity analyses considered the impact of different perspectives, benefit valuation approaches, discounting, complete case analysis, and country subgroup on results. The DCE found that the UK general population valued and were willing to pay for more frequent dental recalls as well as to avoid dental decay and bleeding gums. In those eligible for 24-month recalls, the longer recall interval showed no statistically significant cost differences from an NHS-only perspective; statistically significant cost savings were found, however, when combining all cost burden (to patients and the health service). Results from the CUA generated using EQ-5D-based QALYs were highly uncertain and the optimal recall strategy was unclear. When using the DCE to value dental health benefits (bleeding and caries outcomes), the 24-month recall was the most likely optimal strategy, with a $65 \%$ to $99 \%$ chance of positive net benefits across all sensitivity analyses undertaken. There is greater uncertainty, however, regarding whether riskbased or 6-month recalls are the optimal strategy when combining those considered clinically eligible and ineligible for a 24-month recall interval. Risk-based recalls were more likely to generate positive net dental health benefit in Scotland than in England and when a wider perspective of the costing analysis was considered. When using the DCE results to expand the valuation framework to include the broadest perspective of benefits (health and nonhealth), there is a high probability that 6-month recalls are the optimal strategy. This is due to the general population's preference for, and high valuation of, more frequent dental recalls.

The second study we identified was Davenport 2003, a CEA informed by a Markov decision analysis model developed to inform the NICE guidance on dental recall interval (NICE 2004). The model projected the cost-effectiveness (cost per additional tooth affected with decay experience) of different recall intervals ranging from 3 months to 36 months. The analysis perspective was the UK NHS and the time horizon ranged from 6 years (deciduous dentition) to 68 years (permanent dentition). The study found that increasing the frequency of dental recalls (from six to three months) increased costs by GBP 64 and GBP 202 (2001 GBP) per person for deciduous and permanent dentition, respectively, for a small reduction in decay experience for deciduous ( 0.04 to 0.12 teeth over 6 years) and permanent teeth ( 0.22 and 0.41 teeth over 68 years). Increasing the duration of recall intervals from 6 to $12,18,24$ and 36 months led to cost savings but increases in dental decay experience. The model predicted that in general, increasing the length of time between recall intervals was more cost-effective than shortening it. For example, moving from 6 - to 12 -month recalls was found to generate cost savings of about GBP 30 (2001 GBP) over 6 years for deciduous teeth and between GBP 75 and GBP 95 (2001 GBP) over 68 years for permanent teeth. The cost savings were accompanied by increases in the numbers of teeth modelled to have decay experience of between 0.07 and 0.20 deciduous teeth over 6 years and between 0.14 and 0.21 permanent teeth over 68 years. Importantly, the impact of extending recall intervals on the average number of teeth per person with decay experience was modelled to be greatest in non-fluoridated areas and hence underlying population risk was an important driver of the most cost-effective policy.

We did not subject the identified economic evaluations to critical appraisal and we do not attempt to draw any firm or general conclusions regarding the relative costs or efficiency of different recall intervals. However, evidence collected from these economic evaluations indicates that, from an economic perspective, the use of longer recall intervals may generate cost savings to patients and the healthcare system, particularly in those patients who are at lower risk of dental disease.

Ultimately, the decision regarding the best value for money rests in a normative judgement about what it is the health system should maximise (e.g. dental health, general health, patient satisfaction) and whose costs should be considered (health system, patients or both). It is noted that both of the identified economic evaluations were conducted in the UK setting. End users of this review will need to assess the extent to which methods and results of identified economic evaluations may be applicable (or transferable) to their own setting (Shemilt 2011).

\section{Quality of the evidence}

The body of evidence for our first comparison (24-month versus 12 -month recall intervals) was derived from one small trial and we assessed the certainty of evidence as very low for all reported 
outcomes. We downgraded the certainty of evidence by two levels for risk of bias and by one level for imprecision.

The body of evidence for the remaining comparisons considered in this review was derived from one large well-conducted trial that compared 24-month, risk-based and 6-month recall intervals. The numbers of participants included in the analyses for reported outcomes ranged from 279 to 1551. The evidence for all key outcomes (dental caries, gingival bleeding and oral-health-related quality of life) was generally assessed as moderate- to highcertainty. In all instances where we downgraded the certainty of evidence, this was due to imprecision - the confidence intervals accompanying effect estimates included little to no difference but also appreciable difference that exceeded the minimal important difference.

\section{Potential biases in the review process}

We used a sensitive search strategy in this review and made every effort to identify all relevant studies through searching of multiple databases, with no restriction on language or publication status. We attempted to contact study authors for clarification on eligibility or risk of bias issues. Two authors carried out screening of search results, data extraction and risk of bias assessment independently and in duplicate in order to minimise error and individual bias. One included study involved four review authors (PF, HW, JC, DB) (INTERVAL 2020), but they were not involved in data extraction, assessment of risk of bias or assessment of the certainty of the evidence for this study.

\section{Agreements and disagreements with other studies or reviews}

We are aware of three systematic reviews that have evaluated the effectiveness of routine dental check-ups of different recall intervals.

(1) A review that was carried out as part of the National Health Service (NHS) Research and Dissemination Health Technology Assessment (HTA) Programme in the UK (the date of the last search carried out for this HTA review was February 2001) (Davenport 2003).

(2) An update of this HTA review that was undertaken as part of the guideline development process for a National Institute for Health and Care Excellence guideline on appropriate recall intervals between dental check-ups (this guideline was reviewed in June 2018 with no new evidence found that affected the recommendations) (NICE 2004).

(3) A review that evaluated the effect of recall intervals on dental caries only (the date of the last search for this review was September 2008) (Patel 2010).

The selection criteria for these reviews differed from this Cochrane Review, most notably because they included non-randomised studies. All of the reviews were critical of the methodological quality of the non-randomised studies and consistently highlighted the paucity of reliable evidence from randomised controlled trials to inform clinical practice. This Cochrane Review is the only review conducted to date that has been able to incorporate evidence from a methodologically rigorous randomised controlled trial.

\section{AUTHORS' CONCLUSIONS}

\section{Implications for practice}

For adults receiving dental check-ups in primary care settings, there is high-certainty evidence that there is little to no difference in oral health outcomes (tooth surfaces with any caries, gingivitis and oral-health-related quality of life) when comparing 6-month recall interval with a risk-based recall interval. In addition, there is moderate- to high-certainty evidence that there is little to no difference in oral health outcomes when comparing a 24-month recall interval with either 6 -month or risk-based intervals.

When comparing risk-based recall with 6-month recall intervals, there is little to no difference in the number of tooth surfaces with any caries, percentage of sites with gingival bleeding and oralhealth-related quality of life over a 4-year period (high-certainty evidence). There is probably little to no difference between the recall strategies in the prevalence of moderate to extensive caries over the same time period (moderate-certainty evidence).

When comparing 24-month with either 6-month or risk-based recall intervals, there is moderate- to high-certainty evidence that there is little to no difference in the number of tooth surfaces with any caries, percentage of sites with gingival bleeding and oral-healthrelated quality of life over a 4-year period.

The available evidence on recall intervals between dental checkups for children and adolescents is uncertain.

The two trials included in the review did not assess adverse effects of different recall strategies.

\section{Implications for research}

Further studies comparing dental recall intervals for adults in primary care seem unnecessary, given the moderate to high certainty of the evidence for the outcomes of this review. Given the uncertainty of the evidence from one study on recall intervals between dental check-ups for children and adolescents, there is a need for well-conducted randomised controlled trials in this area, including a sufficient number of participants to detect a true difference, if any; similar outcome measures to this review; and of adequate duration.

Future research could focus on potential harms of providing dental recalls at different intervals, for example fluorosis or overtreatment. Consideration of different primary study designs, for example non-randomised studies, may allow assessment of the effect of different recall intervals on the clinical outcomes that were not evaluated in the primary studies in this review, for example presence/absence of mucosal lesions, potentially malignant lesions or cancerous lesions, size and stage of cancerous lesions at diagnosis or dento-facial development.

\section{ACKNOWLEDGEMENTS}

This update: we wish to thank Anne Littlewood (Cochrane Oral Health) for her assistance with literature searching and the PRISMA flow diagram, Laura MacDonald (Cochrane Oral Health) for her help with the preparation of this review, and Carolyn Hughes for her help with the preparation of the plain language summary. We also thank Jenny Godson and Professor Tanya Walsh (Cochrane Oral Health) 
for their comments on this update, and Jason Elliot-Smith for copy editing.

Previous versions: we would like to thank and acknowledge the help of Andrew Forgie in writing the protocol. We wish to thank Anne Littlewood (Cochrane Oral Health) for designing and carrying out the literature searches; Luisa Fernandez Mauleffinch and Laura MacDonald (Cochrane Oral Health) for their editorial help in the preparation of the past and present versions of the review; Regina
Mitezki for translating three German articles; Nina Wang, Lowell Smith, Ram Nanda and Jan Lindhe for responding to requests for information on specific trials. The review authors are also grateful for the comments of members of the Guideline Development Group on recall intervals between routine dental examinations conducted under the auspices of the National Institute for Health and Care Excellence (NICE) and co-ordinated by the National Collaborating Centre for Acute Care (NCC-AC). In particular, the review authors would like to thank Jacqueline Dutchak and Nigel Pitts. 


\section{REFERE N C E S}

\section{References to studies included in this review}

INTERVAL 2020 \{unpublished data only\}

Clarkson JE, Pitts NB, Goulao B, Boyers D, Ramsay CR, Floate R, et al. INTERVAL. ISRCTN95933794. Data provided by study authors 2020.

\section{Wang 1992 \{published data only\}}

Wang N, Marstrander P, Holst D, Ovrum L, Dahle T. Extending recall intervals - effect on resource consumption and dental health. Community Dentistry and Oral Epidemiology 1992;20(3):122-4.

\section{References to studies excluded from this review}

\section{Grimm 1986 \{published data only\}}

Grimm WD, Curth K, Rumler KD, Walther C. Clinically controlled studies of the optimum recall interval of public health care patients [Klinisch-kontrollierte untersuchung uber den optimalen recallabstand dispensairebetreuter patienten]. Stomatologie der DDR 1986;36(12):728-32.

Schulz 1989 \{published data only\}

Schulz R, Seefeld G. Therapy of gingivitis. Investigations of the effectiveness of preventive care program in dental practice [Untersuchungen uber die Effektivitat von praventiven betreuungsprogrammen unter den bedingungen einer stomatiologischen praxis]. Stomatologie der DDR 1989;39(1):12-6.

\section{Additional references}

\section{AAPD 2013}

American Academy of Pediatric Dentistry. Guideline on periodicity of examination, preventive dental services, anticipatory guidance/counseling, and oral treatment for infants, children, and adolescents. Pediatric Dentistry 2013;35(5):148-56.

\section{AHRQ 2012}

Treadwell J, Uhi S, Tipton K, Singh S, Santaguida L, Sun X, et al. Assessing equivalence and noninferiority. Methods research report (prepared by the EPC Workgroup under Contract No. 290-2007-10063). Rockville (MD): Agency for Healthcare Research and Quality 2012.

\section{Anthonappa 2008}

Anthonappa RP, King NM. Six-month recall dental appointments, for all children, are (un)justifiable. Journal of Clinical Pediatric Dentistry 2008;33(1):1-8.

\section{Audit Commission 2002}

Audit Commission. Dentistry: Primary Dental Care Services in England and Wales. London: Audit Commission 2002.

\section{Baba 2008}

Baba K, Inukai M, John MT. Feasibility of oral health-related quality of life assessment in prosthetic patients using abbreviated Oral Health Impact Profile questionnaires. Journal of Oral Rehabilitation 2008;35(3):224-8.

\section{Bassetti 2016}

Bassetti RG, Mericske-Stern R, Enkling NI. Are there differences in the changes in oral health-related quality of life depending on the type (rigidity) of prosthetic treatment? Quintessence International 2016;47(9):749-57.

\section{BDA 2000}

British Dental Association. Opportunistic Oral Cancer Screening. BDA Occasional Paper. London: British Dental Association, 2000.

\section{Brothwell 1998}

Brothwell DJ, Jutai DK, Hawkins RJ. An update of mechanical oral hygiene practices: evidence-based recommendations for disease prevention. Journal of the Canadian Dental Association 1998;64(4):295-306

\section{Brown 1995}

Brown LJ, Selwitz RH. The impact of recent changes in the epidemiology of dental caries on guidelines for the use of dental sealants. Journal of Public Health Dentistry 1995;55(5):274-91.

\section{Burt 1999}

Burt B, Eklund SA. Dentistry, Dental Practice and the Community. 5th edition. Philadelphia: WB Saunders Company, 1999.

\section{Burton 2020}

Burton MJ, Clarkson JE, Goulao B, Glenny A-M, McBain AJ, Schilder AGM, et al. Antimicrobial mouthwashes (gargling) and nasal sprays administered to patients with suspected or confirmed COVID-19 infection to improve patient outcomes and to protect healthcare workers treating them. Cochrane Database of Systematic Reviews 2020, Issue 9. Art. No: CD013627. [DOI: 10.1002/14651858.CD013627.pub2]

\section{Clarkson 2009}

Clarkson JE, Amaechi BT, Ngo H, Bonetti D. Recall, reassessment and monitoring. Monographs in Oral Science 2009;21:188-98.

\section{Clovis 2002}

Clovis JB, Horowitz AM, Poel DH. Oral and pharyngeal cancer: practices and opinions of dentists in British Columbia and Nova Scotia. Journal of the Canadian Dental Association 2002;68(7):421-5.

\section{Cohen 1988}

Cohen J. Statistical Power Analysis in the Behavioral Sciences. 2nd edition. Hillsdale (NJ): Lawrence Erlbaum Associates, Inc., 1988.

\section{Conway 2002}

Conway DI, Macpherson LM, Gibson J, Binnie VI. Oral cancer: prevention and detection in primary dental healthcare. Primary Dental Care 2002;9(4):119-23. 


\section{Dal-Ré 2018}

Dal-Ré R, Janiaud P, loannidis JPA. Real-world evidence: how pragmatic are randomized trials labelled as pragmatic? BMC Medicine 2018;16(1):19. [DOI: 10.1186/s12916-018-1038-2]

\section{Davenport 2003}

Davenport C, Elley K, Salas C, Taylor-Weetman CL, Fry-Smith A, Bryan $S$ et al. The clinical effectiveness and cost-effectiveness of routine dental checks: a systematic review and economic evaluation. Health Technology Assessment 2003;7(7):1-127.

\section{Deep 2000}

Deep P. Screening for common oral diseases. Journal of the Canadian Dental Association 2000;66(6):298-9.

\section{DH 2000}

Department of Health (UK). Modernising NHS Dentistry Implementing the NHS Plan. London: Department of Health, 2000.

\section{DH 2002}

Department of Health (UK). NHS Dentistry: Options for Change. London: Department of Health, 2002.

\section{DH 2011}

Department of Health, England. NICE Recall Intervals and Oral Health - a Briefing for Dentists and Practice Teams, March 2011. Available from www.gov.uk/government/uploads/ system/uploads/attachment_data/file/215663/dh_126005.pdf (accessed 08 December 2013).

\section{DHSC 2018}

Department of Health and Social Care (UK). Dental Contract Reform: Evaluation of the First Year of Prototyping 2016-2017. Available from assets.publishing.service.gov.uk/government/ uploads/system/uploads/attachment_data/file/709555/ evaluation-report-2016-2017.pdf. May 2018.

\section{DTB 1985}

Drug and Therapeutics Bulletin. Routine six-monthly checks for dental disease? Drug and Therapeutics Bulletin 1985;23(18):69-72.

\section{Egger 1997}

Egger M, Smith GD, Schnerder M, Minder C. Bias in meta-analysis detected by a simple, graphical test. BMJ 1997;315(7109):629-34.

\section{Elderton 1985a}

Elderton RJ. Six-monthly examinations for dental caries. British Dental Journal 1985;158(10):370-4.

\section{Elderton 1985b}

Elderton RJ. Routine six-monthly checks for dental disease? British Dental Journal 1985;159(9):277-8.

\section{Field 1995}

Field EA, Morrison T, Darling AE, Parr TA, Zakrzewska JM. Oral mucosal screening as an integral part of routine dental care. British Dental Journal 1995;179(7):262-6.

\section{Ford 2016}

Ford I, Norrie J. Pragmatic trials. New England Journal of Medicine 2016;375:454-63.

\section{Foster 2012}

Foster N, Little P. Methodological issues in pragmatic trials of complex interventions in primary care. British Journal of General Practice 2012;62(594):10-11.

\section{Frame 2000}

Frame PS, Sawai R, Bowen WH, Meyerowitz C. Preventive dentistry: practitioners' recommendations for low-risk patients compared with scientific evidence and practice guidelines. American Journal of Preventive Medicine 2000;18(2):159-62.

\section{GRADE 2004}

GRADE Working Group. Grading quality of evidence and strength of recommendations. BMJ 2004;328(7454):1490.

\section{Gussy 2013}

Gussy MG, Bracksley SA, Boxall A. How Often Should You Have Dental Visits? Deeble Institute, Australian Healthcare and Hospitals Association, 2013. Available from oralhealthplan.com.au/sites/default/files/130626evidence_brief-dental_visits-template_version_0.pdf.

\section{Hausen 1997}

Hausen $\mathrm{H}$. Caries prediction - state of the art. Community Dentistry and Oral Epidemiology 1997;25(1):87-96.

\section{HDA 2001}

Health Development Agency. The Scientific Basis of Dental Health Education: a Policy Document. Revised 4th edition. London: Health Development Agency, 2001.

\section{Higgins 2011a}

Higgins JPT, Altman DG, Sterne JAC (editors). Chapter 8: Assessing risk of bias in included studies. In: Higgins JPT, Green S (editors). Cochrane Handbook for Systematic Reviews of Interventions Version 5.1.0 (updated March 2011). Available from www.handbook.cochrane.org. The Cochrane Collaboration, 2011.

\section{Higgins 2011b}

Higgins JPT, Green S (editors). Cochrane Handbook for Systematic Reviews of Interventions Version 5.1.0 (updated March 2011). The Cochrane Collaboration, 2011. Available from www.cochrane-handbook.org.

\section{Higgins 2019}

Higgins JPT, Thomas J, Chandler J, Cumpston M, Li T, Page MJ, Welch VA (editors). Cochrane Handbook for Systematic Reviews of Interventions version 6.0 (updated July 2019). Cochrane, 2019. Available from www.training.cochrane.org/handbook.

\section{Information Services Division 2019}

Information Services Division and NSS Practitioner Services on behalf of the Scottish Dental Practice Board. Primary Care Dentistry in Scotland Annual Report 2018/19. www.isdscotland.org/Health-Topics/Dental-Care/GeneralDental-Service/treatments-provided-by-dentists.asp. 


\section{Kay 1999}

Kay EJ. How often should we go to the dentist? BMJ 1999;319(7204):204-5.

\section{Kumbargere Nagraj 2020}

Kumbargere Nagraj S, Eachempati P, Paisi M, Nasser M, Sivaramakrishnan $\mathrm{G}$, Verbeek JH. Interventions to reduce contaminated aerosols produced during dental procedures for preventing infectious diseases. Cochrane Database of Systematic Reviews 2020, Issue 10. Art. No: CD013686. [DOI: 10.1002/14651858.CD013686.pub2]

\section{Lahti 2001}

Lahti SM, Hausen HW, Widstrom E, Eerola A. Intervals for oral health examinations among Finnish children and adolescents: recommendations for the future. International Dental Journal 2001;51(2):57-61.

\section{Lam 2012}

Lam S, Baros H, O'Grady M, Kendall G, Messer L, Slack-Smith L. Patterns of attendance of children under 12 years at school dental service in Western Australia. The Open Dentistry Journal 2012;6:69-73.

\section{Lamont 2018}

Lamont T, Worthington HV, Clarkson JE, Beirne PV. Routine scale and polish for periodontal health in adults. Cochrane Database of Systematic Reviews 2018, Issue 12. Art. No: CD004625. [DOI: 10.1002/14651858.CD004625.pub5]

\section{Lang 2009}

Lang NP, Schatzle MA, Loe H. Gingivitis as a risk factor in periodontal disease. Journal of Clinical Periodontology 2009;36(10):3-8.

\section{Lefebvre 2011}

Lefebvre C, Manheimer E, Glanville J. Chapter 6: Searching for studies. In: Higgins JP, Green S, editor(s). Cochrane Handbook for Systematic Reviews of Interventions Version 5.1.0 (updated March 2011). The Cochrane Collaboration, 2011. Available from handbook.cochrane.org.

\section{Lock 1986}

Lock S. Getting the balance right. BMJ 1986;292(6518):428-9.

\section{Locker 2004}

Locker D, Jokovic A, Clarke M. Assessing the responsiveness of measures of oral health-related quality of life. Community Dentistry and Oral Epidemiology 2004;32:10-8.

\section{Mansournia 2017}

Mansournia MA, Higgins JPT, Sterne JAC, Hernan MA. Biases in randomized trials - a conversation between trialists and epidemiologists. Epidemiology 2017;28(1):54-9.

\section{Mejare 1999}

Mejare I, Kallest IC, Stenlund H. Incidence and progression of approximal caries from 11 to 22 years of age in Sweden: A prospective radiographic study. Caries Research 1999;33(2):93-100.

\section{Mejare 2004}

Mejare I, Stenlund H, Zelezny-Holmlund C. Caries incidence and lesion progression from adolescence to young adulthood: a prospective 15-year cohort study in Sweden. Caries Research 2004;38(2):130-41.

\section{National Health Service 2020}

National Health Service. What Happens When You Visit An NHS Dentist. Available from www.nhs.uk/using-the-nhs/nhsservices/dentists/what-happens-when-you-visit-the-dentist/ (accessed 1 September 2020).

\section{National Health Service Regulations 2010}

National Health Service (General Dental Services) (Scotland) Regulations 2010. Statement of Dental Remuneration. Available from https://nhsnss.org/services/practitioner/dental/ regulations/.

\section{NHS Digital 2019}

NHS Digital. NHS Dental Statistics for England 2018-19, Annual Report. Available from digital.nhs.uk/data-and-information/ publications/statistical/nhs-dental-statistics/2018-19-annualreport-pas. 2019.

\section{NICE 2004}

National Health Service, National Institute for Clinical Excellence Guideline. Dental Recall: Recall Interval Between Routine Dental Examinations. NICE 2004. Available from www.nice.org.uk/CG019.

\section{NICE 2015}

National Institute for Health and Care Excellence. Oral Health Promotion: General Dental Practice. 2015. Available from www.nice.org.uk/guidance/ng30.

\section{NICE 2018}

National Health Service, National Institute for Clinical Excellence Guideline. Surveillance Report 2018 - Dental Checks: Intervals Between Oral Health Reviews (2004) NICE Guideline CG19. Available from www.nice.org.uk/guidance/ cg19/resources/surveillance-report-2018-dental-checksintervals-between-oral-health-reviews-2004-nice-guidelinecg19-pdf-6347813014213.

\section{Patel 2010}

Patel S, Bay RC, Glick M. A systematic review of dental recall intervals and incidence of dental caries. Journal of the American Dental Association 2010;141(5):527-39.

\section{Perlus 1994}

Perlus J. Determining recall frequency: a controversial issue. Ontario Dentist 1994;71(7):31-5.

\section{Pitts 1983}

Pitts NB. Monitoring of caries progression in permanent and primary posterior approximal enamel by bitewing radiography. Community Dentistry and Oral Epidemiology 1983;11(4):228-35.

\section{Public Health England 2014}

Public Health England. Delivering Better Oral Health: an Evidence-based Toolkit for Prevention 3rd edition. 
Available from assets.publishing.service.gov.uk/government/ uploads/system/uploads/attachment_data/file/605266/ Delivering_better_oral_health.pdf 2014.

\section{Purkayastha 2018}

Purkayastha M, McMahon A, Gibson J, Conway DI. Is detecting oral cancer in general dental practices a realistic expectation? A population-based study using population linked data in Scotland. British Dental Journal 2018;225:241-6.

\section{Renson 1977}

Renson CE. The six-monthly dental examination. Dental Update 1977;4:421-3.

\section{Renson 2000}

Renson T. The professor, the newspaper and the six-monthly check-up. Primary Dental Care 2000;7(3):91.

\section{Righolt 2018}

Righolt AJ, Jevdjevic M, Marcenes W, Listl S. Global-, regional-, and country-level economic impacts of dental diseases in 2015. Journal of Dental Research 2018;97(5):501-7.

\section{Riordan 1997}

Riordan PJ. Can organised dental care for children be both good and cheap? Community Dentistry and Oral Epidemiology 1997;25(1):119-25.

\section{Royal College 1997}

The Faculty of Dental Surgery of the Royal College of Surgeons of England. National Clinical Guidelines. London: Royal College of Surgeons of England, 1997.

\section{Rücker 2008}

Rücker G, Schwarzer G, Carpenter J. Arcsine test for publication bias in meta-analyses with binary outcomes. Statistics in Medicine 2008;27(5):746-63.

\section{Santesso 2019}

Santesso N, Glenton C, Dahm P, Garner P, Akl EA, Alper B, et al, for the GRADE Working Group. GRADE guidelines 26: informative statements to communicate the findings of systematic reviews of interventions. Journal of Clinical Epidemiology 2020;119:126-35. [DOI: 10.1016/j.jclinepi.2019.10.014]

\section{Schünemann 2009}

Schünemann H, Brożek J, Guyatt G, Oxman A, editor(s). Handbook for grading the quality of evidence and the strength of recommendations using the GRADE approach (updated October 2013). GRADE Working Group, 2013. Available from gdt.guidelinedevelopment.org/app/handbook/handbook.html.

\section{Scott 2002}

Scott G, Brodeur JM, Olivier M, Benigeri M. Parental factors associated with regular use of dental services by second-year secondary school students in Quebec. Journal of the Canadian Dental Association 2002;68(10):604-8.

\section{SDCEP 2020}

Scottish Dental Clinical Effectiveness Programme. Mitigation of Aerosol Generating Procedures in Dentistry. A Rapid Review.
Version 1.0. www.sdcep.org.uk/wp-content/uploads/2020/09/ SDCEP-Mitigation-of-AGPS-in-Dentistry-Rapid-Review.pdf (accessed 25 September 2020).

\section{Sheiham 1977}

Sheiham $A$. Is there a scientific basis for six-monthly dental examinations? Lancet 1977;2(8035):442-4.

\section{Sheiham 1980}

Sheiham A. Is the six-monthly dental examination generally necessary? British Dental Journal 1980;148(4):94-5.

\section{Sheiham 2000}

Sheiham A. Routine check-ups (letter to the editor). British Dental Journal 2000;189(4):181-2.

\section{Shemilt 2011}

Shemilt I, Mugford M, Byford S, Drummind M, Eisenstein E, Knapp M, et al, on behalf of the Campbell and Cochrane Economics Methods Group. Chapter 15: Incorporating economics evidence. In: Higgins JPT, Green S (editors). Cochrane Handbook for Systematic Reviews of Interventions Version 5.1.0. Available from www.handbook.cochrane.org (updated March 2011), 2011.

\section{Shemilt 2019}

Shemilt I, Aluko P, Graybill E, Craig D, Henderson C Drummond $\mathrm{M}$, et al, on behalf of the Campbell and Cochrane Economics Methods Group. Chapter 20: Economic evidence. Higgins JPT, Thomas J, Chandler J, Cumpston M, Li T, Page MJ, Welch VA (editors). Cochrane Handbook for Systematic Reviews of Interventions version 6.0 (updated July 2019). Cochrane, 2019. Available from www.training.cochrane.org/handbook.

\section{Spencer 2009}

Spencer AJ. Frequency of Dental Check-Ups. Working Paper No 11, Australian Research Centre for Population Oral Health, The University of Adelaide, South Australia 2009.

\section{Steele 2009}

Steele J. NHS Dental Services in England - An Independent Review led by Professor Jimmy Steele. Available from www.sigwales.org/wp-content/uploads/dh_101180.pdf. 2009.

\section{Sterne 2011}

Sterne JAC, Egger M, Moher D. Chapter 10: Addressing reporting biases. In: Higgins JPT, Green S, editor(s). Cochrane Handbook for Systematic Reviews of Interventions Version 5.1.0 (updated March 2011). The Cochrane Collaboration, 2011.

\section{Tan 2006}

Tan EH, Batchelor P, Sheiham A. A reassessment of recall frequency intervals for screening in low caries incidence populations. International Dental Journal 2006;56(5):277-82.

\section{Wang 1995}

Wang NJ, Holst D. Individualizing recall intervals in child dental care. Community Dentistry and Oral Epidemiology 1995;23(1):1-7. 


\section{Worthington 2015}

Worthington $\mathrm{H}$, Clarkson J, Weldon J. Priority oral health research identification for clinical decision-making. Evidencebased Dentistry 2015;16(3):69-71.

\section{References to other published versions of this review \\ Beirne 2005 \\ Beirne P, Forgie A, Clarkson JE, Worthington HV. Recall intervals for oral health in primary care patients. Cochrane Database of Systematic Reviews 2005, Issue 2. Art. No: CD004346. [DOI: 10.1002/14651858.CD004346.pub2]}

\section{CHARACTERISTICS OF STUDIES}

Characteristics of included studies [ordered by study ID]

\section{Beirne 2007}

Beirne P, Clarkson JE, Worthington HV. Recall intervals for oral health in primary care patients. Cochrane Database of Systematic Reviews 2007, Issue 4. Art. No: CD004346. [DOI: 10.1002/14651858.CD004346.pub3]

\section{Riley 2013}

Riley P, Worthington HV, Clarkson JE, Beirne PV. Recall intervals for oral health in primary care patients. Cochrane Database of Systematic Reviews 2013, Issue 12. Art. No: CD004346. [DOI: 10.1002/14651858.CD004346.pub4]

INTERVAL 2020

\section{Study characteristics}

Methods

Trial design: parallel-group RCT: 2-strata design with those classified by recruiting dentist as clinically suitable (the decision that a patient was eligible for a 24-month recall was based on routine clinical examination and risk assessment) for 24-month interval randomised to either 6-month, 24-month or riskbased interval, and those clinically unsuitable randomised to either a 6-month or risk-based interval

Location: general dental practices in the UK (including Scotland, Wales, Northern Ireland and England)

Number of centres: 51 dental practices

\section{Participants}

Inclusion criteria: dentate (at least 1 tooth) adults (18+ years of age), visited dentist at least once within previous 2 years, received dental care in part or fully as a National Health Service patient (including dental examination)

Exclusion criteria: medical condition indicating increased risk of bleeding, immunocompromised (patients whose medical condition changed during the study were allowed to continue their participation)

Baseline caries: not reported

Baseline periodontal disease: not reported

Baseline oral health related quality of life (mean and SD): patients eligible for 24-month recall: riskbased: 4.5 (7); 24-month: 4.7 (6.4); 6-month: 4.4 (6.1); patients ineligible for 24-month recall: risk-based: 5.8 (6.9); 6-month: 6.1 (7.7) (OHIP-14 0 to 56 scale - lower score is better outcome)

Age at baseline (mean and SD): overall mean 45 years; patients eligible for 24-month recall: riskbased: 43.3 (15.1); 24-month: 43.5 (14.5); 6-month: 44.2 (15.2); patients ineligible for 24-month recall: risk-based: 48.1 (14.5); 6-month: 48.8 (15.3)

Sex (\% female): patients eligible for 24-month recall: risk-based: 59; 24-month: 56; 6-month: 53; patients ineligible for 24-month recall: risk-based: 58; 6-month: 57

Number randomised: overall 2372; patients eligible for 24-month recall: risk-based: 217; 24-month: 215; 6-month: 216; patients ineligible for 24-month recall: risk-based: 861; 6-month: 863

Number evaluated: varied substantially by outcome

\section{Comparison: risk-based recall versus 24-month recall versus 6-month recall}

A standard NHS dental check-up involves clinical examination, advice, charting including monitoring of periodontal status and report. The content of the 6-month and 24-month recalls remained as per current practice. Risk-based intervals were individualised and determined by the evidence-based process outlined in the 2004 NICE guideline on Dental Recall. This involved consideration of the pertinent risk 
INTERVAL 2020 (Continued)

and protective factors, consideration of an appropriate recall interval and its agreement with the patient, and review of the appropriateness of the recall interval at the following check-up and its adjustment or maintenance. The recommendation was that the recall interval range for adults should vary from 3 to 24 months, based on risk

Duration of study: 4 years

Outcomes Clinical status outcomes

- Dental caries: 1) ICDAS reported as prevalence of caries of different severity (we used moderate to extensive caries - ICDAS 3 to 6 ); 2) mean number of surfaces with caries of different severity (we used any caries - ICDAS 1 to 6 ); 3) prevalence of root caries

- Periodontal disease: 1 ) percentage of sites bleeding; 2) mean pocket depth ( $\mathrm{mm}$ )

\section{Psychosocial (patient-centred) outcomes}

- Patient satisfaction with actual care received: 1 to 7 scale where higher score is better

- Oral-health-related quality of life: OHIP-14 0 to 56 scale where lower score is better

\section{Economic costs}

- Costs to patient: GBP per patient over 4-year period

- Costs to provider (NHS): GBP per patient over 4-year period

\section{Other outcomes}

- Oral health knowledge: 1 to 9 where higher score is better

- Oral health attitudes: 1 to 7 where higher score is better

- Oral health behaviours: 1 to 9 where higher score is better

Sample size calculation: patients eligible for 24-month recall (235 per arm); patients ineligible for 24month recall (515 per arm)

Statistical analysis: statistical analyses were adjusted for the protocol minimisation variables used in participant randomisation within the 2 strata

Declarations/conflicts of interest: none

Trials registration number: ISRCTN95933794

\section{Risk of bias}

\begin{tabular}{lll}
\hline Bias & Authors' judgement & Support for judgement \\
\hline $\begin{array}{l}\text { Random sequence genera- } \\
\text { tion (selection bias) }\end{array}$ & Low risk & $\begin{array}{l}\text { "randomised in equal proportions within each of the two strata according to a } \\
\text { minimisation algorithm" }\end{array}$ \\
\hline $\begin{array}{l}\text { Allocation concealment } \\
\text { (selection bias) }\end{array}$ & Low risk & $\begin{array}{l}\text { "The trial utilised the automated central randomisation service at the Centre } \\
\text { for Healthcare Randomised Trials (CHaRT), University of Aberdeen" }\end{array}$ \\
\hline $\begin{array}{l}\text { Blinding of outcome as- } \\
\text { sessment (detection bias) } \\
\text { - patient-assessed out- } \\
\text { comes } \\
\begin{array}{l}\text { All outcomes } \\
\text { Blinding of outcome as- } \\
\text { sessment (detection bias) }\end{array}\end{array}$ & Low risk & $\begin{array}{l}\text { We judged that patient assessment of oral-health related quality of life was un- } \\
\text { likely to have been influenced by knowledge of the recall interval to such an } \\
\text { extent that it would introduce a material bias }\end{array}$ \\
\hline
\end{tabular}


INTERVAL 2020 (Continued) - clinician-assessed outcomes

All outcomes

Incomplete outcome data Low risk (attrition bias)

All outcomes

\begin{abstract}
"For most participants, reasons for non-attendance were unknown" and "We used multiple imputation for the primary clinical outcome (gingival bleeding) ... The sensitivity analyses did not change the interpretation of the results"

Comment: consistently high attrition across all arms and outcomes ranging from $25 \%$ to $37 \%$. However, as reasons for missing data were not known, it is not possible to say whether or not reasons were related to the true values of the missing data. Also, sensitivity analyses indicated that the results were robust
\end{abstract}

\begin{tabular}{lll}
\hline $\begin{array}{l}\text { Selective reporting (re- } \\
\text { porting bias) }\end{array}$ & Low risk & Outcomes fully reported \\
\hline Other bias & Low risk & No other apparent biases \\
\hline
\end{tabular}

Wang 1992

\section{Study characteristics}

$\begin{array}{ll}\text { Methods } & \text { Trial design: parallel-group RCT ( } 2 \text { arms) } \\ & \text { Location: public dental clinic, Tromsø, Norway } \\ & \text { Number of centres: } 1\end{array}$

Participants Inclusion criteria: children and adolescents who received regular dental care in 1 public dental clinic in Norway; participants entering the trial were either 3, 16 or 18 years of age

Exclusion criteria: children classified as 'at risk'. Criteria for classification of 'risk patients':

3 years: more than $0 \mathrm{dmft}$

16 years: at least 1 decayed surface and 4 or more initial carious lesions and more than 10 DMFT

18 years: at least 1 decayed surface and 4 or more initial carious lesions and more than 12 DMFT

Baseline caries (DMFS) (mean and SD): 3-year-olds (12-month group: $0 \pm 0$; 24-month group: $0 \pm 0$ ); 16-year-olds (12-month group: $10.6 \pm 7.7$; 24-month group: $11.4 \pm 5.7$ ); 18-year-olds (12-month group: $11.9 \pm 6.7 ; 24$-month group: $13.7 \pm 6.8$ )

Baseline periodontal disease: not reported

Baseline oral health related quality of life: not reported

Age at baseline: stratified into 3-, 16-, and 18-year-olds

Sex: not reported

Number randomised: 241; 3-year-olds (12-month group: 35; 24-month group: 35); 16-year-olds (12month group: 50; 24-month group: 51); 18-year-olds (12-month group: 35; 24-month group: 35 )

Number evaluated: 185; 3-year-olds (12-month group: 27; 24-month group: 31); 16-year-olds (12month group: 43; 24-month group: 35); 18-year-olds (12-month group: 23; 24-month group: 26)

\section{Comparison: 12-month recall versus 24-month recall}

1 dentist and 1 hygienist provided all dental care. The hygienist examined 3-year-old patients at the initial, intermediate and final visits. The dentist examined the 16- and 18-year-olds and provided operative treatment for all the children 
Wang 1992 (Continued)

Duration of study: 24 months

Clinical status outcomes
Outcomes Dental caries: dmfs/DMFS increment
Economic costs
Costs to provider
- Dentist, hygienist, therapist time and other personnel time: total time (the sum of clinical examina-
tion time, operative treatment, acute visits (unscheduled extra visits initiated by the participant) and
minutes wasted when the participant did not show up)

Notes

Funding source: not reported

Sample size calculation: not reported

Declarations/conflicts of interest: not reported

Trials registration number: not reported

\section{Risk of bias}

\begin{tabular}{|c|c|c|}
\hline Bias & Authors' judgement & Support for judgement \\
\hline $\begin{array}{l}\text { Random sequence genera- } \\
\text { tion (selection bias) }\end{array}$ & Unclear risk & $\begin{array}{l}\text { Quote: "The participating children were randomly allocated to two groups" } \\
\text { Comment: insufficient information }\end{array}$ \\
\hline $\begin{array}{l}\text { Allocation concealment } \\
\text { (selection bias) }\end{array}$ & Unclear risk & $\begin{array}{l}\text { Quote: "The participating children were randomly allocated to two groups" } \\
\text { Comment: insufficient information }\end{array}$ \\
\hline $\begin{array}{l}\text { Blinding of outcome as- } \\
\text { sessment (detection bias) } \\
\text { - clinician-assessed out- } \\
\text { comes } \\
\text { All outcomes }\end{array}$ & High risk & $\begin{array}{l}1 \text { dentist and } 1 \text { dental hygienist provided all dental care and examined the par- } \\
\text { ticipants. Therefore blinding of outcome assessment was not carried out }\end{array}$ \\
\hline $\begin{array}{l}\text { Incomplete outcome data } \\
\text { (attrition bias) } \\
\text { All outcomes }\end{array}$ & Low risk & $\begin{array}{l}22 \% \text { dropped out from the } 12 \text {-month group; } 24 \% \text { dropped out from the } 24- \\
\text { month group; all dropouts were due to leaving the area }\end{array}$ \\
\hline $\begin{array}{l}\text { Selective reporting (re- } \\
\text { porting bias) }\end{array}$ & Low risk & Outcomes stated in the Methods section were reported in full \\
\hline Other bias & Low risk & No other apparent biases \\
\hline
\end{tabular}

DMFS = decayed, missing, filled surfaces; DMFT/dmft = decayed, missing, filled teeth; GBP = British pound sterling; NICE = National Institute for Health and Care Excellence; NIHR HTA = National Institute for Health Research Health Technology Assessment programme; RCT = randomised controlled trial; $\mathrm{SD}=$ standard deviation

Characteristics of excluded studies [ordered by study ID] 


\begin{tabular}{ll}
\hline Study & Reason for exclusion \\
\hline Grimm 1986 & $\begin{array}{l}\text { Not a randomised controlled trial. In this study treatment and control groups were formed accord- } \\
\text { ing to the age of participants }\end{array}$ \\
\hline Schulz 1989 & Unable to contact authors to determine if this study was a randomised controlled trial (paper in \\
German). & \\
This study was fully translated with a view to determining its eligibility. We were unable, howev- \\
er, to ascertain from this translation if it was a randomised trial. In addition the interventions and \\
comparison groups were poorly described. The authors state that "55 test persons participated \\
in this study. They had gingivitis caused by plaque at the age 15 and 25 years (17.7 years on aver- \\
age). Not included were pregnant women, patients with internal diseases, with prosthetic restora- \\
tions and untreated caries. 15 test persons took part in 3 different programmes, over a period \\
of 3 months that had the following objectives: oral hygiene instructions and motivation (dental \\
nurse) as well as professional tooth cleaning (dentist). 1 group made up of 10 test persons (group \\
IV) served as the control group. The programme of group III with 1 motivation session without teeth \\
cleaning training was designed to check which results the frequent examination with an oral hy- \\
giene pass/check book produces. From the results of the test group we expected indications of the \\
motivating effect of the professional teeth cleaning and of the importance for the reduction of gin- \\
givitis as such"
\end{tabular}

\section{DATA AND ANALYSES}

Comparison 1. 24 months versus 12 months: 2 -year outcome data

\begin{tabular}{|c|c|c|c|c|}
\hline Outcome or subgroup title & $\begin{array}{l}\text { No. of } \\
\text { studies }\end{array}$ & $\begin{array}{l}\text { No. of } \\
\text { partici- } \\
\text { pants }\end{array}$ & Statistical method & Effect size \\
\hline 1.1 Caries (dmfs/DMFS increment) & 1 & & Mean Difference (IV, Random, 95\% Cl) & Subtotals only \\
\hline 1.1.1 3-5 year olds (primary teeth) & 1 & 58 & Mean Difference (IV, Random, 95\% CI) & $0.90[-0.16,1.96]$ \\
\hline $\begin{array}{l}1.1 .216-20 \text { year olds (permanent } \\
\text { teeth) }\end{array}$ & 1 & 127 & Mean Difference (IV, Random, 95\% Cl) & $0.86[-0.03,1.75]$ \\
\hline
\end{tabular}


Analysis 1.1. Comparison 1: 24 months versus 12 months: 2year outcome data, Outcome 1: Caries (dmfs/DMFS increment)

\begin{tabular}{|c|c|c|c|c|c|c|c|c|c|}
\hline \multirow[b]{2}{*}{ or Subgroup } & \multicolumn{3}{|c|}{24 months } & \multicolumn{3}{|c|}{12 months } & \multicolumn{2}{|r|}{ Mean Difference } & Mean Difference \\
\hline & Mean & SD & Total & Mean & SD & Total & Weight & IV, Random, 95\% CI & IV, Random, $95 \%$ CI \\
\hline
\end{tabular}

1.1.1 3-5 year olds (primary teeth)

$\begin{array}{lllllllll}\text { Wang } 1992 & 1.8 & 2 & 31 & 0.9 & 2.1 & 27 & 100.0 \% & 0.90[-0.16,1.96] \\ \text { Subtotal (95\% CI) } & & & \mathbf{3 1} & & & \mathbf{2 7} & \mathbf{1 0 0 . 0 \%} & \mathbf{0 . 9 0}[-\mathbf{- 0 . 1 6}, \mathbf{1 . 9 6}]\end{array}$

Heterogeneity: Not applicable

Test for overall effect: $\mathrm{Z}=1.66(\mathrm{P}=0.10)$

1.1.2 16-20 year olds (permanent teeth)

$\begin{array}{lllllllll}\text { Wang } 1992 & 1.65 & 3.27 & 61 & 0.79 & 1.47 & 66 & 100.0 \% & 0.86[-0.03,1.75] \\ \text { Subtotal (95\% CI) } & & & \mathbf{6 1} & & & \mathbf{6 6} & \mathbf{1 0 0 . 0 \%} & \mathbf{0 . 8 6}[-\mathbf{0 . 0 3}, \mathbf{1 . 7 5}]\end{array}$

Heterogeneity: Not applicable

Test for overall effect: $\mathrm{Z}=1.89(\mathrm{P}=0.06)$

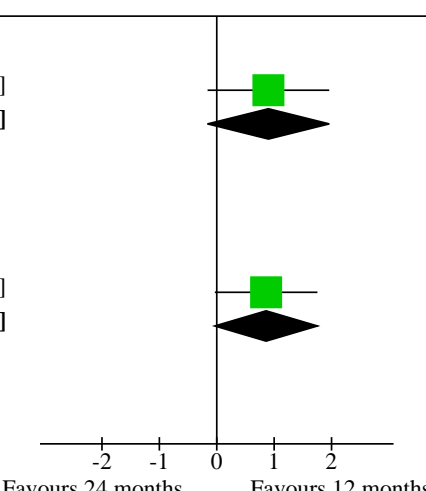

Favours 24 months $\quad$ Favours 12 months

Comparison 2. Risk based versus 6 months: 4-year outcome data

\begin{tabular}{llllll}
\hline Outcome or subgroup title & $\begin{array}{l}\text { No. of } \\
\text { studies }\end{array}$ & $\begin{array}{l}\text { No. of } \\
\text { partici- } \\
\text { pants }\end{array}$ & Statistical method & Effect size \\
\hline $\begin{array}{l}\text { 2.1 Prevalence of moderate to extensive } \\
\text { caries (ICDAS 3 to 6) }\end{array}$ & 1 & 1478 & Risk Ratio (M-H, Random, 95\% CI) & 1.04 [0.99, 1.09] \\
\hline $\begin{array}{l}\text { 2.2 Mean number of surfaces with any caries } \\
\text { (ICDAS 1 to 6) }\end{array}$ & 1 & 1478 & $\begin{array}{l}\text { Mean Difference (IV, Random, 95\% } \\
\text { Cl) }\end{array}$ & 0.15 [-0.77, 1.08] \\
\hline $\begin{array}{l}\text { 2.3 Gingival bleeding: percentage of sites } \\
\text { 2.4 Probing pocket depth (mm) }\end{array}$ & 1 & 1472 & $\begin{array}{l}\text { Mean Difference (IV, Random, 95\% } \\
\text { Cl) }\end{array}$ & 0.78 [-1.17, 2.73] \\
\hline $\begin{array}{l}\text { 2.5 Patient OHIP-14 (0 to 56 scale where lower } \\
\text { score is better) }\end{array}$ & 1 & 1551 & $\begin{array}{l}\text { Mean Difference (IV, Random, 95\% } \\
\text { Cl) }\end{array}$ & -0.35 [-1.02, 0.32] \\
\hline
\end{tabular}

Analysis 2.1. Comparison 2: Risk based versus 6 months: 4-year outcome data, Outcome 1: Prevalence of moderate to extensive caries (ICDAS 3 to 6)

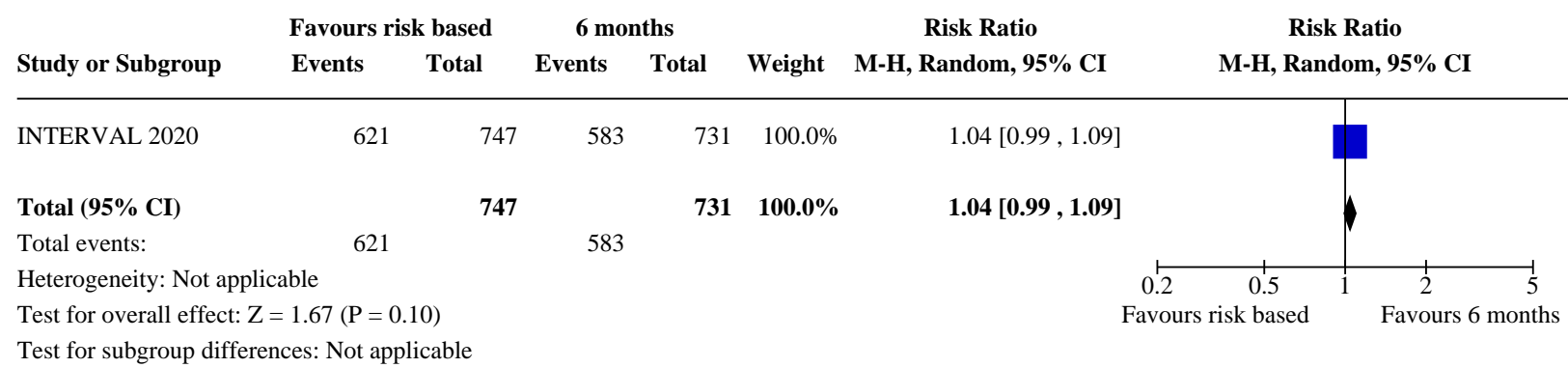


Analysis 2.2. Comparison 2: Risk based versus 6 months: 4-year outcome data, Outcome 2: Mean number of surfaces with any caries (ICDAS 1 to 6)

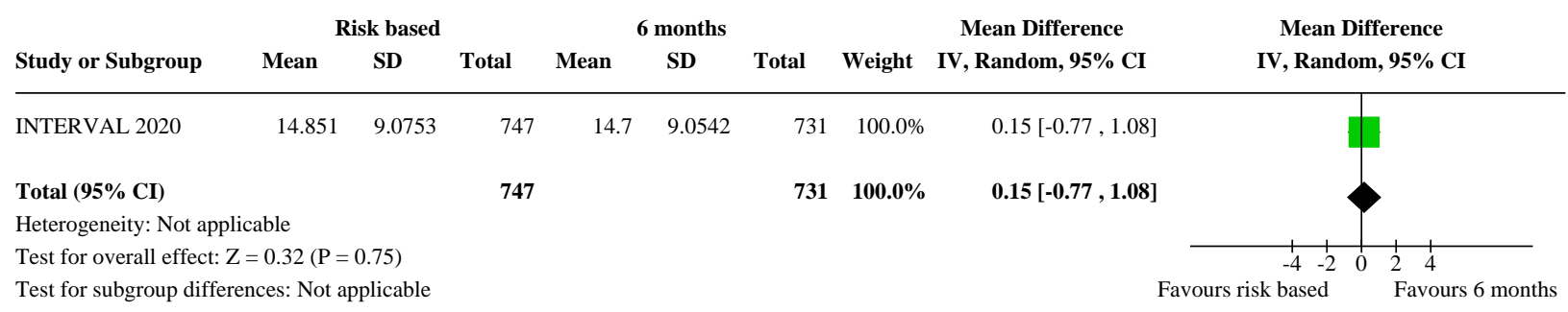

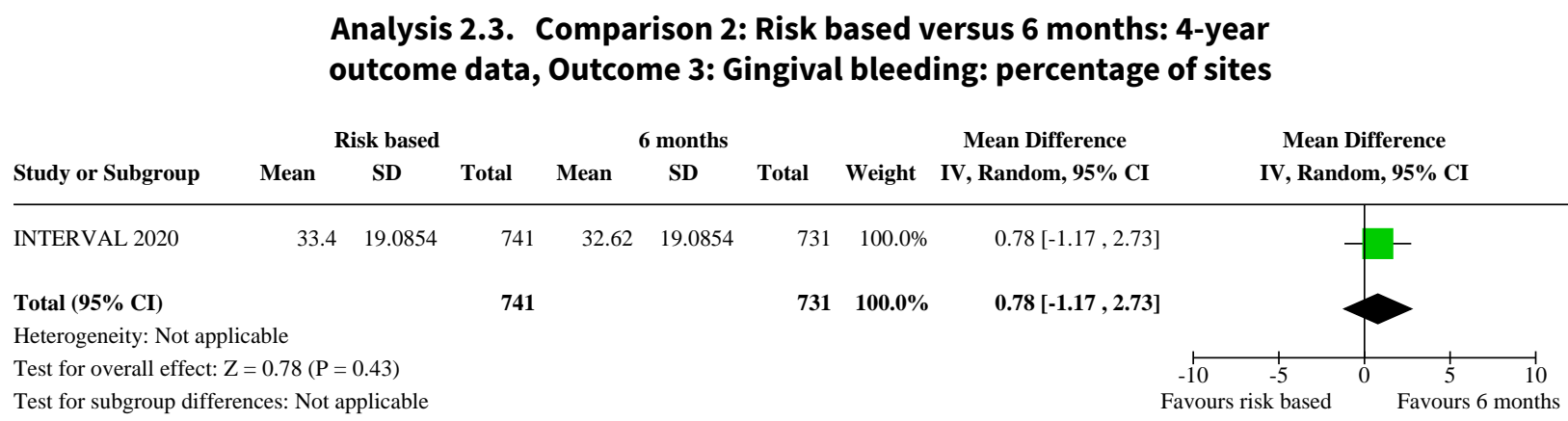

Analysis 2.4. Comparison 2: Risk based versus 6 months: 4year outcome data, Outcome 4: Probing pocket depth ( $\mathrm{mm})$

\begin{tabular}{|c|c|c|c|c|c|c|c|c|c|}
\hline \multirow[b]{2}{*}{ Study or Subgroup } & \multicolumn{3}{|c|}{ Risk based } & \multicolumn{3}{|c|}{6 months } & \multirow[b]{2}{*}{ Weight } & \multirow{2}{*}{$\begin{array}{c}\text { Mean Difference } \\
\text { IV, Random, 95\% CI }\end{array}$} & \multirow{2}{*}{$\begin{array}{c}\text { Mean Difference } \\
\text { IV, Random, 95\% CI }\end{array}$} \\
\hline & Mean & SD & Total & Mean & SD & Total & & & \\
\hline INTERVAL 2020 & 2.2 & 0.3915 & 736 & 2.17 & 0.3915 & 727 & $100.0 \%$ & $0.03[-0.01,0.07]$ & \\
\hline Total $(95 \%$ CI) & & & 736 & & & 727 & $100.0 \%$ & $0.03[-0.01,0.07]$ & 4 \\
\hline \multicolumn{10}{|c|}{ Heterogeneity: Not applicable } \\
\hline \multirow{2}{*}{\multicolumn{4}{|c|}{ Test for overall effect: $\mathrm{Z}=1.47(\mathrm{P}=0.14)$}} & & & & & -1 & -0.5 \\
\hline & & & & & & & & Favou & isk based \\
\hline
\end{tabular}

Analysis 2.5. Comparison 2: Risk based versus 6 months: 4-year outcome data, Outcome 5: Patient OHIP-14 (0 to 56 scale where lower score is better)

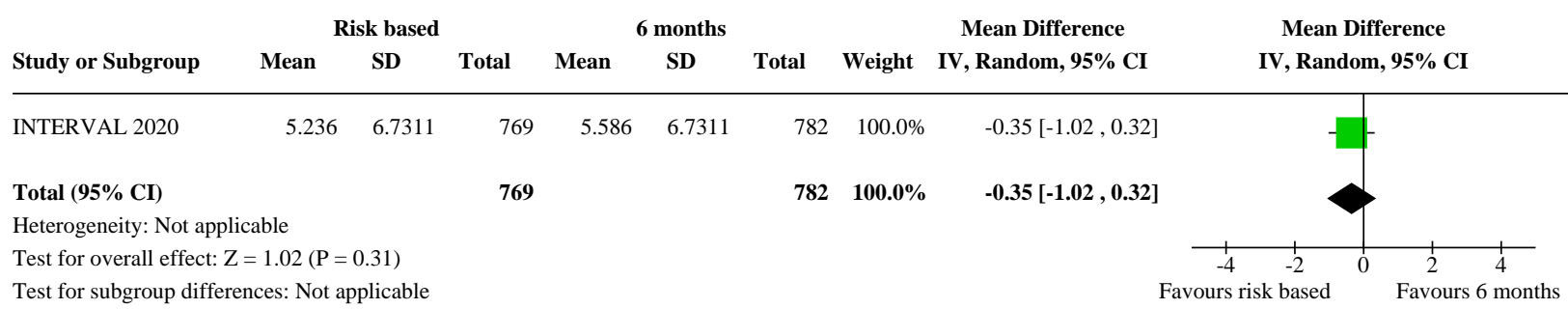


Comparison 3. 24 months versus 6 months: 4 -year outcome data

\begin{tabular}{lllll}
\hline Outcome or subgroup title & $\begin{array}{l}\text { No. of } \\
\text { studies }\end{array}$ & $\begin{array}{l}\text { No. of } \\
\text { partici- } \\
\text { pants }\end{array}$ & Statistical method & Effect size \\
\hline $\begin{array}{l}\text { 3.1 Prevalence of moderate to extensive } \\
\text { caries (ICDAS 3 to 6) }\end{array}$ & 1 & 271 & Risk Ratio (M-H, Random, 95\% CI) & 1.05 [0.92, 1.20] \\
\hline $\begin{array}{l}\text { 3.2 Mean number of surfaces with any caries } \\
\text { (ICDAS 1 to 6) }\end{array}$ & 1 & 271 & $\begin{array}{l}\text { Mean Difference (IV, Random, 95\% } \\
\text { Cl) }\end{array}$ & -0.60 [-2.54, 1.34] \\
\hline $\begin{array}{l}\text { 3.3 Gingival bleeding: percentage of sites } \\
\text { 3.4 Probing pocket depth (mm) }\end{array}$ & 1 & 271 & $\begin{array}{l}\text { Mean Difference (IV, Random, 95\% } \\
\text { Cl) }\end{array}$ & -0.91 [-5.02, 3.20] \\
\hline $\begin{array}{l}\text { 3.5 Patient OHIP-14 (0 to 56 scale where low- } \\
\text { er score is better) }\end{array}$ & 1 & 305 & $\begin{array}{l}\text { Mean Difference (IV, Random, 95\% } \\
\text { Cl) }\end{array}$ & -0.24 [-1.55, 1.07] \\
\hline
\end{tabular}

Analysis 3.1. Comparison 3: 24 months versus 6 months: 4-year outcome data, Outcome 1: Prevalence of moderate to extensive caries (ICDAS 3 to 6)

\begin{tabular}{|c|c|c|c|c|c|c|c|}
\hline \multirow[b]{2}{*}{ Study or Subgroup } & \multicolumn{2}{|c|}{24 months } & \multicolumn{2}{|c|}{6 months } & \multicolumn{2}{|r|}{ Risk Ratio } & Risk Ratio \\
\hline & Events & Total & Events & Total & Weight & M-H, Random, $95 \%$ CI & M-H, Random, 95\% CI \\
\hline
\end{tabular}

\begin{tabular}{lcccccc}
\hline INTERVAL 2020 & 109 & 138 & 100 & 133 & $100.0 \%$ & $1.05[0.92,1.20]$ \\
$\begin{array}{l}\text { Total (95\% CI) } \\
\text { Total events: }\end{array}$ & 109 & $\mathbf{1 3 8}$ & & $\mathbf{1 3 3}$ & $\mathbf{1 0 0 . 0 \%}$ & $\mathbf{1 . 0 5}[\mathbf{0 . 9 2}, \mathbf{1 . 2 0}]$ \\
\end{tabular}

Heterogeneity: Not applicable

Test for overall effect: $\mathrm{Z}=0.74(\mathrm{P}=0.46)$

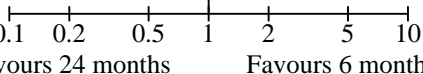

Test for subgroup differences: Not applicable

Analysis 3.2. Comparison 3: 24 months versus 6 months: 4-year outcome data, Outcome 2: Mean number of surfaces with any caries (ICDAS 1 to 6)

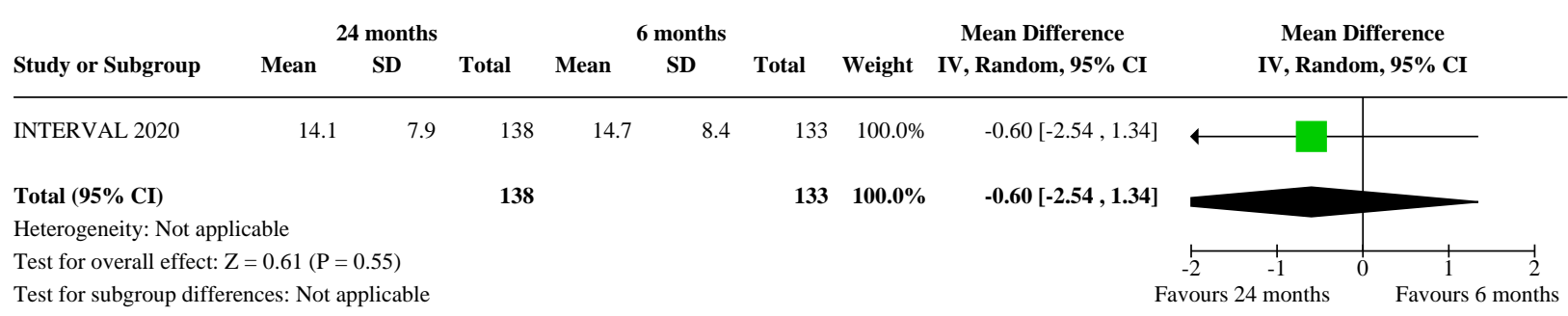


Analysis 3.3. Comparison 3: 24 months versus 6 months: 4-year outcome data, Outcome 3: Gingival bleeding: percentage of sites

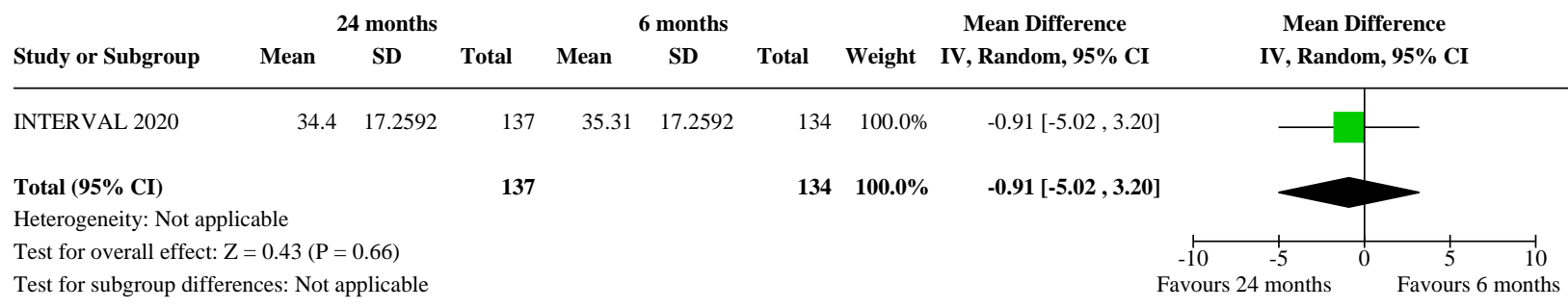

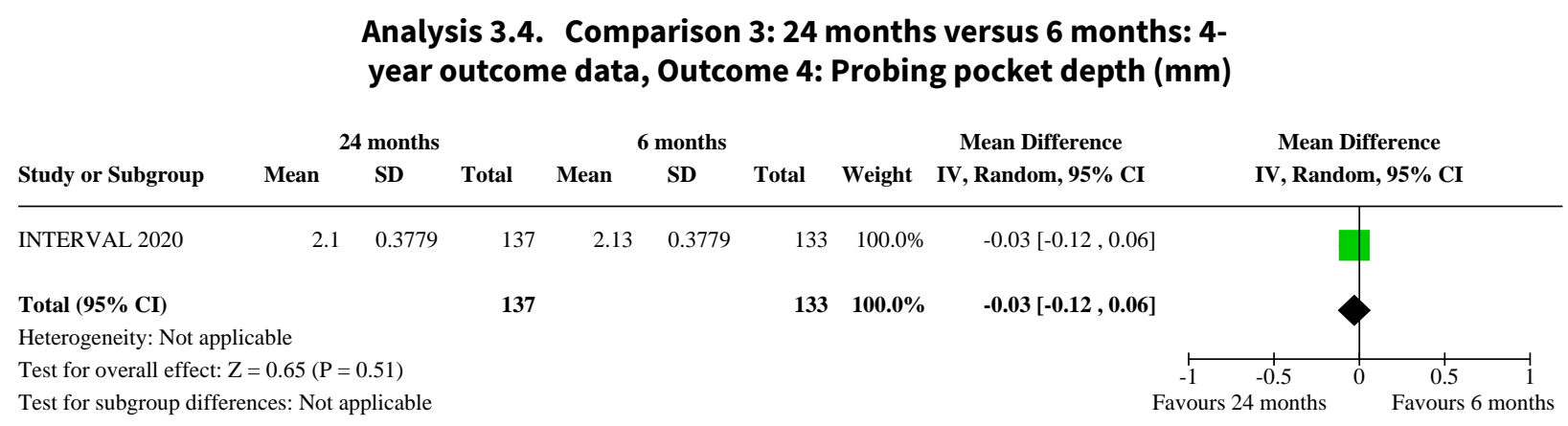

Analysis 3.5. Comparison 3: 24 months versus 6 months: 4-year outcome data, Outcome 5: Patient OHIP-14 (0 to 56 scale where lower score is better)

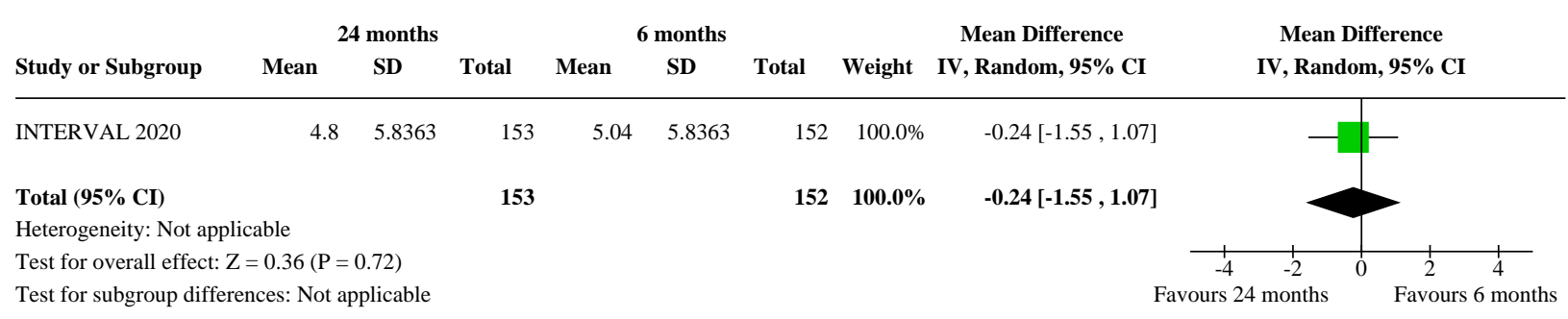

\section{Comparison 4. Risk-based versus 24 months: 4-year outcome data}

\begin{tabular}{llllll}
\hline Outcome or subgroup title & $\begin{array}{l}\text { No. of } \\
\text { studies }\end{array}$ & $\begin{array}{l}\text { No. of } \\
\text { partici- } \\
\text { pants }\end{array}$ & Statistical method & Effect size \\
\hline $\begin{array}{l}\text { 4.1 Prevalence of moderate to extensive } \\
\text { caries (ICDAS 3 to 6) }\end{array}$ & 1 & 279 & Risk Ratio (M-H, Random, 95\% CI) & 1.06 [0.95, 1.19] \\
\hline $\begin{array}{l}\text { 4.2 Mean number of surfaces with any caries } \\
\text { (ICDAS 1 to 6) }\end{array}$ & 1 & 279 & $\begin{array}{l}\text { Mean Difference (IV, Random, 95\% } \\
\text { Cl) }\end{array}$ & 1.40 [-0.69, 3.49] \\
\hline $\begin{array}{l}\text { 4.3 Gingival bleeding: percentage of sites } \\
\text { 4.4 Probing pocket depth (mm) }\end{array}$ & 1 & 279 & $\begin{array}{l}\text { Mean Difference (IV, Random, 95\% } \\
\text { Cl) }\end{array}$ & $-0.07[-4.10,3.96]$ \\
\hline
\end{tabular}




\begin{tabular}{llllll}
\hline Outcome or subgroup title & $\begin{array}{l}\text { No. of } \\
\text { studies }\end{array}$ & $\begin{array}{l}\text { No. of } \\
\text { partici- } \\
\text { pants }\end{array}$ & Statistical method & Effect size \\
\hline $\begin{array}{l}\text { 4.5 Patients OHIP-14 (0 to 56 scale where low- } \\
\text { er score is better) }\end{array}$ & 1 & 298 & $\begin{array}{l}\text { Mean Difference (IV, Random, 95\% } \\
\text { Cl) }\end{array}$ & $-0.37[-1.69,0.95]$ \\
\hline
\end{tabular}

Analysis 4.1. Comparison 4: Risk-based versus 24 months: 4-year outcome data, Outcome 1: Prevalence of moderate to extensive caries (ICDAS 3 to 6)

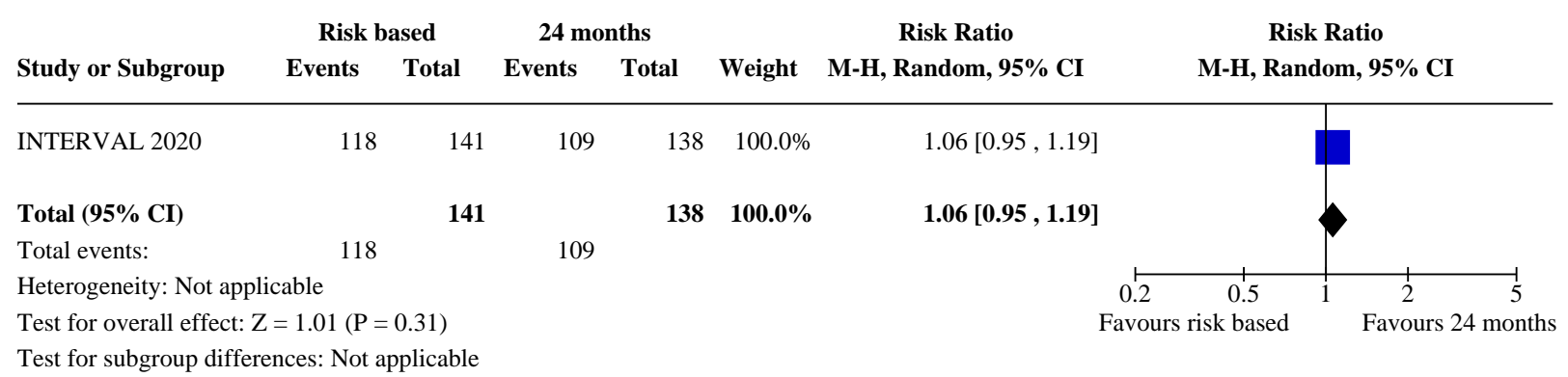

Analysis 4.2. Comparison 4: Risk-based versus 24 months: 4-year outcome data, Outcome 2: Mean number of surfaces with any caries (ICDAS 1 to 6)

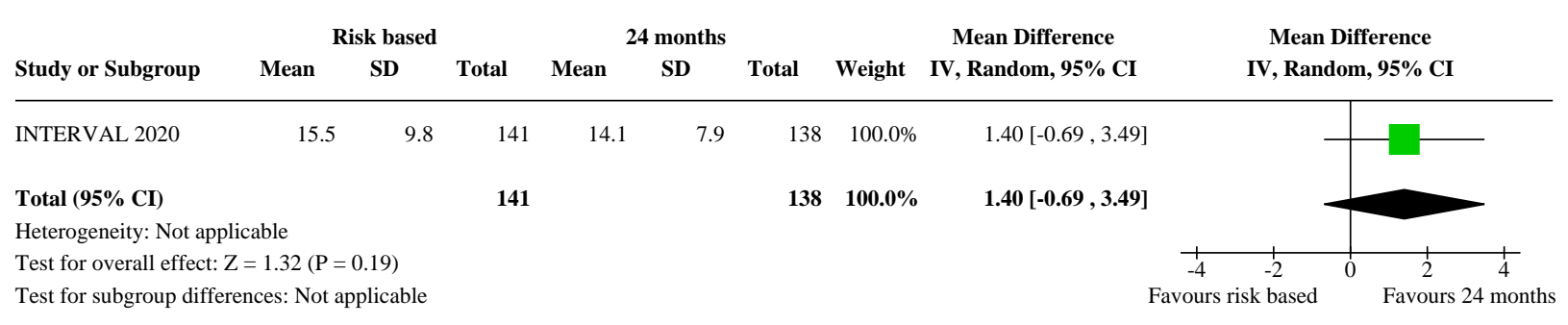

\begin{tabular}{|c|c|c|c|c|c|c|c|c|c|}
\hline \multirow[b]{2}{*}{ Study or Subgroup } & \multicolumn{9}{|c|}{$\begin{array}{l}\text { Analysis 4.3. Comparison 4: Risk-based versus } 24 \text { months: 4-year } \\
\text { outcome data, Outcome 3: Gingival bleeding: percentage of sites }\end{array}$} \\
\hline & \multicolumn{3}{|c|}{ Risk based } & \multicolumn{3}{|c|}{24 months } & Weight & $\begin{array}{l}\text { Mean Difference } \\
\text { IV, Random, } 95 \% \text { CI }\end{array}$ & $\begin{array}{l}\text { Mean Difference } \\
\text { IV, Random, 95\% CI }\end{array}$ \\
\hline INTERVAL 2020 & 35.6 & 17.1573 & 142 & 35.67 & 17.1573 & 137 & $100.0 \%$ & $-0.07[-4.10,3.96]$ & \\
\hline Total $(95 \%$ CI $)$ & & & 142 & & & 137 & $100.0 \%$ & $-0.07[-4.10,3.96]$ & \\
\hline \multicolumn{10}{|c|}{ Heterogeneity: Not applicable } \\
\hline \multicolumn{9}{|c|}{ Test for overall effect: $\mathrm{Z}=0.03(\mathrm{P}=0.97)$} & $\begin{array}{c}1 \\
-2\end{array}$ \\
\hline \multicolumn{9}{|c|}{ Test for subgroup differences: Not applicable } & isk based \\
\hline
\end{tabular}




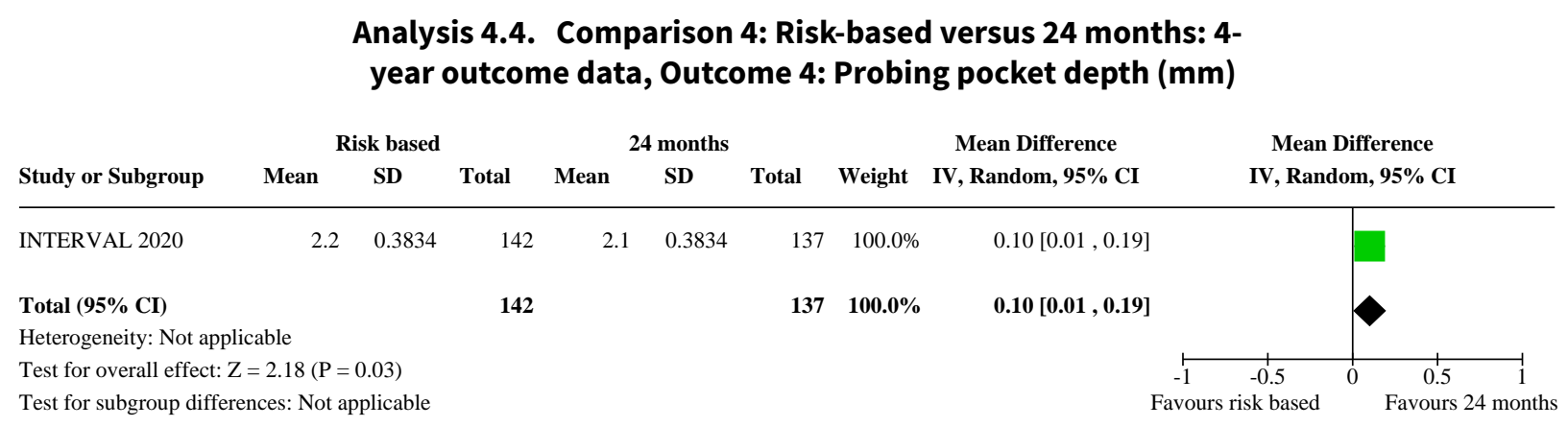

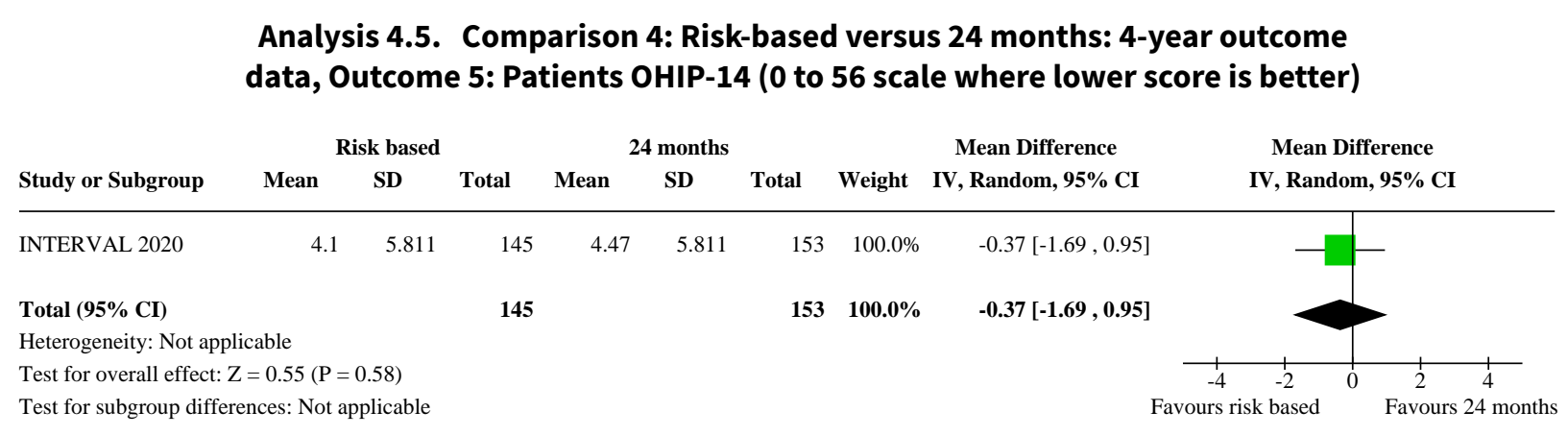

\section{ADDITIONAL TABLES}

Table 1. Comparison 1: 24-month recall versus 12-month recall at 2 years follow-up

\begin{tabular}{|c|c|c|c|c|}
\hline Outcome & Subgroup & 24-month recall & 12-month recall & Effect estimate \\
\hline \multirow{2}{*}{$\begin{array}{l}\text { Cost (health-system perspec- } \\
\text { tive costs and resource use): } \\
\text { total time used by each par- } \\
\text { ticipant (minutes) }\end{array}$} & $\begin{array}{l}3 \text { to } 5 \text { years old (pri- } \\
\text { mary teeth) }\end{array}$ & $\begin{array}{l}\text { mean } 42(\mathrm{SD} 34.7) ; 31 \\
\text { participants }\end{array}$ & $\begin{array}{l}\text { mean } 52(\text { SD 30.2); } 27 \\
\text { participants }\end{array}$ & $\begin{array}{l}M D-10.00(95 \% \mathrm{Cl} \\
-26.70 \text { to } 6.70)\end{array}$ \\
\hline & $\begin{array}{l}16 \text { to } 20 \text { years old } \\
\text { (permanent teeth) }\end{array}$ & $\begin{array}{l}\text { mean } 62.5 \text { (SD 53.8); } 61 \\
\text { participants }\end{array}$ & $\begin{array}{l}\text { mean } 86.2 \text { (SD 58.8); } 66 \\
\text { participants }\end{array}$ & $\begin{array}{l}\mathrm{MD}-23.70(95 \% \mathrm{Cl} \\
-43.28 \text { to }-4.12)\end{array}$ \\
\hline
\end{tabular}

$\mathrm{Cl}=$ confidence interval; $\mathrm{MD}=$ mean difference $\mathrm{SD}=$ standard deviation

Table 2. Comparison 2: Risk-based recall versus 6-month recall at 4 years follow-up

\begin{tabular}{|c|c|c|c|}
\hline Outcome & Risk-based recall & 6-month recall & Effect estimate \\
\hline $\begin{array}{l}\text { Cost (patient perspective costs): GBP per pa- } \\
\text { tient }\end{array}$ & $\begin{array}{l}\text { mean } 197.33 \text { (SD 155.1); } \\
966 \text { participants }\end{array}$ & $\begin{array}{l}\text { mean } 206.82 \text { (SD 149.89); } \\
978 \text { participants }\end{array}$ & $\begin{array}{l}\mathrm{MD}-9.49(95 \% \mathrm{Cl}-23.05 \text { to } \\
4.07) ; \mathrm{P}=0.17\end{array}$ \\
\hline $\begin{array}{l}\text { Cost (healthcare system perspective costs } \\
\text { and resource use): GBP per patient }\end{array}$ & $\begin{array}{l}\text { mean } 123.37 \text { (SD 185.66); } \\
1001 \text { participants }\end{array}$ & $\begin{array}{l}\text { mean } 109.6 \text { (SD 164.09); } \\
1009 \text { participants }\end{array}$ & $\begin{array}{l}\text { MD } 13.77(95 \% \mathrm{Cl}-1.56 \text { to } \\
29.11) ; \mathrm{P}=0.08\end{array}$ \\
\hline Prevalence of root caries & $\begin{array}{l}147 \text { out of } 663 \text { partici- } \\
\text { pants }\end{array}$ & $\begin{array}{l}154 \text { out of } 643 \text { partici- } \\
\text { pants }\end{array}$ & $\begin{array}{l}\mathrm{RR} 0.93(95 \% \mathrm{Cl} 0.76 \text { to } \\
1.13) ; \mathrm{P}=0.45\end{array}$ \\
\hline $\begin{array}{l}\text { Patient satisfaction with actual care received: } \\
1 \text { to } 7 \text { scale where a higher score is a better } \\
\text { outcome }\end{array}$ & $\begin{array}{l}\text { mean } 5.3 \text { (SD 0.6136); } 798 \\
\text { participants }\end{array}$ & $\begin{array}{l}\text { mean } 5.27 \text { (SD 0.6136); } \\
809 \text { participants }\end{array}$ & $\begin{array}{l}\text { MD } 0.03(95 \% \mathrm{Cl}-0.03 \text { to } \\
0.09) ; \mathrm{P}=0.33\end{array}$ \\
\hline
\end{tabular}


Table 2. Comparison 2: Risk-based recall versus 6-month recall at 4 years follow-up (Continued)

\begin{tabular}{llll}
$\begin{array}{l}\text { Patient oral health knowledge: } 1 \text { to } 9 \text { scale } \\
\text { where a higher score is a better outcome }\end{array}$ & $\begin{array}{l}\text { mean 6.5812 (SD 0.2043); } \\
798 \text { participants }\end{array}$ & $\begin{array}{l}\text { mean 6.5912 (SD 0.2043); } \\
806 \text { participants }\end{array}$ & $\begin{array}{l}\mathrm{MD}-0.01(95 \% \mathrm{Cl}-0.03 \text { to } \\
0.01) ; \mathrm{P}=0.33\end{array}$ \\
\hline $\begin{array}{l}\text { Patient attitude to oral health: } 1 \text { to } 7 \text { scale } \\
\text { where a higher score is a better outcome }\end{array}$ & $\begin{array}{l}\text { mean 4.1378 (SD 0.8181); } \\
798 \text { participants }\end{array}$ & $\begin{array}{l}\text { mean 4.0978 (SD 0.8181); } \\
809 \text { participants }\end{array}$ & $\begin{array}{l}\mathrm{MD} \mathrm{0.04} \mathrm{(95 \%} \mathrm{Cl}-0.04 \text { to } \\
0.12) ; \mathrm{P}=0.33\end{array}$ \\
\hline $\begin{array}{l}\text { Patient oral health behaviour: } 1 \text { to } 9 \text { scale } \\
\text { where a higher score is a better outcome }\end{array}$ & $\begin{array}{l}\text { mean 5.4433 (SD 0.1023); } \\
799 \text { participants }\end{array}$ & $\begin{array}{l}\text { mean 5.4433 (SD 0.1023); } \\
809 \text { participants }\end{array}$ & $\begin{array}{l}\mathrm{MD} 0.00(95 \% \mathrm{Cl}-0.01 \text { to } \\
0.01) ; \mathrm{P}=1.00\end{array}$ \\
\hline
\end{tabular}

$\mathrm{Cl}=$ confidence interval; $\mathrm{GBP}=$ British pound sterling; $\mathrm{MD}=$ mean difference; $\mathrm{RR}$ = risk ratio; $\mathrm{SD}$ = standard deviation

Table 3. Comparison 3: 24-month recall versus 6-month recall at 4 years follow-up

\begin{tabular}{|c|c|c|c|}
\hline Outcome & 24-month recall & 6-month recall & Effect estimate \\
\hline Cost (patient perspective costs): GBP per patient & $\begin{array}{l}\text { mean } 116 \text { (SD } 111) \text {; } \\
184 \text { participants }\end{array}$ & $\begin{array}{l}\text { mean } 169 \text { (SD 125); } 191 \\
\text { participants }\end{array}$ & $\begin{array}{l}\mathrm{MD}-53.00(95 \% \mathrm{Cl}-76.91 \text { to } \\
-29.09) ; \mathrm{P}<0.0001\end{array}$ \\
\hline $\begin{array}{l}\text { Cost (healthcare system perspective costs and } \\
\text { resource use): GBP per patient }\end{array}$ & $\begin{array}{l}\text { mean } 80 \text { (SD 146); } 203 \\
\text { participants }\end{array}$ & $\begin{array}{l}\text { mean } 96 \text { (SD 214); } 201 \\
\text { participants }\end{array}$ & $\begin{array}{l}M D-16.00(95 \% \mathrm{Cl}-51.76 \text { to } \\
19.76) ; \mathrm{P}=0.38\end{array}$ \\
\hline Prevalence of root caries & $\begin{array}{l}21 \text { out of } 122 \text { partici- } \\
\text { pants }\end{array}$ & $\begin{array}{l}17 \text { out of } 116 \text { partici- } \\
\text { pants }\end{array}$ & $\begin{array}{l}\text { RR } 1.17(95 \% \mathrm{Cl} 0.65 \text { to } \\
2.11) ; \mathrm{P}=0.59\end{array}$ \\
\hline $\begin{array}{l}\text { Patient satisfaction with actual care received: } \\
1 \text { to } 7 \text { scale where a higher score is a better out- } \\
\text { come }\end{array}$ & $\begin{array}{l}\text { mean } 5 \text { (SD 0.6716); } \\
153 \text { participants }\end{array}$ & $\begin{array}{l}\text { mean } 5.11 \text { (SD 0.6716); } \\
155 \text { participants }\end{array}$ & $\begin{array}{l}\mathrm{MD}-0.11(95 \% \mathrm{Cl}-0.26 \text { to } \\
0.04) ; \mathrm{P}=0.15\end{array}$ \\
\hline $\begin{array}{l}\text { Patient oral health knowledge: } 1 \text { to } 9 \text { scale } \\
\text { where a higher score is a better outcome }\end{array}$ & $\begin{array}{l}\text { mean } 6.6 \text { (SD 0.1791); } \\
153 \text { participants }\end{array}$ & $\begin{array}{l}\text { mean } 6.61 \text { (SD } 0.1791) \\
155 \text { participants }\end{array}$ & $\begin{array}{l}M D-0.01(95 \% \mathrm{Cl}-0.05 \text { to } \\
0.03) ; P=0.62\end{array}$ \\
\hline $\begin{array}{l}\text { Patient attitude to oral health: } 1 \text { to } 7 \text { scale where } \\
\text { a higher score is a better outcome }\end{array}$ & $\begin{array}{l}\text { mean } 4.3 \text { (SD 0.8059); } \\
153 \text { participants }\end{array}$ & $\begin{array}{l}\text { mean } 4.13 \text { (SD 0.8059); } \\
155 \text { participants }\end{array}$ & $\begin{array}{l}\text { MD } 0.17(95 \% \mathrm{Cl}-0.01 \text { to } \\
0.35) ; \mathrm{P}=0.06\end{array}$ \\
\hline $\begin{array}{l}\text { Patient oral health behaviour: } 1 \text { to } 9 \text { scale where } \\
\text { a higher score is a better outcome }\end{array}$ & $\begin{array}{l}\text { mean } 4.9 \text { (SD 0.1343); } \\
153 \text { participants }\end{array}$ & $\begin{array}{l}\text { mean } 4.9 \text { (SD 0.1343); } \\
155 \text { participants }\end{array}$ & $\begin{array}{l}\mathrm{MD} 0.00(95 \% \mathrm{Cl}-0.03 \text { to } \\
0.03) ; \mathrm{P}=1.00\end{array}$ \\
\hline
\end{tabular}

$\mathrm{Cl}=$ confidence interval; $\mathrm{GBP}=$ British pound sterling; $\mathrm{MD}=$ mean difference; $\mathrm{RR}=$ risk ratio; $\mathrm{SD}=$ standard deviation

Table 4. Comparison 4: Risk-based recall versus 24-month recall at 4 years follow-up

\begin{tabular}{|c|c|c|c|}
\hline Outcome & Risk-based recall & 24-month recall & Effect estimate \\
\hline Cost (patient perspective costs): GBP per patient & $\begin{array}{l}\text { mean } 150 \text { (SD 128); } 191 \\
\text { participants }\end{array}$ & $\begin{array}{l}\text { mean } 116(\text { SD } 111) ; 184 \\
\text { participants }\end{array}$ & $\begin{array}{l}\text { MD 34.00 (95\% Cl } 9.78 \text { to } \\
58.22) ; P=0.006\end{array}$ \\
\hline $\begin{array}{l}\text { Cost (healthcare system perspective costs and } \\
\text { resource use): GBP per patient }\end{array}$ & $\begin{array}{l}\text { mean } 97 \text { (SD 174); } 201 \\
\text { participants }\end{array}$ & $\begin{array}{l}\text { mean } 80 \text { (SD 146); } 203 \\
\text { participants }\end{array}$ & $\begin{array}{l}\text { MD } 17.00(95 \% \mathrm{Cl}-14.34 \text { to } \\
48.34) ; P=0.29\end{array}$ \\
\hline Prevalence of root caries & $\begin{array}{l}26 \text { out of } 125 \text { partici- } \\
\text { pants }\end{array}$ & $\begin{array}{l}21 \text { out of } 122 \text { partici- } \\
\text { pants }\end{array}$ & $\begin{array}{l}\text { RR } 1.21(95 \% \mathrm{Cl} 0.72 \text { to } \\
2.03) ; P=0.47\end{array}$ \\
\hline $\begin{array}{l}\text { Patient satisfaction with actual care received: } \\
1 \text { to } 7 \text { scale where a higher score is a better out- } \\
\text { come }\end{array}$ & $\begin{array}{l}\text { mean } 5.2 \text { (SD 0.6672); } \\
151 \text { participants }\end{array}$ & $\begin{array}{l}\text { mean } 5.04 \text { (SD 0.6672); } \\
153 \text { participants }\end{array}$ & $\begin{array}{l}\text { MD } 0.16(95 \% \mathrm{Cl} 0.01 \text { to } \\
0.31) ; \mathrm{P}=0.04\end{array}$ \\
\hline
\end{tabular}


Table 4. Comparison 4: Risk-based recall versus 24-month recall at 4 years follow-up (Continued)

Patient oral health knowledge: 1 to 9 scale where a higher score is a better outcome mean 6.5 (SD 0.1776);

150 participants mean 6.51 (SD 0.1776); 153 participants
MD $-0.01(95 \% \mathrm{Cl}-0.05$ to

$0.03) ; P=0.62$

\begin{tabular}{llll}
$\begin{array}{l}\text { Patient attitude to oral health: } 1 \text { to } 7 \text { scale where } \\
\text { a higher score is a better outcome }\end{array}$ & $\begin{array}{l}\text { mean 4.3 (SD 0.8006); } \\
151 \text { participants }\end{array}$ & $\begin{array}{l}\text { mean 4.32 (SD 0.8006); } \\
153 \text { participants }\end{array}$ & $\begin{array}{l}\mathrm{MD}-0.02(95 \% \mathrm{Cl}-0.20 \text { to } \\
0.16) ; \mathrm{P}=0.83\end{array}$ \\
\hline $\begin{array}{l}\text { Patient oral health behaviour: } 1 \text { to } 9 \text { scale where } \\
\text { a higher score is a better outcome }\end{array}$ & $\begin{array}{l}\text { mean 5.2 (SD 0.1334); } \\
151 \text { participants }\end{array}$ & $\begin{array}{l}\text { mean 5.19 (SD 0.1334); } \\
153 \text { participants }\end{array}$ & $\begin{array}{l}\mathrm{MD} 0.01(95 \% \mathrm{Cl}-0.02 \text { to } \\
0.04) ; \mathrm{P}=0.51\end{array}$
\end{tabular}

$\mathrm{Cl}=$ confidence interval; $\mathrm{GBP}=$ British pound sterling; $\mathrm{MD}=$ mean difference; $\mathrm{RR}$ = risk ratio; $\mathrm{SD}$ = standard deviation

\section{AP PEN DICES}

\section{Appendix 1. Cochrane Oral Health's Trials Register search strategy}

Cochrane Oral Health's Trials Register is available via the Cochrane Register of Studies. For information on how the register is compiled, see https://oralhealth.cochrane.org/trials .

1 (("routine check up" or "routine inspect" or "routine appointment" or "routine examin" or "routine attend" or " routine recall" or "routine visit"”):ti,ab) AND (INREGISTER)

2 (("regular check up" or "regular inspect" or "regular appointment" or "regular examin"” or "regular attend" or " regular recall” or "regular visit"”):ti,ab) AND (INREGISTER)

3 (("periodic check up" or "periodic inspect" or "periodic appointment" or "periodic examin"” or "periodic attend" or " periodic recall" or "periodic visit"):ti,ab) AND (INREGISTER)

4 (("six month check up" or "six month inspect" or "six month appointment" or "six month examin" or "six month attend" or " six month recall" or "six month visit"”):ti,ab) AND (INREGISTER)

5 (("6 month check up" or "6 month inspect " or "6 month appointment" or "6 month examin " or "6 month attend" or "6 month recall" or "6 month visit"):ti,ab) AND (INREGISTER)

6 (("three month check up" or "three month inspect " or "three month appointment" " or "three month examin" or "three month attend" or "three month recall" or "three month visit"”):ti,ab) AND (INREGISTER)

7 ( “3 month check up" or "3 month inspect" or "3 month appointment" or "3 month examin" or "3 month attend" or "3 month recall" or "3 month visit"):ti,ab) AND (INREGISTER)

8 ( " "nine month check up" or "nine month inspect*" or "nine month appointment" or "nine month examin" or "nine month attend" or "nine month recall" or "nine month visit"”):ti,ab) AND (INREGISTER)

9 (("9 month check up" or "9 month inspect" or "9 month appointment" or "9 month examin" or "9 month attend" or "9 month recall" or "9 month visit"):ti,ab) AND (INREGISTER)

10 (("twelve month check up" or "twelve month inspect" or "twelve month appointment" or "twelve month examin" " or "twelve month attend" or "twelve month recall" or "twelve month visit"):ti,ab) AND (INREGISTER)

11 (("12 month check up" or " 12 month inspect" " or " 12 month appointment" " or " 12 month examin " or " 12 month attend" or " 12 month recall" or "12 month visit"”):ti,ab) AND (INREGISTER)

12 ((recall and interval):ti,ab) AND (INREGISTER)

13 (\#1 or \#2 or \#3 or \#4 or \#5 or \#6 or \#7 or \#8 or \#9 or \#10 or \#11 or \#12) AND (INREGISTER)

\section{Appendix 2. Cochrane Central Register of Controlled Clinical Trials (CENTRAL) search strategy}

\#1 [mh "Stomatognathic diseases"]

\#2 [mh Dentistry]

\#3 [mh^"Oral health"]

\#4 [mh ^"Dentists practice patterns"]

\#5 "oral health"

\#6 (tooth or teeth or dental or dentist)

$\# 7$ or \#1-\#6\}

\#8 [mh^"Appointments and schedules"]

\#9 (routine ${ }^{\star}$ near/5 ("check up" or inspect* or appointment ${ }^{\star}$ or examin* or attend ${ }^{\star}$ or recall ${ }^{\star}$ or visit $\left.{ }^{\star}\right)$ )

\#10 (regular* near/5 ("check up" or inspect* or appointment* or examin* or attend* or recall* or visit*))

$\# 11$ (periodic* near/5 ("check up" or inspect* or appointment* or examin ${ }^{\star}$ or attend ${ }^{\star}$ or recall* or visit ${ }^{\star}$ )) 
\#12 (("six month*" or six-month* or three-month* or "three month*" or nine-month* or "nine month*" or "twelve month" or twelvemonth* or "6 month" or "3 month" or "9 month*" or "12 month*") next ("check up" or inspect* or appointment* or examin* or attend* or recall* or visit*))

$\# 13$ (recall ${ }^{\star}$ near/3 interval*)

\#14 \{or \#8-\#13\}

\#15 \#7 and \#14

\section{Appendix 3. MEDLINE Ovid search strategy}

1. exp Stomatognathic diseases/

2. exp Dentistry/

3. Oral health/

4. Practice patterns, Dentist's/

5. "oral health".ti,ab.

6. (tooth or teeth or dental or dentist).ti,ab.

7. or/1-6

8. "Appointments and schedules"/

9. (routine\$ adj5 ("check up" or inspect\$ or appointment\$ or examin\$ or attend\$ or recall\$ or visit\$)).ti,ab.

10. (regular adj5 ("check up" or inspect\$ or appointment\$ or examin\$ or attend\$ or recall\$ or visit\$)).ti,ab.

11. (periodic adj5 ("check up" or inspect\$ or appointment\$ or examin\$ or attend\$ or recall\$ or visit\$)).ti,ab.

12. (("six month\$" or six-month\$ or three-month\$ or "three month\$" or nine-month\$ or "nine month\$" or "twelve month\$" or twelvemonth\$ or "6 month\$" or "3 month\$" or "9 month\$" or "12 month\$") adj ("check up" or inspect\$ or appointment\$ or examin\$ or attend \$or recall\$ or visit\$)).ti,ab.

13. (recall\$ adj3 interval\$).ti,ab.

14. or/8-13

15.7 and 14

This subject search was linked to the Cochrane Highly Sensitive Search Strategy (CHSSS) for identifying randomised trials in MEDLINE: sensitivity-maximising version (2008 revision) as referenced in Chapter 6.4.11.1 and detailed in box 6.4.c of The Cochrane Handbook for Systematic Reviews of Interventions, Version 5.1.0 [updated March 2011] (Lefebvre 2011).

1. randomized controlled trial.pt.

2. controlled clinical trial.pt.

3. randomized.ab.

4. placebo.ab.

5. drug therapy.fs.

6. randomly.ab.

7. trial.ab.

8. groups.ab.

9. or/1-8

10. exp animals/ not humans.sh.

11.9 not 10

\section{Appendix 4. Embase Ovid search strategy}

1. exp Mouth disease/

2. exp Dentistry/

3. "oral health".ti,ab.

4. (tooth or teeth or dental or dentist).ti,ab.

5. or/1-4

6. (routine\$ adj5 ("check up" or inspect\$ or appointment\$ or examin\$ or attend\$ or recall\$ or visit\$)).ti,ab.

7. (regular adj5 ("check up" or inspect\$ or appointment\$ or examin\$ or attend\$ or recall\$ or visit\$)).ti,ab.

8. (periodic adj5 ("check up" or inspect\$ or appointment\$ or examin\$ or attend\$ or recall\$ or visit\$)).ti,ab.

9. (("six month\$" or six-month\$ or three-month\$ or "three month\$" or nine-month\$ or "nine month\$" or "twelve month\$" or twelve-month \$ or "6 month\$" or "3 month\$" or "9 month\$" or "12 month\$") adj ("check up" or inspect\$ or appointment or examin\$ or attend\$ or recall \$ or visit\$)).ti,ab.

10. (recall\$ adj3 interval\$).ti,ab.

11. or/6-10

12. 5 and 11

This subject search was linked to an adapted version of the Cochrane Centralised Search Project filter for identifying RCTs in Embase Ovid (see https://www.cochranelibrary.com/central/central-creation for information:)

1. Randomized controlled trial/

Recall intervals for oral health in primary care patients (Review) 
2. Controlled clinical study/

3. Random\$.ti,ab.

4. randomization/

5. intermethod comparison/

6. placebo.ti,ab.

7. (compare or compared or comparison).ti.

8. ((evaluated or evaluate or evaluating or assessed or assess) and (compare or compared or comparing or comparison)).ab.

9. (open adj label).ti,ab.

10. ((double or single or doubly or singly) adj (blind or blinded or blindly)).ti,ab.

11. double blind procedure/

12. parallel group $\$ 1 . t i, a b$.

13. (crossover or cross over).ti,ab.

14. ((assign\$ or match or matched or allocation) adj5 (alternate or group $\$ 1$ or intervention $\$ 1$ or patient $\$ 1$ or subject $\$ 1$ or participant

\$1)).ti,ab.

15. (assigned or allocated).ti,ab.

16. (controlled adj7 (study or design or trial)).ti,ab.

17. (volunteer or volunteers).ti,ab.

18. trial.ti.

19. or/1-18

20. (exp animal/ or animal.hw. or nonhuman/) not (exp human/ or human cell/ or (human or humans).ti.)

21. 19 not 20

\section{Appendix 5. US National Institutes of Health Ongoing Trials Register (ClinicalTrials.gov) search strategy}

recall and (dental or dentist)

\section{Appendix 6. World Health Organization International Clinical Trials Registry Platform search strategy}

recall and dental or recall and dentist or recall and dentistry

\section{Appendix 7. Medline Ovid search strategy for brief economic commentary}

1. exp Stomatognathic diseases/

2. exp Dentistry/

3. Oral health/

4. Dentists practice patterns/

5. "oral health".ti,ab.

6. (tooth or teeth or dental or dentist).ti,ab.

7. or/1-6

8. "Appointments and schedules"/

9. (routine\$ adj5 ("check up" or inspect\$ or appointment\$ or examin\$ or attend\$ or recall\$ or visit\$)).ti,ab.

10. (regular adj5 ("check up" or inspect\$ or appointment\$ or examin\$ or attend\$ or recall\$ or visit\$)).ti,ab.

11. (periodic adj5 ("check up" or inspect\$ or appointment\$ or examin\$ or attend\$ or recall\$ or visit\$)).ti,ab.

12. (("six month\$" or six-month\$ or three-month\$ or "three month\$" or nine-month\$ or "nine month\$" or "twelve month\$" or twelvemonth\$ or "6 month\$" or "3 month\$" or "9 month\$" or "12 month\$") adj ("check up" or inspect\$ or appointment\$ or examin\$ or attend \$ or recall\$ or visit\$)).ti,ab.

13. (recall\$ adj3 interval\$).ti,ab.

14. or/8-13

15. 7 and 14

This subject search was linked to the Scottish Intercollegiate Guideline Network filter for identifying economic studies in MEDLINE Ovid. Available at: https://www.sign.ac.uk/search-filters.html. 
1 Economics/

2 "costs and cost analysis"/

3 Cost allocation/

4 Cost-benefit analysis/

5 Cost control/

6 Cost savings/

7 Cost of illness/

8 Cost sharing/

9 "deductibles and coinsurance"/

10 Medical savings accounts/

11 Health care costs/

12 Direct service costs/

13 Drug costs/

14 Employer health costs/

15 Hospital costs/

16 Health expenditures/

17 Capital expenditures/

18 Value of life/

19 Exp economics, hospital/

20 Exp economics, medical/

21 Economics, nursing/

22 Economics, pharmaceutical/

23 Exp "fees and charges"/

24 Exp budgets/

25 (low adj cost).mp.

26 (high adj cost).mp.

27 (health?care adj cost\$).mp.

28 (fiscal or funding or financial or finance).tw.

29 (cost adj estimate\$).mp.

30 (cost adj variable).mp.

31 (unit adj cost\$).mp.

32 (economic\$ or pharmacoeconomic $\$$ or price\$ or pricing).tw.

33 Or/1-32

\section{Appendix 8. Embase Ovid search strategy for brief economic commentary}

1. exp Mouth disease/ 
2. exp Dentistry/

3. "oral health".ti,ab.

4. (tooth or teeth or dental or dentist).ti,ab.

5. or/1-4

6. (routine\$ adj5 ("check up" or inspect\$ or appointment\$ or examin\$ or attend\$ or recall\$ or visit\$)).ti,ab.

7. (regular adj5 ("check up" or inspect\$ or appointment\$ or examin\$ or attend\$ or recall\$ or visit\$)).ti,ab.

8. (periodic adj5 ("check up" or inspect\$ or appointment\$ or examin\$ or attend\$ or recall\$ or visit\$)).ti,ab.

9. (("six month\$" or six-month\$ or three-month\$ or "three month\$" or nine-month\$ or "nine month\$" or "twelve month\$" or twelve-month \$ or "6 month\$" or "3 month\$" or "9 month\$" or "12 month\$") adj ("check up" or inspect\$ or appointment\$ or examin\$ or attend\$ or recall \$ or visit\$)).ti,ab.

10. (recall\$ adj3 interval\$).ti,ab.

11. or/6-10

12. 5 and 11

This subject search was linked to the Scottish Intercollegiate Guideline Network filter for identifying economic studies in Embase Ovid. Available at: https://www.sign.ac.uk/search-filters.html.

1 Socioeconomics/

2 Cost benefit analysis/

3 Cost effectiveness analysis/

4 Cost of illness/

5 Cost control/

6 Economic aspect/

7 Financial management/

8 Health care cost/

9 Health care financing/

10 Health economics/

11 Hospital cost/

12 (fiscal or financial or finance or funding).tw.

13 Cost minimization analysis/

14 (cost adj estimate\$).mp.

15 (cost adj variable\$).mp.

16 (unit adj cost\$).mp.

17 Or/1-16

\section{Appendix 9. NHS Economic Evaluation Database Ovid search strategy}

1. exp Stomatognathic diseases/

2. exp Dentistry/

3. Oral health/

4. Dentists practice patterns/

5. "oral health".tw.

6. (tooth or teeth or dental or dentist).tw.

7. or/1-6

8. "Appointments and schedules"/

9. (routine\$ adj5 ("check up" or inspect\$ or appointment\$ or examin\$ or attend\$ or recall\$ or visit\$)).tw.

10. (regular adj5 ("check up" or inspect\$ or appointment\$ or examin\$ or attend\$ or recall\$ or visit\$)).tw. 
11. (periodic adj5 ("check up" or inspect\$ or appointment\$ or examin\$ or attend\$ or recall\$ or visit\$)).tw.

12. (("six month\$" or six-month\$ or three-month\$ or "three month\$" or nine-month\$ or "nine month\$" or "twelve month\$" or twelvemonth\$ or "6 month\$" or "3 month\$" or "9 month\$" or "12 month\$") adj ("check up" or inspect\$ or appointment\$ or examin\$ or attend \$or recall\$ or visit\$)).tw.

13. (recall\$ adj3 interval\$).tw.

14. or/8-13

15. 7 and 14

WHAT'S NEW

\begin{tabular}{lll}
\hline Date & Event & Description \\
\hline 17 January 2020 & New search has been performed & Searches updated to 17 January 2020. \\
\hline 9 January 2020 & $\begin{array}{l}\text { New citation required and conclusions } \\
\text { have changed }\end{array}$ & $\begin{array}{l}\text { One new included study. In the previous version, we were unable } \\
\text { to draw any conclusions, but we now have moderate- to high- } \\
\text { certainty evidence that, for adults, there is little difference in } \\
\text { caries, periodontal disease and oral-health-related quality of life } \\
\text { outcomes if dental recalls are provided every 24 months, or at } \\
\text { shorter intervals based on the dentist's judgement, rather than } \\
\text { every } 6 \text { months. }\end{array}$ \\
\hline
\end{tabular}

\section{H I S T O R Y}

Protocol first published: Issue 3, 2003

Review first published: Issue 2, 2005

\begin{tabular}{lll}
\hline Date & Event & Description \\
\hline 19 June 2008 & Amended & Converted to new review format \\
\hline 10 August 2007 & $\begin{array}{l}\text { New citation required but conclusions } \\
\text { have not changed }\end{array}$ & Updated search. Change in authors \\
\hline
\end{tabular}

\section{CONTRIBUTIONS OFAUTHORS}

- Writing the protocol: Paul Beirne (PB), Andrew Forgie (AF), Helen Worthington (HW), Jan Clarkson (JC).

- Screening studies for eligibility: Patrick Fee (PF), Philip Riley (PR). (For the original version of the review, PB and AF decided which studies were eligible.)

- Risk of bias assessment: PR, PB

- Data extraction and analysis: all authors.

- Writing the review: all authors.

- Certainty of the evidence assessment: all authors.

\section{DECLARATIONS OF INTEREST}

PF: was involved with one of the included studies (INTERVAL 2020), but was not involved with the data extraction from this study or assessment of its risk of bias for this review.

PR: no interests to declare

HW: was involved with one of the included studies (INTERVAL 2020), but was not involved with the data extraction from this study or assessment of its risk of bias for this review. Professor Worthington is a Co-ordinating Editor with Cochrane Oral Health. 
JC: was involved with one of the included studies (INTERVAL 2020), but was not involved with the data extraction from this study or assessment of its risk of bias for this review. Professor Clarkson is a Co-ordinating Editor with Cochrane Oral Health.

DB: was involved with one of the included studies (INTERVAL 2020), but was not involved with the data extraction from this study or assessment of its risk of bias for this review.

PB: no interests to declare

\section{SOURCES OF SUPPORT}

\section{Internal sources}

- School of Dentistry, The University of Manchester, UK

- Scottish Executive, UK

- University College Cork, Ireland

- MAHSC, UK

Cochrane Oral Health is supported by the Manchester Academic Health Sciences Centre (MAHSC) and the NIHR Manchester Biomedical Research Centre.

\section{External sources}

- Cochrane Fellowship - Health Research Board, Ireland

- Department of Health Cochrane Review Incentive Scheme, UK

- National Institute for Health Research (NIHR), UK

This project was supported by the NIHR, via Cochrane Infrastructure funding to Cochrane Oral Health. The views and opinions expressed herein are those of the authors and do not necessarily reflect those of the Evidence Synthesis Programme, the NIHR, NHS, or the Department of Health and Social Care.

- Cochrane Oral Health Group Global Alliance, UK

The production of Cochrane Oral Health reviews has been supported financially by our Global Alliance since 2011 (oralhealth.cochrane.org/partnerships-alliances). Contributors in the last two years have been the American Association of Public Health Dentistry, USA; AS-Akademie, Germany; the British Association for the Study of Community Dentistry, UK; the British Society of Paediatric Dentistry, UK; the Canadian Dental Hygienists Association, Canada; the Centre for Dental Education and Research at All India Institute of Medical Sciences, India; the National Center for Dental Hygiene Research \& Practice, USA; New York University College of Dentistry, USA; and Swiss Society of Endodontology, Switzerland.

\section{DIFFERENCES BETWEEN PROTOCOL AND REVIEW}

The protocol for this review was originally published in 2003. In the intervening time period, we have made several modifications to the review to ensure that it satisfies contemporary methodological expectations for Cochrane intervention reviews (the MECIR standards). For example, our review now includes 'Summary of findings' tables and we used the GRADE system to assess the certainty of evidence - these methods were not originally specified in the review protocol. In addition, we also made the following changes to the review.

- We removed a comparison specified in the original protocol that proposed to compare different dental check-up types at the same fixed recall interval (for example 12 months). This comparison evaluated the effects of different types of dental check-ups rather than the effects of different recall intervals between dental check-ups.

- In the Methods section under 'Data synthesis', we altered our intended approach to use random-effects models as standard in any future meta-analyses. This is in line with the advice of Cochrane Oral Health's Statistical Editors.

\section{INDEX TERMS}

\section{Medical Subject Headings (MeSH)}

Age Factors; *Appointments and Schedules; Dental Care [ ${ }^{\star}$ standards]; Dentition, Permanent; *Oral Health; Randomized Controlled Trials as Topic; Time Factors; Tooth, Deciduous

\section{MeSH check words}

Adolescent; Child, Preschool; Humans; Young Adult 